\title{
PUBLICACIONES SOBRE FILOLOGÍA INGLESA EN ESPAÑA (2004-2005)
}

\section{RESUMEN}

Bibliografía relativa a Filología Inglesa publicada en España entre 2004 y 2005.

PALABRAS ClAVE: Filología Inglesa; bibliografía; España.

\section{ABSTRACT}

Bibliography on English Studies publisbed in Spain between 2003 and 2004.

KEY WORDS: English Studies; bibliography; Spain.

ÍNDICE GENERAL
A. LITERATURA INGLESA
B. LITERATURA NORTEAMERICANA
C. LiteraturA POSTCOLONIAL EN LENGUA INGLESA
D. TRAdUCCIÓN
E. Cultura y Cine 


\section{A. LITERATURA INGLESA}

IsABEL MEDRANO mmedrano@flog.uned.es

ANA ZAMORANO aizamorano@flog.uned.es

UNED. Madrid

\section{ÍNDICE}

1. Literatura anglosajona, medieval y renacentista

2. Restauración y siglo XVIII

3. Siglo XIX

4. Siglo XX y época contemporánea

5. Miscelánea

\section{LiterATURA ANGLOSAJONA, MEDIEVAL Y RENACENTISTA}

AbraHAms, Eileen. ««I Nothing Know»: Emilia's Rhetoric of Self-Resistance in Othello». SEDERI 14 (2004): 179-88.

BUENO, Jorge L. Literatura inglesa medieval y renacentista: guía temática y bibliográfica. Oviedo: Septem Ediciones, 2005.

CAIE, Graham D. ««I do not wish to be called auctour, but the pore compilatour»: the Plight of the Medieval Vernacular Poet». Miscelánea 29 (2004): 9-22.

— «New corn from old fields": the Auctor and Compilator in Fourteenth-Century English Literature». Revista Canaria de Estudios Ingleses 47 (2003): 59-71.

CALvo LóPEz, Clara. «Shakespeare, Austen y Angela Carter: Padres e hijas en Wise Children». Shakespeare en la imaginación contemporánea. Revisiones y reescrituras de su obra. Coord. Ángeles de la Concha. Madrid: UNED, 2004. 143-70.

CARrera SuÁrez, Isabel. «La suerte de Miranda: relecturas de The Tempest desde el Nuevo Mundo». Shakespeare en la imaginación contemporánea. Revisiones y reescrituras de su obra. Coord. Ángeles de la Concha. Madrid: UNED, 2004. 187-205.

Carrillo Linares, María José. «What Thing is it that People most (UN)desire? A View on Chaucer's Portrayal of the Process of Ageing. Women Ageing Through Literature and Experience. Ed. Brian J. Worsfold. Lleida: Edicions de la Universitat de Lleida, 2005. 21-30.

CASTRO CARRACEDO, Juan Manuel. «A Controversial Source for Geoffrey of Monmouth's Historia Regium Britanniae: The Oraculla Sybillina and the Sybilline Cycle». AEDEAN: Proceedings of the 27 $7^{\text {th }}$ International Conference. Salamanca: Universidad de Salamanca, 2004. CD-ROM.

— «"To lerne you to dye when ye wyll": John Skelton and the Ars Moriendi Tradition». SEDERI 15 (2005): 5-22.

CEREzo, Marta. «As You Like It como juego de revisiones y reescrituras.» Shakespeare en la imaginación contemporánea. Revisiones y reescrituras de su obra. Coord. Ángeles de la Concha. Madrid: UNED, 2004. 233-59.

- Critical Approaches to Shakespeare. Shakespeare For All Time. Madrid: UNED, 2005. 
CONCHA, Ángeles de la, ed. Shakespeare en la imaginación contemporánea. Revisiones y reescrituras de su obra. Madrid: UNED, 2004.

- Introducción. Shakespeare en la imaginación contemporánea. Revisiones y reescrituras de su obra. Coord. Ángeles de la Concha. Madrid: UNED, 2004. 9-17.

— «El poder de lo excesivo frente a los excesos del poder: Falstaff de Robert Nye». Shakespeare en la imaginación contemporánea. Revisiones y reescrituras de su obra. Coord. Ángeles de la Concha. Madrid: UNED, 2004. 68-87.

— «Indigo de Marina Warner: una (re)versión de The Tempest». Shakespeare en la imaginación contemporánea. Revisiones y reescrituras de su obra. Coord. Ángeles de la Concha. Madrid: UNED, 2004. 205-233.

CORA Alonso, Jesús. «This dream is all amiss interpreted: Julius Caesar, Shakespeare's Alchemical Tragedy». SEDERI 14 (2004): 17-52

Demetriou, Eroulla. «Michael Du Val and Count Gondomar: an Approximation towards the Authorship of The Spanish-English Rose Or The English-Spanish Pomgranet». SEDERI 14 (2004): 53-64.

— «"Iohn de Nicholas \& Sacharles". TheReformed Spaniard and the Black Legend of Spain». El bisturí inglés: literatura de viajes e hispanismo en lengua inglesa. Ed. Carmelo Medina Casado y José Ruiz Mas. Jaén: Universidad de Jaén/UNED, 2004. 75-103.

DíAz FERNÁNDEZ, José Ramón. «Henry $V$ en la pantalla». Shakespeare en la imaginación contemporánea. Revisiones y reescrituras de su obra. Coord. Ángeles de la Concha. Madrid: UNED, 2004. 45-68.

Domínguez Romero, Elena. «Some Considerations on the Pastourelle in Shakespeare's As You Like It». SEDERI 14 (2004): 199-206.

FANEGo LEMA, María Teresa. «"Fare thee well, dame”: Shakespeare's Forms of Address and their Socio-Affective Role». SEDERI 15 (2005): 23-42.

GEORGE, Jodie Ann. «"My brain I'll prove the female of my soul”: King = Queen in Richard II». Grove 11 (2004): 49-58.

- «"A pestelaunce on the crabyd queane": The Hybrid Nature of John Pikeryng's Horestes. SEDERI 14 (2004): 65-76.

GIL SÁEnz, Daniel. «Reading Diego de San Pedro in Tudor England». Revista Alicantina de Estudios Ingleses 17 (2004): 103-15.

Gómez LaRA, Manuel José. «Ambiguous Devices: the Use of Dramatic Emblems in Marlowe's Edward II (1592)». SEDERI 15 (2005): 103-14.

GonZÁlez CAMPos, Miguel Angel. «The Portrayal of Treason in The Tempest: The Fourfold Role of a Machiavellian Duke». SEDERI 14 (2004): 207-16.

HERnÁNDEZ-PÉREZ, María Beatriz. Literature, Gender, Space. Ed. Sonia Villegas-López y Beatriz Domínguez-García. Huelva: Servicio de Publicaciones de la Universidad de Huelva, 2004. 131-141.

HidAlgo ANDREu, Pilar. «El texto shakesperiano como crítica cultural: de Brave New World a «Mrs Caliban». Shakespeare en la imaginación contemporánea. Revisiones y reescrituras de su obra. Coord. Ángeles de la Concha. Madrid: UNED, 2004. 171-87.

LARA RALLO, Carmen. ««The hooly blisful martir for to seke». Una aproximación a los personajes eclesiásticos en el Prólogo General a los Cuentos de Canterbury». Analecta Malacitana 27.1 (2004): 155-68.

— «Flashing into the crystal mirror»: the Recurrence of the Mirror Motif in Three Arthurian Works». Revista Alicantina de Estudios Ingleses 17 (2004): 139-54.

LutTiKhuizen, Frances. «Don Diego Puede-Ser (James Mabbe)'s English Rendering of Cervantes' Novelas ejemplares». Ed. Diego Martínez Torrón y Bernd Dietz. Cervantes y el ámbito anglosajón. Madrid: SIAL Ediciones, 2005. 200-210. 
Mesa VILLAR, José María. «Musings from Ophelia's Watery Voyage: Images of Female Submission in Shakespeare's and Millais' Drowning Maiden». SEDERI 14 (2004): 227-38.

MonTERREY, Tomás. «The Man in the Moone: Godwin's Narrative Experiment and the Scientific Revolution». Revista Canaria de Estudios Ingleses 50 (2005): 71-86.

Mora SenA, María José. «Type-Casting in the Restoration Theatre: Dryden's All for Love, 16771704». Atlantis 27. 2 (2005): 75-86.

— «The Political is Personal: the Attack on Shadwell in Sir Barnaby Whigg». SEDERI 15 (2005): $115-28$.

Mourón FigueroA, Cristina. El Ciclo de York. Sociedad y cultura en la Inglaterra bajomedieval. Santiago de Compostela: Servicio de Publicaciones de la Universidad de Santiago, 2005.

MuÑoz VALDIVIESO, Sofía. «Shakespeare en la cultura popular». Shakespeare en la imaginación contemporánea. Revisiones y reescrituras de su obra. Coord. Ángeles de la Concha . Madrid: UNED, 2004. 19-44.

— «Postmodern Recreations of the Renaissance: Robert Nye's Fictional Biographies of William Shakespeare». SEDERI 15 (2005): 43-62.

NISA CÁCERES, Daniel. «"Be My Trew Mistres Still, Not My Faignd Pag”: Truth and Disguise in Donne's Elegy 16'». Atlantis 26.1 (2004): 37-47.

O’NeILl, Maria. «Sexuality and Ageing as Depicted in The Canterbury Tales: Gender, Economics and Morality». Women Ageing Through Literature and Experience. Ed. Brian J. Worsfold. Lleida: Edicions de la Universitat de Lleida, 2005. 73-81.

PHILLIPS, Bill. «The Rape of Mother Earth in Seventeenth Century English Poetry: An Ecofeminist Interpretation». Atlantis 26.1 (2004): 49-60.

- "The taint of a fault": Purgatory, Relativism and Humanism in Sir Gawain and the Green Knight». Revista Alicantina de Estudios Ingleses 17 (2004): 227-37.

PORTILlO GARCíA, Rafael. «Staging Restoration Dramas: Practical Aspects of their Performance». SEDERI 15 (2005): 63-80.

Prieto Pablos, Juan Antonio. «Audience Deception and Farce in John Lacy's Sir Hercules Buffoon». Atlantis 27.1 (2005): 65-78.

PRIOR BARBARROJA, Balbina. «La conciencia de género a través de los textos que tratan el matrimonio de conveniencia, independientemente de la época, sexo o procedencia: Cervantes (1574-1616), Aphra Behn (1640-1689), William Congreve (1670-1729)». Cervantes y el ámbito anglosajón. Ed. Diego Martínez Torrón y Bernd Dietz. Madrid: SIAL Ediciones, 2005. 406-18.

PuJANTE, Angel-Luis y GREGor, Keith. «The Four Neoclassical Spanish Hamlets: Assimilation and revision». SEDERI 15 (2005): 129-44.

Ribes TraVer, Purificación. «Araquistáin's 1929 Version of Volpone». SEDERI 15 (2005): 81-102.

Rodríguez Gómez, Paula María. «Cordelia's Portrait in the Context of King Lear's Individuation».Odisea 6 (2005): 181-200.

SÁEZ HidAlgo, Ana. "Chaucer's "Litel Tragedye" in its Theoretical and Literary Context». AEDEAN: Proceedings of the $27^{\text {th }}$ International Conference. Salamanca: Universidad de Salamanca, 2004. CD-ROM.

SÁncheZ MarTí, Jordi. «The Wild Man in the Middle English Romances». AEDEAN: Proceedings of the $27^{\text {th }}$ International Conference. Salamanca: Universidad de Salamanca, 2004. CD-ROM.

— «Longleat House MS 257: A Description». Atlantis 27.1 (2005): 79-89.

SANDERSON, John D. trad. y ed. El trueque (1622), de Thomas Middleton y William Rowley: Alicante como escenario del teatro jacobeo. Alicante: Instituto Alicantino de Cultura Juan Gil-Albert, 2002.

SELl, Jonathan P. A. «Venetian Masks: Intercultural Allusion, Transcultural Identity, and Two Othellos». Atlantis 26.1 (2004): 74-86. 
— «Cousin to Fortune: on Reading Chaucer's Crisyde». Revista Canaria de Estudios Ingleses 48 (2004): 193-204.

— «Venetian Masks: Intercultural Alllusion, Transcultural Identity, and Two Othellos». Atlantis 26.1 (2004): 73-88.

ShaKeSPeARe, William. Eduardo III. Edición y traducción Antonio Ballesteros González. Madrid: Asociación de Directores de Escena de España (ADE), 2005.

— Medida por medida. Traducción, introducción y notas Ángel Luis Pujante. Madrid: Espasa (col. Austral), 2004.

- Ricardo III. Estudio crítico de Manuela Palacios González. Santiago de Compostela: Xunta de Galicia, 2005.

SHaw, Patricia. «Wits, Fittes and Fancies: Spanish Ingenio in Renaissance England». Estudios Ingleses de la Universidad Complutense 12 (2004): 131-48.

Sir Gawain y el caballero verdelanónimo inglés del siglo XIV. Introducción, notas y bibliografía M. Paloma Rambla Fortes; traducción M. ${ }^{a}$ Paloma Rambla Fortes y Angel Cañete Alvarez-Torrijos. Málaga: Serivicio de Publicaciones de la Universidad de Málaga, 2004.

SuÁrez Toste, Alberto. «The Temple and the Cottage: Architecture in Elizabeth Bishop's Landscapes». AEDEAN: Proceedings of the $27^{\text {th }}$ International Conference. Salamanca: Universidad de Salamanca, 2004. CD-ROM.

TALVET, Jüri . «Between Dreams and Reality: The Message and the Image of Renaissance Humanism». SEDERI 14 (2004): 137-52.

VÉLEZ-NúÑEZ, Rafael. «Gendering Stages in English Pre-Restoration Theatrical Productions». Literature, Gender, Space. Ed. Sonia Villegas-López y Beatriz Domínguez-García. Huelva: Servicio de Publicaciones de la Universidad de Huelva, 2004. 231-38.

ZAmorano RuEdA, Ana. I. «Nunca una mujer escribirá como Shakespeare. ¿Acaso debería?». Shakespeare en la imaginación contemporánea. Revisiones y reescrituras de su obra. Coord. Ángeles de la Concha. Madrid: UNED, 2004. 123-42.

ZOZAYA ARIZTIA, Pilar. «Juicio a Shakespeare: una aproximación a Lear (1971) y a Bingo (1973) de Edward Bond. Shakespeare en la imaginación contemporánea. Revisiones y reescrituras de su obra. Coord. Ángeles de la Concha.Madrid: UNED, 2004. 103-22.

Zunino GARRIDO, María de la Cinta. «Boscán and Garcilaso as Rhetorical Models in the English Renaissance: The Case of Abraham Fraunce's The Arcadian Rhetorike». Atlantis 27.2 (2005): 119-34.

\section{RESTAURACIÓN Y SIGLO XVIII}

Álvarez Faedo, María José. A Bio-Bibliography of Eighteenth-Century Religious Women in England and Spain. Lewiston (NY): The Edwin Mellen Press, 2005.

CARRETERo MuÑoz, Rafael. «Apuntes para una vindicación del Reverendo John Bowle, M. A., F.S.A., frente a los cargos vertidos contra él por Mr. Giuseppe Baretti». Cervantes y el ámbito anglosajón. Ed. Diego Martínez Torrón, y Bernd Dietz. Madrid: SIAL Ediciones, 2005. 13-62.

DíAz BILD, María Aída. «A Simple Story o la delicada frontera entre lo permitido y lo prohibido». Odisea 5 (2004): 23-44.

- Charlotte Smith: la literatura como liberación. La Laguna: Servicio de Publicaciones de la Universidad de La Laguna, 2003.

FiELDING, Henry, Don Quijote en Inglaterra, Edición y traducción Antonio Ballesteros González. Madrid: Asociación de Directores de Escena de España (ADE), 2005.

García Martínez, María Isabel, Álvarez Faedo, María José, Simon Schuhmacher, Lioba. La educación de la mujer en el siglo XVIII en España e Inglaterra. Lewiston (NY): The Edwin Meller Press, 2005. 
GASCUEÑa GAHETE, Javier. «Don Quijote y Robinson Crusoe: puntos de contacto». Cervantes y el ámbito anglosajón. Ed. Diego Martínez Torrón, y Bernd Dietz. Madrid: SIAL Ediciones, 2005. 118-36.

Hoyas Solís, José Antonio. «Salamanca y su Universidad en los relatos de viaje ingleses del siglo XVIII». Anuario de Estudios Filológicos 28 (2005): 117-29.

LARA Rallo, Carmen. «La visión del "otro" en Robison Crusoe y Oroonoko». Analecta Malacitana 28. 2 (2005): 641-58.

Lennox, Charlotte. La mujer Quijote. Ed. Cristina Garrigós. Madrid: Cátedra, 2004.

LóPez-Peláez Casellas, Jesús. «The Neo-Stoic Revival in English Literature of the Sixteenth and Seventeenth Centuries: an Approach». SEDERI 14 (2004): 93-116.

Martínez Torrón, Diego. «El Quijote de John Bowle». Cervantes y el ámbito anglosajón. Ed. Diego Martínez Torrón y Bern Dietz. Madrid: SIAL Ediciones, 2005. 118-36.

MiLton, John. Paradise Lost. Introducción Fernando Galván. Traducción y notas de Esteban Pujals. Madrid: Espasa Calpe, 2003.

Pardo García, Pedro Javier. «Satire on Learning and the Type of the Pedant in Eighteenth-Century Literature». BELLS, 13 (2004). Edición electrónica.

Trofimova, Violetta. «Crossing the Boundaries: Aphra Behn and John Wilkins Popularizing the "New Science"». Revista Canaria de Estudios Ingleses 50 (2005): 87-100.

VALDÉS MirAYES, J. Rubén. «The Prejudices of Education: Educational Aspects of the Scottish Enlightenment». Atlantis 27. 2 (2005): 101-18.

VILlEgas LóPEZ, Sonia. «Aphra Behn's Sentimental History: The Case Study of Agnes de Castro, or the Force of Generous Love (1688)». SEDERI 14 (2004): 239-48.

WollstoneCRAFt, Mary. Vindicación dos dereitos da muller. Introd. M. ${ }^{a}$ Jesús Lorenzo Modia. Traducción y notas M. ${ }^{a}$ Fe González Fernández. Santiago de Compostela: Xunta de Galicia y Sotelo Blanco Edicións, 2004.

\section{SigLO XIX}

ALBERICH, José. «El carácter español según los románticos ingleses». El bisturí inglés: literatura de viajes e hispanismo en lengua inglesa. Ed. Carmelo Medina Casado y José Ruiz Más. Jaén: Universidad de Jaén/UNED, 2004. 37-60.

BALlesteros GonZÁLeZ, Antonio. Escrito por brujas. Lo sobrenatural en la vida y la literatura de grandes mujeres del siglo XIX. Madrid: Oberon (Grupo Anaya), 2005.

BERNAL RODRíGUEZ, Manuel. «Andalucía durante la invasión napoleónica según un enviado especial británico». El bisturí inglés: literatura de viajes e hispanismo en lengua inglesa. Ed. Carmelo Medina Casado y José Ruiz Más. Jaén: Universidad de Jaén/UNED, 2004. 63-72.

Constán VAlverde, Sergio. «Abel Sánchez o la lección aprendida del Dorian Gray: decadentismo wildiano en Unamuno». AEDEAN: Proceedings of the $27^{\text {th }}$ International Conference. Salamanca: Universidad de Salamanca, 2004. CD-ROM.

Flores Moreno, Cristina. «What Did S.T. Coleridge Really Read of Ralph Cudworth's The True Intellectual System of the Universe?: a philological research». Grove 11 (2004): 37-48.

FREIRE, Espido. Querida Jane, querida Charlotte: por la ruta de Jane Austen y las hermanas Brontë. Madrid: Suma de Letras, 2005.

Gómez Castro, Cristina. «Wuthering Heights: a Gothic Novel?». Estudios de Filología Moderna, 4, (2004): 7-16.

GonZÁLEZ Moreno, Beatriz. «Breaking Aesthetics and Universalising Plague in Mary Shelley's The Last Man». Odisea 5 (2004): 71-80. 
KLEIN, Herbert S. «World into Calculus: The Reduction of Reality in the English Detective Novel of the 19th Century». Revista Canaria de Estudios Ingleses 50 (2005): 131-44.

KraUel Heredia, Blanca. «"Spanish Ladies”. La visión del viajero». El bisturí inglés: literatura de viajes e hispanismo en lengua inglesa. Ed. Carmelo Medina Casado y José Ruiz Más. Jaén: Universidad de Jaén/UNED, 2004. 141-70.

MEdinA CASADO Carmelo. «Escritores viajeros: tres ingleses de principios del siglo XIX en Jaén». El bisturí inglés: literatura de viajes e hispanismo en lengua inglesa. Ed. Carmelo Medina Casado y José Ruiz Mas. Jaén: Universidad de Jaén/UNED, 2004. 223-59.

NgEZEM, Eugene. «Alfred Lord Tennyson: a Poetic Analysis». Grove 11 (2004): 105-24.

PARDO GARCÍA, Pedro Javier. «La heroína quijotesca en la novela inglesa del XIX: Jane Austen, George Eliot y otros novelistas». Cervantes y el ámbito anglosajón. Ed. Diego Martínez Torrón y Bern Dietz. Madrid: SIAL Ediciones, 2005. 356-75.

Ramos RAmos, M. ${ }^{a}$ del Rocío. «La parodia romántica: parodiando a los románticos o los románticos parodian». AEDEAN: Proceedings of the $27^{\text {th }}$ International Conference. Salamanca: Universidad de Salamanca, 2004. CD-ROM.

RodríGueZ Martín, María Elena. «"Unfaithfulness" to Jane Austen?: Communicating Readings and Interpretations of her Novels Through their Films Adaptations». ES 26 (2005): 189-200.

VÁzquez de Prada Merino, María Teresa. «La ironía en el "Quijote" y en "Bleak House"». ES 26 (2005): 223-40.

— «La perseverancia del Quijote en Dickens: Great Expectations». Lenguaje y textos, 20 (2002): 103-16.

Zarandona FernándeZ, Juan Miguel. «The English Letters by Don Manuel Álvarez Espriella, Pseudo-Translated by Robert Southey (1807)». Odisea 5 (2004): 187-98.

\section{Siglo XX Y CONTEMPORÁNEA}

ABAD-García, Pilar. «Mixing genres and genders: Carol Ann Duffy's Postmodern Satire: The World's Wife». Actas XXVIII Congreso Internacional AEDEAN. Ed. Juan José García de Leonardo, Jesús Tronch Pérez, Milagros del Saz Rubio, Carme Manuel Cuenca, Barry Pennock Speck and María José Coperías Aguilar. Valencia: Universidad de Valencia, 2005. CDROM.

Acosta Bustamante, Leonor. «Sexual violence deconstructed: Simone de Beavoir, Angela Carter and Rikki Ducornet Investigate Sade». Odisea 6 (2005): 7-18.

Álvarez CAlleja, M. ${ }^{a}$ Antonia. «Seamus Heaney's Inter-Generational Autobiography». Thistles. A Homage to Brian Hughes. Essays in Memorian, vol. 2. Ed. José Mateo y Francisco Yus. Alicante: Secretariado de Publicaciones de la Universidad de Alicante, 2005. 19-26.

ANDRÉs CUEVAS, Isabel María. «On Holy Boughs and Sacred Fools: Virginia Woolf Under the Shadow of Jane Harrison». Odisea 6 (2005): 19-28.

— «Literally Meaning Cohesion: The Zeal for Togetherness in Virginial Woolf's Between the Acts». Ed. Luis Quereda, Neil McLaren, José Luis Dueñas Espejo y Carmen Pérez Basanta. Towards an Understanding of the English Language, Past, Present and Future: Studies in Honour of Fernando Serrano. Granada: Editorial Universidad de Granada, 2005. 177-191.

— «The Laughter of the Woolf: A Trip into the Grotesque in Virginia Woolf's Novels» Actas XXVIII Congreso Internacional AEDEAN. Ed. Juan José García de Leonardo, Jesús Tronch Pérez, Milagros del Saz Rubio, Carme Manuel Cuenca, Barry Pennock Speck and María José Coperías Aguilar. Valencia: Universidad de Valencia, 2005. CD-ROM.

ARAgAY, Mireia y ZOZAYA Pilar. «The State of British Theatre Now: An Interview with Michael Billington». Atlantis 26.1 (2004): 89-100. 
ARIAS DoBlas, Rosario. «La reconstrucción del pasado (materno) y el discurso científico en Life before Man, de Margaret Atwood». Clepsydra: Revista de Estudios de Género y Teoría Feminista 3 (2004): 67-88.

— «The Past Has a Great Future: History and Desire in Sarah Waters's Neo-victorian Fiction». Actas del XXVII Congreso Internacional de AEDEAN. Ed. Antonio R. Celada, Daniel Pastor García y Pedro Javier Pardo García. Salamanca: Ambos Mundos, 2004. CD-ROM.

— «Back to the Future: Gendered Spaces and Territories in Doris Lessing's The Marriages Between Zones Three, Four and Five». Literature, Gender, Space. Ed. Sonia Villegas-López y Beatriz Domínguez-García. Huelva: Servicio de Publicaciones de la Universidad de Huelva, 2004. 35-41.

— «Talking with the Dead: Revisiting the Victorian Past and the Occult in Margaret Atwood's Alias Grace and Sarah Water's Affinity». Estudios Ingleses de la Universidad Complutense 13 (2005): 85-105.

— «Between Spiritualism and Hysteria: Science and Victorian Mediumship in Michèle Roberts' In the Red Kitchen». Revista Canaria de Estudios Ingleses 50 (2005): 161-180.

— «Moments of Ageing: The Reifungsroman in Contemporary Fiction». Women Ageing Through Literature and Experience. Ed. Brian J. Worsfold. Lleida: Edicions de la Universitat de Lleida, 2005. 3-12.

BARRIO, José M y ABAD Pilar, eds. Estudios de literatura en lengua inglesa de los siglos XX y XXI (7). Valladolid: Universidad de Valladolid, 2004.

— Estudios de literatura en lengua inglesa de los siglos XX y XXI (8). Valladolid: Universidad de Valladolid, 2005.

BASSETT, Troy J. «Mining in Malaya: The Literary Appropriation of Southeast Asia in the Short Stories of W. Somerset Maugham». Géneros en contacto. Viajes, crimen, novela femenina y humor. Miscelánea de literatura inglesa y norteamericana. Coord. Santiago J. Henríquez Jiménez. Las Palmas de Gran Canaria: Servicio de Publicaciones de la Universidad de Las Palmas de Gran Canaria/La Caja de Canarias, 2004. 13-32.

BASTIDA RodríGueZ, Patricia «The Muddle of Life: Thematic Parallels in Zadie Smith's White Teeth and Laurence Stern's Tristram Shandy». Actas XXVIII Congreso Internacional AEDEAN. Ed. Juan José García de Leonardo, Jesús Tronch Pérez, Milagros del Saz Rubio, Carme Manuel Cuenca, Barry Pennock Speck and María José Coperías Aguilar. Valencia: Universidad de Valencia, 2005. CD-ROM.

BENITO DE LA Iglesia, Tamara. «Lo universal y lo (nor)irlandés en la narrativa breve de Bernard Mac Alberti». Creadores de evocación. Nuevos artículos sobre relatos cortos de autores británicos contemporáneos. Ed. José Francisco Fernández Sánchez. Almería: Servicio de Publicaciones de la Universidad de Almería, 2005. 77-90.

CÁmARa Arenas, Enrique. «The Human End of Characterization: Towards a Logic of Character Traits». Estudios de literatura en lengua inglesa de los siglos XX y XXI (8). Ed. José M. Barrio y Pilar Abad. Valladolid: Universidad de Valladolid, 2005. 79-88.

CANEdA CABRERA, Teresa. «Modernist Women Writers and the Construction of Alternative Spaces: Unveiling Secret Pleasures in Katherine Mansfield's "Bliss"». Literature, Gender, Space. Ed. Sonia Villegas-López y Beatriz Domínguez-García. Huelva: Servicio de Publicaciones de la Universidad de Huelva, 2004. 241-48.

—- «"Do You See the Story? Do You See Anything": The Aesthetics and Politics of Impressionism in Heart of Darkness». Actas XXVIII Congreso Internacional AEDEAN. Ed. Juan José García de Leonardo, Jesús Tronch Pérez, Milagros del Saz Rubio, Carme Manuel Cuenca, Barry Pennock Speck and María José Coperías Aguilar. Valencia: Universidad de Valencia, 2005. CDROM.

CANo ECHEVARRía, Berta. «George Orwell's Spain: Stereotypes, Disorganization and Revolutionary Discipline». Actas XXVIII Congreso Internacional AEDEAN. Ed. Juan José García de 
Leonardo, Jesús Tronch Pérez, Milagros del Saz Rubio, Carme Manuel Cuenca, Barry Pennock Speck and María José Coperías Aguilar. Valencia: Universidad de Valencia, 2005. CD-ROM.

CARMona RodrígueZ, Pedro. «Walking the Streets Dressed Like a Woman: Gender Trouble and the Collapse of the Gender-Sex Equation in Shani Mootoo's Cereus Blooms at Night». Actas XXVIII Congreso Internacional AEDEAN. Ed. Juan José García de Leonardo, Jesús Tronch Pérez, Milagros del Saz Rubio, Carme Manuel Cuenca, Barry Pennock Speck and María José Coperías Aguilar. Valencia: Universidad de Valencia, 2005. CD-ROM.

CARRERA SUÁREZ, Isabel. «Nómada, polícroma o sexuada: La Escocia imaginada en los relatos de Jackie Kay». Creadores de evocación. Nuevos artículos sobre relatos cortos de autores británicos contemporáneos. Ed. José Francisco Fernández Sánchez. Almería: Servicio de Publicaciones de la Universidad de Almería, 2005. 175-188.

CARRETERo GonZÁLEZ, Margarita. «El ensalzamiento del humilde en los relatos cortos de J.R.R. Tolkien». Creadores de evocación. Nuevos artículos sobre relatos cortos de autores británicos contemporáneos. Ed. José Francisco Fernández Sánchez. Almería: Servicio de Publicaciones de la Universidad de Almería, 2005. 15-28.

CASADO Gual, Nuria. «The Gulf Between Books and Experience Is a Lonely Ocean.» An Interview with Zadie Smith». The Polemics of Ageing as Reflected in Literatures in English. Ed. M. Vidal Grau y N. Casado Gual. Lleida: Universitat de Lleida, 2004. 37-44.

Clark, David M. «Lo absurdo de lo cotidiano en la narrativa breve de James Kelman». Creadores de evocación. Nuevos artículos sobre relatos cortos de autores británicos contemporáneos. Ed. José Francisco Fernández Sánchez. Almería: Servicio de Publicaciones de la Universidad de Almería, 2005. 91-106.

Collado Rodríguez, Francisco. El orden del caos: literatura, política y posthumanidad en la narrativa de Thomas Pynchon, Valencia: Biblioteca Javier Coy d' Estudis Nord-Americans, 2004.

COLliER, Gordon. «Light Shed on Darkness: "Homo Senilis" in Philip Larkin's "The Old Fools"». The Polemics of Ageing as Reflected in Literatures in English. Ed M. Vidal Grau y N. Casado Gual. Lleida: Universitat de Lleida, 2004. 45-61.

Constán, Sergio. «Abel Sánchez o la lección aprendida del Dorian Gray: Decadentismo wildiano en Unamuno». Actas del XXVII Congreso Internacional de AEDEAN. Ed. Antonio R. Celada, Daniel Pastor García y Pedro Javier Pardo García. Salamanca: Ambos Mundos, 2004. CDROM.

CoRnut-GentiLle, Chantal. «Merchant and Ivory's Howard's End (1922): How Heritage Speaks to Contemporary Political and Ideological Concerns». Actas XXVIII Congreso Internacional AEDEAN. Ed. Juan José García de Leonardo, Jesús Tronch Pérez, Milagros del Saz Rubio, Carme Manuel Cuenca, Barry Pennock Speck and María José Coperías Aguilar. Valencia: Universidad de Valencia, 2005. CD-ROM.

CResPo Allué, María José. «La visión de España en Joanna Trollope A Spanish Lover y en Sheila O'Flanagan's Isobel's Wedding». Estudios de literatura en lengua inglesa de los siglos XX y XXI (8). Ed. José M. Barrio y Pilar Abad. Valladolid: Universidad de Valladolid, 2005. 133-150.

Douka Kabitoglou, Ekaterine. «Europa in Wonderland: Goblin Market or Sappho's Gymnasium?» En Miscelánea 30 (2004): 51-70.

EAgleton, Mary. «The Danger of Intellectual Masters: Lessons from Harry Potter and Antonia Byatt». Revista Canaria de Estudios Ingleses 48 (2004): 61-76.

EnDER, Evelyne. «Lou Andreas-Salomé, Virginia Woolf, and Annie Ernaux: Towards a Feminist Theory of Narcissism» Revista Canaria de Estudios Ingleses 48 (2004): 15-30.

Elices Agudo, Juan Francisco. «El juego de apariencias y realidad en la tradición épico-burlesca de Don Quijote y An Ice-cream War». Odisea 5 (2004): 61-70. 
Estébanez EstéBAnez, Cayetano. «La versión inglesa de la décima "Estatua Ecuestre", de Jorge Guillén, hecha por George Santayana». Estudios de literatura en lengua inglesa de los siglos XX y XXI (7). Ed. José M. Barrio y Pilar Abad. Valladolid: Universidad de Valladolid, 2004. 79-90.

FERNÁNDEZ SÁNCHEZ, José Francisco, ed. Creadores de evocación. Nuevos artículos sobre relatos cortos de autores británicos contemporáneos. Almería: Servicio de Publicaciones de la Universidad, 2005.

— «La creatividad como salvación. Los relatos de Hanif Kureishi». Creadores de evocación. Nuevos artículos sobre relatos cortos de autores británicos contemporáneos. Ed. José Francisco Fernández Sánchez. Almería: Servicio de Publicaciones de la Universidad de Almería, 2005. 151-162.

FernÁNDEZ RodrígueZ, Carolina. «The Chinese Lobster de A.S. Byatt. Análisis intertextual». Estudios de literatura en lengua inglesa de los siglos XX y XXI (7). Ed. José M. Barrio y Pilar Abad. Valladolid: Universidad de Valladolid, 2004. 113-122

— «Cuentos de ayer y de hoy: De la "heterosexualidad obligatoria' tradicional a la inscripción del amor lésbico» BELLS 13 (2004): Edición electrónica.

FERNÁNDEZ SUÁREZ, José Ramón. «La biografía: un género tan anglosajón (I)». Estudios de literatura en lengua inglesa de los siglos XX y XXI (7). Ed. José M. Barrio y Pilar Abad. Valladolid: Universidad de Valladolid, 2004. 123-138.

— La biografía: un género tan anglosajón (II)». Estudios de literatura en lengua inglesa de los siglos XX y XXI (8). Ed. José M. Barrio y Pilar Abad. Valladolid: Universidad de Valladolid, 2005. 151-162.

FRANCISCO, Francisco José. «Our Western Furniture de James Fenton, una reescritura lirica o/y narrativa de la historia». Estudios de literatura en lengua inglesa de los siglos XX y XXI (8). Ed. José M. Barrio y Pilar Abad. Valladolid: Universidad de Valladolid, 2005. 163-172.

Galván Reula, Fernando. «"Between Othello and Equiano: Caryl Phillips" Subversive Rewritings». Refracting the Canon in Contemporary British Literature and Film. Ed. Susana Onega y Christian Gutleben. Ámsterdam: Rodopi, 2004. 187-205.

— «Ethnicity and New British Writing: Fusions and Confusions». Estudios de literatura en lengua inglesa de los siglos XX y XXI (8). Ed. José M. Barrio y Pilar Abad. Valladolid: Universidad de Valladolid, 2005. 39-56.

García García, Ana Rosa. «Living the Space: The Personal and Collective Experience in Eavan Boland's Vision». Literature, Gender, Space. Ed. Sonia Villegas-López y Beatriz DomínguezGarcía. Huelva: Servicio de Publicaciones de la Universidad de Huelva, 2004. 125-130.

GARCíA LANDA, José Ángel. «Overhearing Narrative». The Dynamics of Narrative Form: Studies in Anglo-American Narratology. Ed. John Pier. Berlin and New York: Walter de Gruyter, 2004.

GARCía SÁNChEz, María Soraya. «Talking About Women, History, and Writing with Michèle Roberts». Atlantis 27.2 (2005): 137-47.

GILABERT BARBERÀ, Pau. «Was the Classical Tradition Betrayed by J. Ivory's Adaptation of E. M. Forster's Maurice?». BELLS 13 (2004). Edición electrónica

Gomis, Annette, and OnEgA, Susana, eds. George Orwell: A Centenary Celebration, Universitätsverlag Carl Winter: Heidelberg, 2005.

GonZÁlez Arias, Luz Mar. «A Piece of Ground I Can Call My Own: Remapping Dublin in Eavan Boland's The Lost Land». Literature, Gender, Space. Ed. Sonia Villegas-López y Beatriz Domínguez-García. Huelva: Servicio de Publicaciones de la Universidad de Huelva, 2004. 175-83.

GonZÁlez CAscos JiméNEZ, Elena. «Phillip Marlowe: Un detective privado. Su código y su voz. Estudios de literatura en lengua inglesa de los siglos XX y XXI (7). Ed. José M. Barrio y Pilar Abad. Valladolid: Universidad de Valladolid, 2004. 147-164.

GonzÁlez DE la Rosa, María del Pilar. «Bettina Selby y Riding to Jerusalem. A Journey Through Turkey and the Middle East: algunos trazos de su cartografía viajera». Géneros en contacto. 
Viajes, crimen, novela femenina y humor. Miscelánea de literatura inglesa y norteamericana. Coord. Henríquez Jiménez, Santiago J. Las Palmas de Gran Canaria: Servicio de Publicaciones de la Universidad de Las Palmas de Gran Canaria/La Caja de Canarias, 2004.79-94.

GoNZÁLEZ MoRENO, Beatriz «De la montaña al horizonte: La expresión estética de lo numinoso». Actas del XXVII Congreso Internacional de AEDEAN. Ed. Antonio R. Celada, Daniel Pastor García y Pedro Javier Pardo García. Salamanca: Ambos Mundos, 2004. CD-ROM.

Gould, Warwick «Writing the Life of the Text: the Case of W. B. Yeats» Miscelánea 30 (2004): 9-34.

GraY, Billy. ""Lucky the Culture Where the Old Can Talk to the Young and the Young Can Talk to the Old": Narrative, Biology and Ageing in the Works of Doris Lessing». Women Ageing Through Literature and Experience. Ed. Brian J. Worsfold. Lleida: Edicions de la Universitat de Lleida, 2005. 43-50.

Gregorio Godeo, Eduardo de. «Women's Magazines' Problem Pages and the Discourse of Femininity in Contemporary UK». Actas XXVIII Congreso Internacional AEDEAN. Ed. Juan José García de Leonardo, Jesús Tronch Pérez, Milagros del Saz Rubio, Carme Manuel Cuenca, Barry Pennock Speck and María José Coperías Aguilar. Valencia: Universidad de Valencia, 2005. CD-ROM.

GutiérReZ ARranz José María. «Lawrence Norfolk's Argonautics». Estudios de literatura en lengua inglesa de los siglos XX y XXI (7). Ed. José M. Barrio y Pilar Abad. Valladolid: Universidad de Valladolid, 2004. 165-174.

HIDALGo ANDRÉu, Pilar. «El texto shakesperiano como crítica cultural: de Brave New World a "Mrs Caliban"». Shakespeare en la imaginación contemporánea. Revisiones y reescrituras de su obra. Coord. Ángeles de la Concha. Madrid: Ediciones UNED, 2004. 171-185.

— «Representing the Holocaust in Martin Amis's Time's Arrow and Caryl Phillips's The Nature of Blood». Towards an Understanding of the English Language, Past, Present and Future: Studies in Honour of Fernando Serrano. Ed. Luis Quereda, Neil Mclaren, José Luis Dueñas Espejo y Carmen Pérez Basanta. Granada: Editorial Universidad de Granada, 2005. 247-260.

— «From Natural History to Neuroscience: Memory and Perception in A.S. Byatt's Fiction». Revista Canaria de Estudios Ingleses 50 (2005): 145-160.

- «Death, Rebirth and the Ageing Woman in A. S. Byatt's "The Djinn in the Nightingale's Eye"». Actas XXVIII Congreso Internacional AEDEAN. Ed. Juan José García de Leonardo, Jesús Tronch Pérez, Milagros del Saz Rubio, Carme Manuel Cuenca, Barry Pennock Speck and María José Coperías Aguilar. Valencia: Universidad de Valencia, 2005. CD-ROM.

-, ARIAS, Rosario y LARA, Carmen. «La novela del Holocausto en Inglaterra: historia, trauma, representación». Actas XXVIII Congreso Internacional AEDEAN. Ed. Juan José García de Leonardo, Jesús Tronch Pérez, Milagros del Saz Rubio, Carme Manuel Cuenca, Barry Pennock Speck and María José Coperías Aguilar. Valencia: Universidad de Valencia, 2005. CDROM.

HuRTLEY, Jacqueline. «Conquering the Clichés: Sexuality and Violence in the Fiction of Patricia Duncker». Estudios de literatura en lengua inglesa de los siglos XX y XXI (8). Ed. José M. Barrio y Pilar Abad. Valladolid: Universidad de Valladolid, 2005. 57-68.

JiMÉNEZ RodríguEZ, Alicia. «Alexa's Quest in Broderie Anglaise by Violet Trefusis». Estudios de literatura en lengua inglesa de los siglos XX y XXI (7). Ed. José M. Barrio y Pilar Abad. Valladolid: Universidad de Valladolid, 2004. 181-188.

LaRA RAllo, Carmen. «Female Ageing as a Thematic Link: Fictionalising Women's Phases of Life in A.S. Byatt's Sugar and Other Stories». Women Ageing Through Literature and Experience. Ed. Brian J. Worsfold. Lleida: Edicions de la Universitat de Lleida, 2005. 51-61.

— «"Pictorial Intertextuality": A. S. Byatt and "Christ in the House of Martha and Mary"». Actas del XXVII Congreso Internacional de AEDEAN. Ed. Antonio R. Celada, Daniel Pastor García y Pedro Javier Pardo García. Salamanca: Ambos Mundos, 2004. CD-ROM. 
— «The Isle is Full of Unheard Noises": Listening to Sycorax in Marina Warner's Indigo». Actas del XXVII Congreso Internacional de AEDEAN. Ed. Antonio R. Celada, Daniel Pastor García y Pedro Javier Pardo García. Salamanca: Ambos Mundos, 2004. CD-ROM.

LÁzARo, Alberto. H. G. Wells en España: estudio de los expedientes de censura (1939-1978). Madrid: Verbum, 2004.

— «Las novelas de D. H. Lawrence ante la censura española». Estudios de literatura en lengua inglesa de los siglos XX y XXI (7). Ed. José M. Barrio y Pilar Abad. Valladolid: Universidad de Valladolid, 2004. 23-36.

- El modernismo en la novela inglesa. Madrid: Editorial Síntesis, 2005.

Llamas MuÑOz, Eugenia. «Intertext and Cybertext: Towards Interactive Fiction». Estudios de literatura en lengua inglesa de los siglos XX y XXI (8). Ed. José M. Barrio y Pilar Abad. Valladolid: Universidad de Valladolid, 2004. 205-202.

Lojo Rodríguez, Laura M. ${ }^{\mathrm{a}}$. «Virginia Woolf and Michel de Montaigne: Ethics and Aesthetics of the Literary Essay». BELLS 13 (2004). Edición electrónica.

— «Virginia Woolf's "Monday or Tuesday" or the Art of Reading» Estudios de literatura en lengua inglesa de los siglos XX y XXI (7). Ed. José M. Barrio y Pilar Abad. Valladolid: Universidad de Valladolid, 2004. 199-204.

— «"Mosaico de recuerdos": Intertextualidad literaria en Crocodile Tears de A S Byatt». Estudios de literatura en lengua inglesa de los siglos XX y XXI (8). Ed. José M. Barrio y Pilar Abad. Valladolid: Universidad de Valladolid, 2005. 215-222.

— «Virginia Woolf y la autobiografía femenina». Actas XXVIII Congreso Internacional AEDEAN. Ed. Juan José García de Leonardo, Jesús Tronch Pérez, Milagros del Saz Rubio, Carme Manuel Cuenca, Barry Pennock Speck and María José Coperías Aguilar. Valencia: Universidad de Valencia, 2005. CD-ROM.

- y SACIDO RoMERO, Jorge. «Intertextualidad y (re)escritura en Virginia Woolf y Michael Cunningham». Actas del XXVII Congreso Internacional de AEDEAN. Ed. Antonio R. Celada, Daniel Pastor García y Pedro Javier Pardo García. Salamanca: Ambos Mundos, 2004. CD-ROM.

Mansilla Blanco, M. Isabel. «The Ghazal: A Review of its Adaptation to English Prosody». Estudios de literatura en lengua inglesa de los siglos XX y XXI (7). Ed. José M. Barrio y Pilar Abad. Valladolid: Universidad de Valladolid, 2004. 213-222

MARRERo Morales, Sandra. «La figura del detective en la ficción policiaca: rasgos característicos y tipología». Géneros en contacto. Viajes, crimen, novela femenina y humor. Miscelánea de literatura inglesa y norteamericana. Coord. Santiago J. Henríquez Jiménez. Las Palmas de Gran Canaria: Servicio de Publicaciones de la Universidad de Las Palmas de Gran Canaria/La Caja de Canarias, 2004. 95-114.

Martínez Alfaro, María Jesús. «Universal Contiguity and the Spinning of Yarns: A Reading of A. S. Byatt's "Arachne”». Actas XXVIII Congreso Internacional AEDEAN. Ed. Juan José García de Leonardo, Jesús Tronch Pérez, Milagros del Saz Rubio, Carme Manuel Cuenca, Barry Pennock Speck and María José Coperías Aguilar. Valencia: Universidad de Valencia, 2005. CD-ROM.

MEDRANO ViCARIO, Isabel. «Más allá de los límites de la razón: una lectura gótica de Wide Sargasso Sea». Ed. M. ${ }^{a}$ Rosario Ozaeta, Doina Popa-Liseanu y Alicia Yllera. Palabras y recuerdos. Homenaje a Rosa María Calvet Lora. Madrid: UNED, 2004. 139-44.

— «La fantasía como vehículo de lo inexpresable: una lectura de Beloved, de Toni Morrison». Ad amicam amicissime scripta. Homenaje a la profesora María José López de Ayala y Genovés. Coord. Jenaro Costas Rodríguez, vol. 2. Madrid: UNED, 2005. 255-64.

MCNAMEE, Brendan. «The human moment: self, other and suspension in John Banville's Ghosts». Miscelánea 32 (2005): 69-86.

— «What then?": Poststructuralism, Authorial Intention and W. B. Yeats». Revista Alicantina de Estudios Ingleses 18 (2005): 215-226. 
MONFORTE, Enric «English Gay/Queer Theatre in the 1990s: Kevin Elyot's My Night with Reg and Mark Ravenhill's Shopping and Fucking». Actas XXVIII Congreso Internacional AEDEAN. Ed. Juan José García de Leonardo, Jesús Tronch Pérez, Milagros del Saz Rubio, Carme Manuel Cuenca, Barry Pennock Speck and María José Coperías Aguilar. Valencia: Universidad de Valencia, 2005. CD-ROM.

— Fouz Santiago, Hidalgo, Juan Carlos, Zamorano, Ana. «Gay/Lesbian/Queer Theories in 21st Century English Studies». Actas XXVIII Congreso Internacional AEDEAN. Ed. Juan José García de Leonardo, Jesús Tronch Pérez, Milagros del Saz Rubio, Carme Manuel Cuenca, Barry Pennock Speck and María José Coperías Aguilar. Valencia: Universidad de Valencia, 2005. CD-ROM.

Montesdeoca Cubas, María del Pino. «Cuando el autor se convierte en personaje: The Last Testament of Oscar Wilde de Peter Ackroyd». Revista Canaria de Estudios Ingleses 48 (2004): $165-178$.

Morales LADRón, Marisol. «La temporalidad bergsoniana en las estéticas de Antonio Machado y James Joyce». BELLS 13 (2004). Edición electrónica.

Moya GutiérRez, Ana. «From Crusoe to the English Patient, or the Transition from the Western Humanist Enlightenment Subject to the White Male Colonialist». BELLS 13 (2004). Edición electrónica.

Nicolás Román, Susana. «Ecos de Fuenteovejuna en Human Canon de Edward Bond». Grove 11 (2004): 125-138.

— «Mujeres de ficción y realidad: una retrospectiva de la guerra civil española en Human Cannon de Edward Bond». Analecta Malacitana 17(2005). Edición electrónica.

Oliete AldEA, Elena. «Reborn from Hybrid "Ashes": Troubled Identities and Nostalgic Views in The Far Pavilions». Odisea 6 (2005): 161-170.

Oliva Cruz, Juan Ignacio, Pascual Nieves, GonZÁlez, M. ${ }^{a}$ Luz. «Representations of Gendered Pain in Contemporary British Writing». Actas XXVIII Congreso Internacional AEDEAN. Ed. Juan José García de Leonardo, Jesús Tronch Pérez, Milagros del Saz Rubio, Carme Manuel Cuenca, Barry Pennock Speck and María José Coperías Aguilar. Valencia: Universidad de Valencia, 2005. CD-ROM.

Onega, Susana, and Gutleben Christian, eds. Refracting the Canon in Contemporary Literature and Film. (Postmodern Studies Series, 35). Amsterdam: Rodopi, 2004.

O’NeILl, María. «Virginia Wolf: The Architecture of Gender». Literature, Gender, Space. Ed. Sonia Villegas-López y Beatriz Domínguez-García. Huelva: Servicio de Publicaciones de la Universidad de Huelva, 2004. 85-95.

Oró PIQUERAs, Maricel. «The Ups and Downs of Ageing in Rose Tremain's Sadler's Birthday and The Cupboard». The Polemics of Ageing as Reflected in Literatures in English. Ed M. Vidal Grau y N. Casado Gual. Lleida: Universitat de Lleida, 2004. 113-123.

— «From Childhood to Old Age with a Sigh in Julian Barnes's Staring at the Sun». Women Ageing Through Literature and Experience. Ed. Brian J. Worsfold. Lleida: Edicions de la Universitat de Lleida, 2005. 83-89.

Palacios GonzÁlez, Manuela. «Ian McEwan y la lectura zozobrante». Creadores de evocación. Nuevos artículos sobre relatos cortos de autores británicos contemporáneos. Ed. José Francisco Fernández Sánchez. Almería: Servicio de Publicaciones de la Universidad de Almería, 2005. 121-132.

PALKA, Ewa. «The secular and the divine in T. S. Eliot's "Ash-Wednesday' and John Donne's "Devotions"». Estudios Ingleses de la Universidad Complutense, 13 (2005): 123-137.

Pérez Díez, Carmen. «Harry Potter and the Philosopher's Stone: la magia de la palabra vs. la magia de la imagen». Estudios de literatura en lengua inglesa de los siglos XX y XXI (7). Ed. José M. Barrio y Pilar Abad. Valladolid: Universidad de Valladolid, 2004. 247-252. 
PÉREZ GIL, María del Mar. «Exploraciones virtuales: el tiempo y la pasión en The PowerBook, de Jeannette Winterson». Géneros en contacto. Viajes, crimen, novela femenina y humor. Miscelánea de literatura inglesa y norteamericana. Coord. Henríquez Jiménez, Santiago J. Las Palmas de Gran Canaria: Servicio de Publicaciones de la Universidad de Las Palmas de Gran Canaria/La Caja de Canarias, 2004. 115-126.

PÉREZ VAldÉs, Auxiliadora. «Religious Prisoners: Convents and Workhouses for Irish Single Mothers in Marita Conlon-Mckenna's The Magdalen (1994)». Literature, Gender, Space. Ed. Sonia Villegas-López y Beatriz Domínguez-García. Huelva: Servicio de Publicaciones de la Universidad de Huelva, 2004. 53-62.

Pezzulich, Evelyn. «Breaking the Last Taboo: The Ageing Female Protagonist in Literature». Women Ageing Through Literature and Experience. Ed. Brian J. Worsfold. Lleida: Edicions de la Universitat de Lleida, 2005. 91-98.

RodríGUEZ GonZÁLEZ, Carla, Jackie Kay: biografías de una Escocia transcultural. Oviedo: KRK, 2005.

— «An Interview with Liz Lochhead» Atalntis 26.1 (2004): 101-110.

— «Parodying and Transvesting the Historic: Liz Lochhead's Mary Queen of Scots Got Her Head Chopped Off». Odisea 5 (2004): 143-156.

— «Alternativas genealógicas en The Adoption Papers de Jackie Kay». Actas XXVIII Congreso Internacional AEDEAN. Ed. Juan José García de Leonardo, Jesús Tronch Pérez, Milagros del Saz Rubio, Carme Manuel Cuenca, Barry Pennock Speck and María José Coperías Aguilar. Valencia: Universidad de Valencia, 2005. CD-ROM.

RodríGUEZ GuerRero-STRACHAN, Santiago. «¿Híbrido, postmoderno o simplemente cuento? Los relatos de Ben Okri». Creadores de evocación. Nuevos artículos sobre relatos cortos de autores británicos contemporáneos. Ed. José Francisco Fernández Sánchez. Almería: Servicio de Publicaciones de la Universidad de Almería, 2005. 163-174.

Rodríguez Montón, Sonia. "Verses About a "Crime": Gwendolyn Brooks" "The Mother" and Lucille Clifton's "The Lost Baby Poem"». Estudios de literatura en lengua inglesa de los siglos XX y XXI (8). Ed. José M. Barrio y Pilar Abad. Valladolid: Universidad de Valladolid, 2005. 267-271.

RODRÍGUEZ SALAS, Gerardo. «Desenmascarando la maternidad: la imitación intencionada en Katherine Mansfield». El Cuento en Red. Revista electrónica de teoría de la ficción breve 10 (2004): 1-16.

— «Demystifying the wickedness of women: the femme fatale in Katherine Mansfield». Considering Evil and Human Wickedness. Eds. Daniel E. Keen y Pamela Rossi Keen. Oxford: InterDisciplinary Press, 2004. 211-222.

— «Diálogos para una voz: la narrativa experimental de Katherine Mansfield». Towards an Understanding of the English language, Past, Present and Future: Studies in Honour of Fernando Serrano. Eds. Luis Quereda, Neil McLaren, José Luis Dueñas Espejo y Carmen Pérez Lasanta. Granada: Editorial Universidad de Granada, 2005. 347-60.

— «The Postmodernist Katherine Mansfield: Beyond the Self of Modernism in "The GardenParty"». Agora: A Humanities Online Journal 3.2 (2005): 1-11.

Rogobete, Daniela. «Fuera del laberinto. Las representaciones textuales y visuales en las historias cortas de Alasdair Gray». Creadores de evocación. Nuevos artículos sobre relatos cortos de autores británicos contemporáneos. Ed. José Francisco Fernández Sánchez. Almería: Servicio de Publicaciones de la Universidad de Almería, 2005. 45-62.

Román, Susana N. «Después de Brecht: el teatro de Edward Bond». Odisea 5 (2004): 169-178.

RossinI, Manuela. «Figurations of Posthumanity in Contemporary Science / Fiction: All Too Human(ist)?». Revista Canaria de Estudios Ingleses 48 (2004): 21-37.

RuIz MÁs, José. «A la búsqueda del dorado: "Expatriates” en España (1940-2002) según sus relatos de viajes». El bisturí inglés: literatura de viajes e hispanismo en lengua inglesa. Ed. 
Carmelo Medina Casado y José Ruiz Mas. Jaén: Universidad de Jaén/UNED, 2004. 262306.

SACIDO Romero, Jorge. «The Master-Slave Dialectic in Joseph Conrad's The Nigger of the Narcissus» Estudios de literatura en lengua inglesa de los siglos XX y XXI (7). Ed. José M. Barrio y Pilar Abad. Valladolid: Universidad de Valladolid, 2004. 305-314.

— «It Is-Hell": Imaginary Intersubjectivity in Conrad's Lord Jim: A Tale». Actas XXVIII Congreso Internacional AEDEAN. Ed. Juan José García de Leonardo, Jesús Tronch Pérez, Milagros del Saz Rubio, Carme Manuel Cuenca, Barry Pennock Speck and María José Coperías Aguilar. Valencia: Universidad de Valencia, 2005. CD-ROM.

SÁNCHEZ CALVo, Arsenio. «E.M Forster y la novela moderna». Estudios de literatura en lengua inglesa de los siglos XX y XXI (8). Ed. José M. Barrio y Pilar Abad. Valladolid: Universidad de Valladolid, 2005. 279-288.

SÁNCHEZ CuERVo, Margarita Esther. «The Gendered Sentence in the Essays of Virginia Woolf». Actas del XXVII Congreso Internacional de AEDEAN. Ed. Antonio R. Celada, Daniel Pastor García y Pedro Javier Pardo García. Salamanca: Ambos Mundos, 2004. CD-ROM.

Sánchez-Palencia Carazo, Carolina. «Postales desde la diáspora: los relatos de Salman Rushdie». Creadores de evocación. Nuevos artículos sobre relatos cortos de autores británicos contemporáneos. Ed. José Francisco Fernández Sánchez. Almería: Servicio de Publicaciones de la Universidad de Almería, 2005. 107-120.

SÁNCHEZ-PARDO, Esther, «"What Phantasmagoria the Mind Is": Reading Virginia Woolf's Parody of Gender». Atlantis 26.2 (2004): 75-86.

SANTos VILA, Sonia. «Huellas místicas en la lírica de T. S. Eliot y Dámaso Alonso». Actas XXVIII Congreso Internacional AEDEAN. Ed. Juan José García de Leonardo, Jesús Tronch Pérez, Milagros del Saz Rubio, Carme Manuel Cuenca, Barry Pennock Speck and María José Coperías Aguilar. Valencia: Universidad de Valencia, 2005. CD-ROM.

SHATTOCK, Joanne. «La literatura de viajes victoriana y moderna: una reseña sobre investigaciones recientes» Nerter: Revista dedicada a la literatura, el arte y el conocimiento 7 (2004): $39-41$.

Sierra Ayala, Lina. «Dos discursos diferentes en The House in Paris de Elizabeth Bowen: Pragmatismo versus romanticismo, realidad versus fantasía». Estudios de literatura en lengua inglesa de los siglos XX y XXI (7). Ed. José M. Barrio y Pilar Abad. Valladolid: Universidad de Valladolid, 2004. 343.

— «Maternidad, familia y sociedad en The Return of The Soldier y The Judge de Rebecca West» Estudios de literatura en lengua inglesa de los siglos XX y XXI (8). Ed. José M. Barrio y Pilar Abad. Valladolid: Universidad de Valladolid. 2005. 315-324.

Silva CAMPAÑón, Carlos. «Through the Looking Glass: America in Martin Amis's Money: A Suicide Note». Atlantis 26.2 (2004): 87-96.

SutTon, Philip. «Pioneering Postmodernism in Sixties Television Fantasy: The Avengers and The Prisoner». Estudios de literatura en lengua inglesa de los siglos XX y XXI (8). Ed. José M. Barrio y Pilar Abad. Valladolid: Universidad de Valladolid, 2005. 329-348.

TABAREs PÉREZ, Patricia. "The Lady of Verse Has the Language on the Ropes" An Introduction to Carol Ann Duffy's Poetry». Estudios de literatura en lengua inglesa de los siglos XX y XXI (8). Ed. José M. Barrio y Pilar Abad. Valladolid: Universidad de Valladolid, 2005. 349-356.

TERRAZAS, Melania. Relational Structures in Wyndham Lewis's Fiction: Complexity and Value. München: Lincom Europa, 2005.

UsandiZAGa SÁINZ, María Aranzazu. «Love that Kills: Anita Brookner's Revision of the Romance in The Rules of Engagement». Revista Canaria de Estudios Ingleses 48 (2004): 89-104.

-, MonicKendaM, Andrew y CuRBET, Joan. «Embattled Cities: London in the Literary Imagination». Actas XXVIII Congreso Internacional AEDEAN. Ed. Juan José García de Leonardo, Jesús 
Tronch Pérez, Milagros del Saz Rubio, Carme Manuel Cuenca, Barry Pennock Speck and María José Coperías Aguilar. Valencia: Universidad de Valencia, 2005. CD-ROM.

VALVERDE JIMÉNEZ, Beatriz. «Acercamiento a la obra de Graham Greene». Grove, 11 (2004): 191-208.

VILLAR FloR, Carlos. «Graham Greene, a Cinematic Novelist. Some Theoretical Aspects of the Influence of Cinema on Greene's Fiction» Estudios de literatura en lengua inglesa de los siglos XX y XXI (8). Ed. José M. Barrio y Pilar Abad. Valladolid: Universidad de Valladolid, 2005. 377-384.

- y MurraY, Robert, eds. Waugh Without End. New Trends in Evelyn Waugh Studies. Bern: Peter Lang, 2005.

VILLEGAS LóPEZ, Sonia. «El relato breve como autobiografía feminista en The Ice is Singing, de Jane Rogers». Creadores de evocación. Nuevos artículos sobre relatos cortos de autores británicos contemporáneos. Ed. José Francisco Fernández Sánchez. Almería: Servicio de Publicaciones de la Universidad de Almería, 2005. 133-150.

Wallhead, Celia. «A.S. Byatt y su metáforas de creatividad». Creadores de evocación. Nuevos artículos sobre relatos cortos de autores británicos contemporáneos. Ed. José Francisco Fernández Sánchez. Almería: Servicio de Publicaciones de la Universidad de Almería, 2005. 63-76.

— «The Breakdown of the Individual's Defences in Charismatic Cults: A.S.Byatt's A Whistling Woman». Actas del XXVII Congreso Internacional de AEDEAN. Ed. Antonio R. Celada, Daniel Pastor García y Pedro Javier Pardo García. Salamanca: Ambos Mundos, 2004. CD-ROM.

Wells-Lassagne, Shanon. «Irlanda y los angloirlandeses en los relatos de Elizabeth Bowen». Creadores de evocación. Nuevos artículos sobre relatos cortos de autores británicos contemporáneos. Ed. José Francisco Fernández Sánchez. Almería: Servicio de Publicaciones de la Universidad de Almería, 2005. 29-44.

ZAMORANO, Ana. «Our Radical Strangeness and the Space in Between: Intertextuality and Abjection». European Intertexts: Women Writing in English in a European Context. Ed. Patsy Stoneman y Ana María Sánchez-Arce with Angela Leighton. Oxford, Frankfurt, New York: Peter Lang, 2005: 127-148.

Zamorano Llena, Carmen. «"Words we can grow old and die in": Female Reconstruction of the Irish Literary Idiom in Eavan Boland's Later Poetry». Women Ageing Through Literature and Experience. Ed. Brian J. Worsfold. Lleida: Edicions de la Universitat de Lleida, 2005. 127-38.

\section{MisCELÁNEA}

Álvarez Amorós, José Antonio, Miguel Alfonso, Ricardo, Ballesteros GonzÁlez, Antonio y CAPORAle BIZZINI, Silvia.. Teoría literaria y enseñanza de la literatura. Barcelona: Ariel, 2004.

ANTÓN-PACHECO, Ana et al. eds. Estudios de la mujer VII: discursos e identidades. Madrid: Universidad Complutense de Madrid, 2005.

Ballesteros GonzÁlez, Antonio. Escrito por brujas. Lo sobrenatural en la vida y la literatura de grandes mujeres del siglo XIX. Madrid: Oberon, 2005.

Bastida Rodríguez, Patricia, Fresno Calleja Paloma, English Literature: An Anthology. Palma de Mallorca: Servicio de Publicaciones de la Universitat de las Illes Balears, 2005.

Bengoechea, Mereces, Cerezo, Marta, Concha Ángeles de la. «Literatura y violencia de género: cuestiones de representación». Actas del XXVIII Congreso Internacional de Aedean. Mesa redonda. Valencia: Ediciones de la Universitat de Valencia, 2005. CD-ROM.

BERnal RodrígueZ, Manuel. «Andalucía durante la invasión napoleónica según un enviado espacial británico: Las Cartas de William Jacob». El bisturí inglés: literatura de viajes e hispanismo en lengua inglesa. Ed. Carmelo Medina Casado y José Ruiz Mas. Jaén: Universidad de Jaén/UNED, 2004. 63-74. 
CARABí, Àngels and Josep M. Armengol, eds. Debating Masculinity/La masculinidad a debate. Barcelona: Publicacions de la Universitat de Barcelona, 2005. DVD.

CARAmÉs Lage, José Luis, MenÉndez Rodríguez, Natalia. Literatura contemporánea inglesa. Temarios: Literaturas en lengua inglesa. Liceus.com., 2005.

-, MenÉndez RodríGuez, Natalia y Escobedo DE TAPIA, Carmen. Literatura contemporánea en lengua inglesa. Oviedo: Trabe, 2005.

CELADA, Antonio R. et al., eds. Actas del XXVII Congreso Internacional de AEDEAN. Salamanca: Ambos Mundos, 2004. CD-ROM.

CONCHA, Ángeles de la y OsBORNE, Raquel, coords. Las mujeres y los niños primero: discursos de la maternidad. Barcelona: Icaria, 2004.

— «Introducción.» Las mujeres y los niños primero: discursos de la maternidad. Barcelona: Icaria, 2004. 7-42.

— «La figura materna: un problema transcultural. Reflexiones sobre su representación en la novela de autoría femenina». Las mujeres y los niños primero: discursos de la maternidad. Coord. Ángeles de la Concha y Raquel Osborne. Barcelona: Icaria, 2004. 155-178.

— «El conflicto entre la historia y su representación. Tempestades reales, pictóricas y literarias». Estudios de Filología Inglesa en honor de Antonio Garnica. Ed. Francisco Garrudo Carabias y Joaquín Comesaña Rincón. Sevilla: Secretariado de Publicaciones de la Universidad de Sevilla, 2005. 129-142.

CORA Alonso, Jesús. Literatura extranjera, literatura inglesa. Madrid: Universidad Nacional de Educación a Distancia, 2005.

DEMETRIou, Eroulla y RuIz Más, José. English Travel Literature in Cyprus (1878-1960). Granada: Centro de Estudios Bizantinos, Neogriegos y Chipriotas en asociación con la A.G. Leventis Foundation, 2004.

Elices Agudo, Juan Francisco. Historical and Theoretical Approaches to English Satire. München: LINCOM Studies in English Linguistics 08, 2005.

EstéVEZ SAÁ, Margarita. «Espacios fantasmales: evolución de los espacios liminales en las narraciones de fantasmas en lengua inglesa escritas por mujeres». Mujeres, espacio y poder. Coord. Mercedes Arriaga Flórez. Sevilla: ArCiBel Editores, 2004. 253-265.

FERNÁNDEZ RodríGUEZ, Carolina. «Cuentos de ayer y de hoy: de la heterosexualidad obligatoria tradicional a la inscripción del amor lésbico». BELLS, 13 (2004). Edición electrónica.

Fresno Calleja, Paloma. «Travesías literarias en el pacífico: de los mares del sur a la nueva Oceanía». BELLS, 13 (2004). Edición electrónica.

GARCíA DE LeONARdo, Juan José et al., eds. Actas XXVIII Congreso Internacional AEDEAN. Valencia: Universidad de Valencia, 2005. CD-ROM.

GarCíA LANDA, José Ángel. 2005. A Bilbiography of Literary Theory, Criticism and Philology. $10^{\text {th }}$ edition. Edición electrónica.

— «The Hermeneutic Spiral from Schleiermacher to Goffman: Retroactive Thematization, Interaction, and Interpretation». BELL (Belgian English Language and Literature) 2 (2004): 155-66.

— «Tematización retroactiva, interacción e interpretación: La espiral hermenéutica de Schleiermacher a Goffman». Hans-Georg Gadamer: Ontología estética y hermenéutica. Ed. Teresa Oñate y Zubía, Cristina García Santos y Miguel Ángel Quintana Paz. Madrid: Dickinson, 2005. 679-88.

GARCíA-Romeral PÉREZ, Carlos. «El viajero anglosajón por España: de la curiosidad al conocimiento». El bisturí inglés: literatura de viajes e hispanismo en lengua inglesa. Ed. Carmelo Medina Casado y José Ruiz Más. Jaén: Universidad de Jaén/UNED, 2004. 105-39.

GARRIGós GonZÁLEZ, Cristina. «Hacia una estética poliglósica de constructos heteroglósicos: literatura comparada e interculturalidad». BELLS, 13 (2004). Edición electrónica. 
GUIJARRo OJEA, Juan Ramón. «El teatro en lengua inglesa: perspectivas didácticas para una educación axiológica». Publicaciones de la Facultad de Educación y Humanidades del Campus de Melilla 34 (2004): 81-94.

— «Educar para la otredad: usos didácticos de la poesía en lengua inglesa». Lenguaje y textos 23 (2005): 139-148.

HenRíQUez JimÉNEZ, Santiago J., Géneros en contacto. Viajes, crimen, novela femenina y humor. Miscelánea de literatura inglesa y norteamericana. Las Palmas de Gran Canaria: Universidad de Las Palmas de Gran Canaria/La Caja de Canarias, 2004.

— «Values and Visions in Dalrymple's Travel Writing: A Sort of Interview». Géneros en contacto. Viajes, crimen, novela femenina y humor. Miscelánea de literatura inglesa y norteamericana. Coord. Henríquez Jiménez, Santiago J., Las Palmas de Gran Canaria: Servicio de Publicaciones de la Universidad de Las Palmas de Gran Canaria/La Caja de Canarias, 2004. 179-184.

Humm, Maggie. «Into the Millenium: Feminist Literary Criticism» Revista Canaria de Estudios Ingleses 48 (2004): 45-60.

JiMÉNEZ VílCHEZ, Teresa et. al. Palabra de mujer. Sevilla: Junta de Andalucía, 2005. CD-ROM.

KraUel HerediA, Blanca. «"Spanish Ladies": la visión del viajero». El bisturí inglés: literatura de viajes e hispanismo en lengua inglesa. Ed. Carmelo Medina Casado y José Ruiz Mas. Jaén: Universidad de Jaén/UNED, 2004. 141-172.

LEACH, Heather. «Crossing the Line». Women Ageing Through Literature and Experience. Ed. Brian J. Worsfold. Lleida: Edicions de la Universitat de Lleida, 2005. 63-71.

LÓPEZ, Gema y MOYA GuTIÉREZ, Ana. Literatura anglesa dels orígens al segle XVIII/ English Literature from its Origins to the 17th Century. Barcelona: Publicacions I Edicions, Universitat de Barcelona, 2005.

LóPEz Burgos, María Antonia. Stand and Deliver!: Spanish Bandits of Olden Times. Benalmádena, Málaga: Caligrama, 2004.

— «Viajeras por España: audaces, intrépidas y aventureras». El bisturí inglés: literatura de viajes e hispanismo en lengua inglesa. . Ed. Carmelo Medina Casado y José Ruiz Más. Jaén: Universidad de Jaén/UNED, 2004. 173-220.

López-Peláez Casellas, Jesús, Malcolm, David, y Sánchez Calle, Pilar, eds. Masquerades. Disguise in Literature in English from the Middle Ages to the Present. Gdansk: Gdansk University Press, 2004.

Martínez Torrón, Diego y Dietz, Bernd eds. Cervantes y el ámbito anglosajón. Madrid: SIAL Ediciones, 2005.

Medina CASADO; Carmelo y Ruiz Más, José, eds.. El bisturí inglés. Literatura de viajes e hispanismo en lengua inglesa. Jaén: Universidad de Jaén, 2004.

— «Introducción: Viajeros e hispanistas, compañeros de ruta». El bisturí inglés: literatura de viajes e hispanismo en lengua inglesa. Ed. Carmelo Medina Casado y José Ruiz Mas. Jaén: Universidad de Jaén/UNED, 2004.11-33.

MEDRANO, Isabel y ZAMORANO, Ana. «Publicaciones sobre Filología Inglesa en España (20022003). Literatura Inglesa». Epos XX/XXI (2004-2005): 292-314.

MonterReY, Tomas. «Literature and Science». Revista Canaria de Estudios Ingleses 50 (2005): 17-21.

PARdo GARCía, Pedro Javier. «El Quijote y la novela inglesa: de Laurence Sterne a James Joyce». La ficción novelesca en los Siglos de Oro y la literatura europea. Coord. María Cruz Buitrago Gómez y Ricardo Senabre Sempere. Madrid: Ministerio de Educación y Ciencia, 2005. 57-71.

Pascual Garrido, M. ${ }^{a}$ Luisa et al. eds. Jornadas de Filología Inglesa: Actas de las IV Jornadas de Filología Inglesa. Córdoba: Servicio de Publicaciones de la Universidad de Córdoba, 2004.

— «Acomodándose a los tiempos: Cervantes a través de las relecturas de La española inglesa en la cultura anglófona». Cervantes y el ámbito anglosajón. Ed. Diego Martínez Torrón y Bern Dietz. Madrid: SIAL Ediciones, 2005. 376-405. 
Pascual Soler, María Nieves. «Writing Pain as an Act of Self-injury». Revista Canaria de Estudios Ingleses 48 (2004): 205-222.

Quereda, Luis, Mclaren, Neil, Dueñas Espejo, José Luis y Pérez Basanta, Carmen, eds. Towards an understanding of the English Language, Past, Present and Future: Studies in Honour of Fernando Serrano Granada: Editorial Universidad de Granada. 2005.

Soto García, Isabel. Comentario de textos literarios ingleses: Guía Didáctica. Madrid: UNED, 2005.

SPIES, Marion. «Travellers, Exiles, Colonists: Their Perspectives of European Literary Tradition». Géneros en contacto. Viajes, crimen, novela femenina y humor. Miscelánea de literatura inglesa y norteamericana. Coord. Henríquez Jiménez, Santiago J., Las Palmas de Gran Canaria: Servicio de Publicaciones de la Universidad de Las Palmas de Gran Canaria/La Caja de Canarias, 2004. 133-158.

Stoneman, Patsy y SÁnchez-Arce, Ana María con Angela Leighton, eds. European Intertexts: Women Writing in English in a European Context. Oxford, Frankfurt, New York: Peter Lang, European Connections Series 13, 2005.

Tazón Salces, Juan E. e Isabel Carrera SuÁrez, eds. Post-Imperial Encounters: Anglo-Hispanic Cultural Relations (Studies in Comparative Literature 45). Amsterdam and New York: Rodopi, 2005.

VERA CAZORLA, «Marian Keyes: el humor de lo cotidiano». Géneros en contacto. Viajes, crimen, novela femenina y humor. Miscelánea de literatura inglesa y norteamericana. Coord. Henríquez Jiménez, Santiago J., Las Palmas de Gran Canaria: Servicio de Publicaciones de la Universidad de Las Palmas de Gran Canaria/La Caja de Canarias, 2004. 159-176.

VIDAL Grau, María y CASADO GuAL, Nuria eds. The Polemics of Ageing as Reflected in Literatures in English. Lleida: Edicions de la Universitat de Lleida, 2004.

Villegas-LóPez, Sonia, y Domínguez-García, Beatriz, eds. Literature, Gender, Space. Huelva: Servicio de Publicaciones de la Universidad de Huelva, 2004.

VIVIÈs, Jean. «La mano del alfarero: el relato de viajes en la literatura inglesa». Quimera 246-247 (2004): 47-50.

WORSFOLD, Brian J. ed. Women Ageing Through Literature and Experience. Lleida: Edicions de la Universitat de Lleida, 2005. 


\title{
B. LITERATURA NORTEAMERICANA
}

\author{
M. ${ }^{a}$ Antonia Álvarez Calleja \\ malvarez@flog.uned.es \\ GRETCHEN DOBROTT \\ gdobrott@flog.uned.es \\ UNED. Madrid
}

ÍNDICE

1. Siglos XVII-XVIII

2. Siglo XIX

3. Siglo xx y Contemporánea

\section{SIGLOS XVII-XVIII}

Gallego Durán, Mar. «Eighteenth Century Sentimental Novels: Forging a Female Space». Literature, Gender, Space. Ed. Sonia Villegas-López y Beatriz Domínguez-García. Huelva: Servicio de Publicaciones de la Universidad de Huelva, 2004. 211-20.

Lerate de Castro, Jesús y Flores Ruiz, Eva M. ${ }^{\mathrm{a}}$ «Puritan Women Facing Suffering: Texts as Tests of Survival in Bradstreet's "Verses upon the Burning of our House" and Rowlandson's The Sovereignty and Goodness of God». Revista de Estudios Norteamericanos 10 (2004): 95-110.

ManUEl, Carme. «The Day of Doom and the Memory of Slavery: Octavia E. Butler's Prophetic Vision in "Parable of the Sower"». Revista de Estudios Norteamericanos 10 (2004): 111-24.

Martín SalvÁn, Paula. «Don Diego Puede-Ser (James Mabbe)'s English rendering of Cervantes' Novelas Ejemplares. Cervantes y el ámbito anglosajón. Eds. Diego Martínez Torrón y Bernd Dietz. Madrid: SIAC. 2005.

Martínez Falquina, Silvia. «Entries into Autobiographical I, or the Ethics of Native American Storytelling». Actas XXVIII Congreso Internacional AEDEAN. Valencia: Universidad de Valencia (CD-Rom), 2004. 369-77.

UrbinA, Eduardo. «La ficción que no cesa: Cervantes y Paul Auster». Cervantes y el ámbito anglosajón. Ed. Diego Martínez Torrón y Bernd Dietz. Madrid: SIAL Ediciones, 2005. 433-42.

SIGLO XIX

Álvarez Calleja, M. a Antonia. «The Theme of Freedom vs Love in "The Story of an Hour", by Kate Chopin». Anglo-Saxónica. Revista do Centro de Estudos Anglisticos da Universidade de Lisboa 2. 21 (2004): 41-52.

— «The Breach Between Henry James's Novels and Movies». Filmowe gry z Twórczoscia Henry' ego Jamesa. Transpozycje, komentarze, analogie. Ed. Miroslawy Buchholtz. Torun, Polonia: Wydawnictwo Uniwersytetu Mikolaja Kopernika. 2005. 137-48.

— «Eric Haralson: Henry James and Queer Modernity». Interactions. Ege Journal of English and American Studies 13.2 (Fall, 2004): 41-47. 
CASADO DA Rocha, Antonio. «Javier Alcoriza y Antonio Lastra: Walden, de Henry David Thoreau». Atlantis 27.2 (2005): 191-95.

CRUZ ACEVEDO, David. «Lecturas y andanzas: la influencia de Cervantes en Melville y Pynchon». Cervantes y el ámbito anglosajón. Eds. Diego Martínez Torrón y Bernd Dietz. Madrid: SIAC. 2005.

GolkhosRavi, Mehrad. «"Panentheistic" View of Divine Love in Man and Nature: a Comparative Study in Whitman's Leaves of Grass and Maulana Jalal-al-Dim Rumi's Mathnavi». BELLS 13 (2004).

MARTín GonZÁLEZ, Matilde. «A Backward Glance: Theorizing Edith Wharton's Autobiographical Subjectivity». Revista canaria de estudios ingleses 48 (2004): 147-64.

NARbona CARrión, María Dolores. «La atalanta de "Doctor Zay": testimonio del uso y de la recreación de la mitología clásica por parte de las escritoras norteamericanas del siglo XIX». Odisea 5 (2004): 109-20.

— La obra de Elizabeth Stuart Phelps: de la "true woman" a la "new woman". Málaga: Universidad de Málaga, 2004.

Oliva CRUZ, Juan Ignacio. «Stephen Crane, el valor de la moral o la moral del valor: una nueva edición de The Red Badge of Courage». Revista canaria de estudios ingleses 50 (2005): 139-62.

Olivares Merino, Julio Ángel. «Interpreting and Handling (with care) Henry James's "The turn of the Screw"». Grove 11 (2004): 139-55.

ÖZYRUT KYLYÇ, Mine. «Demythologizing History: Jeanette Winterson's Fictions and His/Tories». Feminismo/s 4 (2004): 127-34.

PALKA, Ewa. «The escular and the Divine in T. S. Eliot's "Ash-Wednesday' and John Donne's "Devotions". Estudios ingleses de la Universidad Complutense 13 (2005): 123-37.

RODRÍGUEZ RodRíGUEZ, Félix. «Supervivencia, testimonio y envejecimiento: la escritura necrológica de Mark Twain y Roland Barthes». Estudios ingleses de la Universidad Complutense 12 (2004): 179-88.

RuIz MAS, José. "Authority, Sexual Maturity, Homosexuality, "Canes", "Cudgels", "Swords" and "Staffs" in Nathaniel Hawthorne's "My Kinsman, Major Molineux"». Odisea 5 (2004): 179-86.

\section{SigLO XX Y CONTEMPORÁNEA}

AdÁN-Lifante, Virginia. «Rewriting History and Culture: "El baúl de Miss Florence" by Ana Lydia Delgado». Revista de Estudios Norteamericanos 10 (2004): 9-20.

Aguilera Linde, Mauricio D. «Hemingway and Gender: Biography Revisited» Atlantis 27.2 (2005): 15-26.

Allen, Woody. «Mi filosofía.» Trans. Marcelo Covián. Enfocartea 22 (2003). 2 Sept. 2004 $<$ http://www.enfocarte.com/3.22/filosofia2/html>.

Alonso Gallo, Laura P. y MurRieta, Fabio, eds. Guayaba Sweet: literatura cubana en Estados Unidos. Cádiz: Aduana Vieja, D.L. 2004.

Alsina RísQuez, Cristina. «"Men and Women: Contemporary American Women Writing about Men". Re-visiting Grand Narratives of Hegemonic Masculinity. The Desmitification of Technomuscular Masculinity in Bobbie Ann Mason's In Country and Jane Anne Phillips' Machine Dreams». Actas XXVIII Congreso Internacional AEDEAN. Valencia: Universidad de Valencia (CD-Rom), 2004. 686-96.

Álvarez Calleja, M. ${ }^{a}$ Antonia. «Búsqueda de identidad en el discurso chicano: Woman Hollering Creek, de Sandra Cisneros». Estudios de Filología Inglesa en honor de Antonio Garnica. Serie Lingüística 25. Sevilla: Secretariado de Publicaciones Universidad, 2005. 37-52. 
— «Narrative Power from the Metaphor of Witnessing: Written Testimonio by Ethnic Groups». Biography versus Fiction: The Value of Testimony. La Review LISA/LISA II. 4 (2004): 183-94.

— «La autobiografía norteamericana como expresión de identidad nacional». Religión y Cultura $\mathrm{L}$ (abril-junio, 2004): 293-326.

— «Floyd Collins's Seamus Heaney: The Crisis of Identity». The AnaChronist 10 (2004): 203-06.

ANDRÉS, Rodrigo. «"Men and Women: Contemporary American Women Writing about Men". Ahab's Wife. Contemporary Re-writing of Melvillean Masculinities». Actas XXVIII Congreso Internacional AEDEAN. Valencia: Universidad de Valencia (CD-Rom), 2004. 683-86.

ARIAS Doblas, Rosario. «Talking with the Dead: Revisiting the Victorian Past and the Occult in Margaret Atwood's "Alias Grace" and Sarah Water's "Affinity"». Estudios ingleses de la Universidad Complutense 13 (2005): 85-105.

Armengol, Joseph M. «Attention, Attention must be Finally Paid to such a Person: A Men's Studies Rereading of Arthur Miller's Death of a Salesman». Revista de Estudios Norteamericanos 10 (2004): 21-46.

— «Angels vs. Whores? Women in Arthur Miller's Death of a Salesman». Actas XXVIII Congreso Internacional AEDEAN. Valencia: Universidad de Valencia (CD-Rom), 2004. 23-30.

Baelo Allué, Sonia. «When Context Hides Context: A Retrospective Reading of "Glamorous Ama's (1998) Reception”». Revista de Estudios Norteamericanos 10 (2004): 47-56.

BARRIO MARCO, José Manuel. «El viaje como género y arquetipo cultural de la literatura nortea-

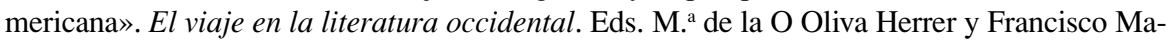
nuel Marino. 2004. 199-208.

BARRIOS, Olga y Frances Smith Foster, eds. Family in Africa and the African Diáspora: A Multidisciplinary Approach. Salamanca: Almar, 2004.

Brito, Manuel; Martín GonZÁlez, Matilde y Power, Kevin. «Anthologies, Social Practice and Language in Late 20th Century American Poetry and Poetics». Actas XXVIII Congreso Internacional AEDEAN. Valencia: Universidad de Valencia (CD-Rom), 2004. 591-602.

— «Singladuras poéticas americanas desde el modernismo hasta hoy». Géneros en contacto: viajes, crímenes, novela femenina y humor. Miscelánea de literatura inglesa y norteamericana. Ed. Santiago José Henríquez Jiménez. Las Palmas de Gran Canaria: Servicio de Publicaciones de la Universidad. La Caja de Canarias. 2004. 33-51.

CABallero Aceituno, Yolanda. «Double Revolutions: Chicana Fiction and the Revitalisation of the Social Function of Literary Discourse: Sandra Cisneros' Example» Grove 11 (2004): 25-36.

CABELlo PINO, Manuel. «El plan infinito o la sociedad norteamericana de postguerra según Isabel Allende». La literatura en la literatura. Actas del XIV Simposio de la Sociedad Española de Literatura General y Comparada. Ed. Magdalena León Gómex. 2004. 361-68.

CAESAR, Terry. «Driving in America. Looking for Asia». Géneros en contacto: viajes, crímenes, novela femenina y humor. Miscelánea de literatura inglesa y norteamericana. Ed. Santiago José Henríquez Jiménez. Las Palmas de Gran Canaria: Servicio de Publicaciones de la Universidad. La Caja de Canarias. 2004. 187-218.

CAÑAdAs RodrígueZ, Emilio. «Europe in the Writings of Truman Capote or the Steps to the Creation of the Non-fiction Novel». ES 26 (2005): 43-70.

CARabí Ribera, Angels. "Men and Women: Contemporary American Women Writing about Men”. Studies of Masculinities and Women's Literature». Actas XXVIII Congreso Internacional AEDEAN. Valencia: Universidad de Valencia (CD-Rom), 2004. 682-83.

Andrés GonzÁlez, Rodrigo, Armengol CARrera, José María. «A Men's Studies Approach to American Literature: Theory into Practice» Actas del XXVII Congreso Internacional de AE$D E A N$. Ed. Antonio R. Celada, Daniel Pastor García y Pedro Javier Pardo García. Salamanca: Ambos Mundos (CD-Rom), 2004. 
Carmona Rodríguez, Pedro. «A Male Giant Violating the Earth: Communal Spirit, Sexual Dissidence, and Regional Colour in Twentieth-century Prairie Canadian Fiction». Estudios ingleses de la Universidad Complutense 12 (2004): 149-65.

— «A Dark Night of the Soul: Sexuality, Subjectivity and Autobiographical Modes in Marian Engel's "The Glassy Sea"». Odisea 5 (2004): 7-22.

— «Walking the Streets Dressed as a Woman: Gender Trouble and the Collapse of the Gender-Sex quation in Shani Mootoo's Cereus Blooms at Night. Actas XXVIII Congreso Internacional AEDEAN. Valencia: Universidad de Valencia (CD-Rom), 2004. 93-103.

— «Remember First to Possess his Books: Appropriation and the Abrogation of Colonialists Authority in Malene Nourbese Phillip's "Miranda Sotires"». Actas XXVIII Congreso Internacional AEDEAN. Valencia: Universidad de Valencia (CD-Rom), 2004. 104-113.

CARmona Rodríguez, Pedro M. «(Geo-)graphies of Love, Voyage and Adventure: (Re)defining a Postmodern Gendered Space in Kathy Acker's Don Quixote y George Bowering's Caprice». Literature, Gender, Space. Ed. Sonia Villegas-López y Beatriz Domínguez-García. Huelva: Servicio de Publicaciones de la Universidad de Huelva, 2004. 201-10.

Cascajosa Virino, Concepción. El espejo deformado: procesos de hipertextualidad en la ficción audiovisual norteamericana. Tesis doctoral. Dir. Inmaculada Gordillo Álvarez, Universidad de Sevilla, Departamento de Comunicación Audiovisual, Publicidad y Literatura, 2004.

Coleman, Philip. «Nightmares of Eden: John Berryman's Homage to Mistress Bradstreet». Revista de Estudios Norteamericanos 10 (2004): 57-70.

COllado-ROdRíGuEZ, Francisco. «Back to Myth and Ethical Compromise: García Márquez's Traces on Jeffrey Eugenides's The Virgin Suicides». Atlantis 27. 2 (2005): 27-40.

— «Against Categorical Thinking: Hybridism, Time and Ethics in Jeffrey Eugenides's Middlesex». Actas XXVIII Congreso Internacional AEDEAN. Valencia: Universidad de Valencia (CDRom), 2004. 150-53.

COMA, Javier. La ficción bélica: grandes novelas americanas (y sus versiones cinematográficas) sobre la Segunda Guerra Mundial. Barcelona: Inédita. 2005.

Coy, Juan José. Entre el espejo y el mundo: texto literario y contexto histórico en la literatura norteamericana. Valencia: Universidad de Valencia, 2004.

Deleyto AlcalÁ, Celestino et al. «"Interpretation Unlimited”: Myster River en contexto». Actas XXVIII Congreso Internacional AEDEAN. Valencia: Universidad de Valencia (CD-Rom), 2004. 742-54.

Díez Coвo, Rosa. «American Alliteration in a Terminal Postmodern Age: Don DeLillo's Aboulic Heroes in Americana and Cosmopolis». Actas XXVIII Congreso Internacional AEDEAN. Valencia: Universidad de Valencia (CD-Rom), 2004. 184-93.

DobrotT BERNARD, Gretchen. «Flannery O'Connor's Written Correspondence: An Inside Glimpse at the Forging of Art and Persona». Atlantis 26.2 (2004): 25-34.

— «Flannery O'Connor's Fractured Families: Mothers and Daughters in Conflict». Revista de Estudios Norteamericanos 10 (2004): 71-82.

— «Flannery O'Connor and Regina, the "Parent": The Implications of an Abrupt and Imposed Return Home». Actas XXVIII Congreso Internacional AEDEAN. Valencia: Universidad de Valencia (CD-Rom), 2004. 194-202.

Domínguez Minguela, Antonia. Paisajes de ida y vuelta: la narrativa puertorriqueña en Estados Unidos. Huelva: Universidad de Huelva, 2005.

Escoda Agusti, Clara. «Strategies of Subversion: The Deconstruction of Madness in Eva's Man, Corregidora, and Beloved». Atlantis 27.1 (2005): 29-38.

ESPEJO Romero, Ramón. «Edward Albee's Three Tall Women and its Existential Background». Revista de Estudios Norteamericanos 10 (2004): 83-94. 
ESTÉBANEZ EstÉBANEZ, Cayetano. «El significado del concepto de imaginación en Wallace Stevens y su origen en la obra de George Santayana». ES 26 (2005): 103-14.

FERNÁNDEZ MoRAles, Marta. «Communicating the Experience of War: The "us" vs. "them" Dialectic in Eve Ensler's “Necessary Targets”». ES 26 (2005): 115-30.

FERNÁNDEZ RUIZ, Francisco Javier. «Sadismo en la literatura norteamericana». Encuentro de Lenguas y Literaturas. Eds. Margarita García Casado, Sean Seurfield, Gonzalo Martínez Camino, 2004. 191-96.

FERNÁNDEZ SUÁREZ, José Ramón. «El color del agua». ES 25 (2003-2004): 53-70.

— «"A Connecticut Yankee”: la afirmación de la cultura americana». ES 26 (2005): 131-46.

GÁmEZ FERNÁNDEZ, Cristina M. ${ }^{a}$ «Descendientes del Quijote en América: Female Quixotism de Tabitha G. Tenney». Cervantes y el ámbito anglosajón. Eds. Diego Martínez Torrón y Bernd Dietz. Madrid: SIAC. 2005.

GARCía GonZÁLEZ, M. ${ }^{a}$ Luisa. «Una reescritura de The Tempest desde la perspectiva anfronorteamericana: Tar Baby de Toni Morrison». Epos 20-21 (2004):

García LANDA, José Ángel. «The Poetics of Subliminal Awareness: Rereading Intention and Narrative Structure in Nabokov's "Christmas Story"». European Journal of English Studies 8.1 (2004): 27-48.

— «Hindsight, Intertextuality, and Interpretation: A Symbol in Nabokov's "Christmas Story"». Symbolism: An International Annual of Critical Aesthetics 5 (2004): 267-94.

García LoRENZo, María M., ed. American Literature after 1900. Madrid: UNED, D.L., 2005.

GIBERT, Teresa. «The Aesthetics of Ageing in Margaret Atwood's Fiction». Women Ageing Through Literature and Experience. Ed. Brian J. Worsfold. Lleida: Edicions de la Universitat de Lleida, 2005. 31-42.

GonZÁLEZ, María Luz. «Caronte y la Luna: arquetipos míticos en "The armies of the moon de Gwendolyn MacEwen"». Revista canaria de estudios ingleses 48 (2004): 147-64.

GonZÁlez CruZ, Isabel. «Lengua e identidad en Thins Fall Apart, de Chinau Achete». Géneros en contacto: viajes, crímenes, novela femenina y humor. Miscelánea de literatura inglesa y norteamericana. Ed. Santiago José Henríquez Jiménez. Las Palmas de Gran Canaria: Servicio de Publicaciones de la Universidad. La Caja de Canarias. 2004. 53-77.

GonZÁlez Mínguez, María Teresa. «Cummings and Campion: Are Literary Works Definitely Over?» Babel afial 14 (2005): 165-74.

GonzÁLez DE LA Rosa, M. a Pilar. «"Settina Selby y Riding to Jerusalén. A Journey through Turkey and the Middle East": algunos trazos de su cartografía». Géneros en contacto: viajes, crímenes, novela femenina y humor. Miscelánea de literatura inglesa y norteamericana. Ed. Santiago José Henríquez Jiménez. Las Palmas de Gran Canaria: Servicio de Publicaciones de la Universidad. La Caja de Canarias. 2004. 79-94.

GoodsPEED-CHADWICK, Julie Elaine. «Sexual Politics in The Waste Land: Eliot's Treatment of Women and Their Bodies in "Game of Chess" and "The Fire Sermon"». Feminismo/s 4 (2004): 117-25.

HenRíQuez JiMÉNEZ, Santiago José. «Values and Visions in Dalrymple's Travel Writing: A Sort of Interview». Géneros en contacto: viajes, crímenes, novela femenina y humor. Miscelánea de literatura inglesa y norteamericana. Ed. Santiago José Henríquez Jiménez. Las Palmas de Gran Canaria: Servicio de Publicaciones de la Universidad. La Caja de Canarias. 2004. 179-83.

Herrera-SobeK, María; Juan Francisco Lomelí; Juan Antonio Perles Rochel, coord. Perspectivas transatlánticas en la literatura chicana: ensayos y creatividad. Málaga: Universidad de Málaga, 2004.

Herrero Villapalos, Rosa. «Tema, estructura y marco narrativo en "Luz de Agosto" de William Faulkner». Cauce 27 (2004): 209-219.

IBARRARAN Bigalondo, Amaia. «Redefinición de Conquista en Sapogonia de Ana Castillo». Babel afial 13 (2004): 5-14. 
IBARROLA-ARMENDÁRIZ, Aitor. «North of Myself: A Refashioning of Masculinity in two Best-selling Novels on both Sides of the Atlantic». ES 26 (2005): 157-70.

IndURAIN ERASSO, Carmen. «Riding on Divergent but Similar Roads: "Airbag" or the Spanish Experience in the American Road Movie». Estudios Ingleses de la Universidad Complutense 13 (2005): 107-21.

JILL LEVINE, Suzanne. «El boom: una perspectiva norteamericana». Cuadernos Hispanoamericanos 651-652 (2004): 9-24.

LAGMANEVICH, David. «Nuevas tendencias en la ficción policial norteamericana». Quimera 245 (2004): 46-55.

LÁZARO, María Luisa. «Intertextualidad, (auto)biografía y novela policíaca como elementos estructurales en "The City of Glass" de Paul Auster». Grove 11 (2004): 71-88.

LÓPEZ ROPERO, M. ${ }^{a}$ Lourdes. «William Boelhower et al: Sites of Ethnicity. Europe and the Americas». Atlantis 27.2 (2005): 209-13.

LóPEZ RÚA, Paula. «The Manipulative Power of Word-formation Devices in Margaret Atwood's Oryx and Crake». Revista Alicantina de Estudios Ingleses 18 (2005): 149-65.

MARRERo Morales, Sandra. «La figura del detective en la ficción policíaca: rasgos característicos y tipología». Géneros en contacto: viajes, crímenes, novela femenina y humor. Miscelánea de literatura inglesa y norteamericana. Ed. Santiago José Henríquez Jiménez. Las Palmas de Gran Canaria: Servicio de Publicaciones de la Universidad. La Caja de Canarias. 2004. 95-114.

Martín Alegre, Sara. «Celestino Deleyto: Ángeles y demonios. Representación e ideología en el cine contemporáneo de Hollywood». Atlantis 27.2 (2005): 215-19.

MARTín JUNQUERA, Imelda. Las literaturas chicana y nativo-americana ante el realismo mágico. León: Universidad de León, 2005.

MartínEZ Falquina, Silvia. «Entries into the Autobiographical $I$, or the Ethics of Native American Storytelling». Actas XXVIII Congreso Internacional AEDEAN. Valencia: Universidad de Valencia (CD-Rom), 2004.

MÉNDEZ García, M. ${ }^{a}$ del Mar. Retórica de la esquizofrenia en los epígonos del modernismo: memoria para optar al grado de doctor. Madrid: Universidad Complutense, 2005.

Moreno Rojas, Elizabeth. «La fecundación de la ciudad en la novela norteña mexicana». Revista de Humanidades 17 (2004): 13-32.

PÉREZ GARCÍA, M. ${ }^{a}$ del Mar. «Exploraciones virtuales: el tiempo y la pasión en The Power Book, de Jeannette Winterson». Géneros en contacto: viajes, crímenes, novela femenina y humor. Miscelánea de literatura inglesa y norteamericana. Ed. Santiago José Henríquez Jiménez. Las Palmas de Gran Canaria: Servicio de Publicaciones de la Universidad. La Caja de Canarias. 2004. 115-25.

PINEDA HERNÁNDEZ, Inmaculada. «Domestic Artists: The Kitchen as a Confining or Liberating Space in African American Women's Literature». Literature, Gender, Space. Ed. Sonia VillegasLópez y Beatriz Domínguez-García. Huelva: Servicio de Publicaciones de la Universidad de Huelva, 2004. 143-50.

REDONDO OLMEDILLA, José Carlos. «La nueva pseudoliteratura norteamericana: los best-sellers y la expansión del patrón anglonorteamericano del thriller canónico». Lenguaje y Textos 22 (2004): 123-27.

Río Alvaro, Constanza del. «Genre and Fantasy: Melodrama, Horror, and the Gothic in Martin Scorsese's Cape Fear». Atlantis 26. 1 (2004): 61-72.

RodríGuez RamíRez, M. ${ }^{a}$ Carmen. «Rare and Beautiful Flowers: The Questioning of the Feminist Discourse in Mulan». Actas XXVIII Congreso Internacional AEDEAN. Valencia: Universidad de Valencia (CD-Rom), 2004. 484-92.

Santana Quintana, M. a del Pino. «"Off the Beaten Track”: Bill Bryson's Journey to Kenya». Géneros en contacto: viajes, crímenes, novela femenina y humor. Miscelánea de literatura inglesa 
y norteamericana. Ed. Santiago José Henríquez Jiménez. Las Palmas de Gran Canaria: Servicio de Publicaciones de la Universidad. La Caja de Canarias. 2004. 127-32.

SANTOS VILA, Sonia. «Simbología topográfica en los relatos fantásticos de Ambrose Bierce: El barranco». Estudios Humanísticos Filología 26 (2004): 335-41.

— «Huellas místicas en la Lírica de T. S. Eliot y Dámaso Alonso». Actas XXVIII Congreso Internacional AEDEAN. Valencia: Universidad de Valencia (CD-Rom), 2004. 522-30.

SPIES, Marion. «Travellers, Exiles, Colonists: Their Perspectives of European Literary Traditions». Géneros en contacto: viajes, crímenes, novela femenina y humor. Miscelánea de literatura inglesa y norteamericana. Ed. Santiago José Henríquez Jiménez. Las Palmas de Gran Canaria: Servicio de Publicaciones de la Universidad. La Caja de Canarias. 2004. 133-57.

SuÁreZ-Galbán Guerra, Eugenio. «The Minimal Magnified: Spain in The Glass Menagerie». Estudios ingleses de la Universidad Complutense 12 (2004): 167-177.

— «Visions of the True West: Sam Shepard, Identity and Myth». Revista alicantina de estudios ingleses 17 (2004): 283-96.

VÁSQUEZ, Mary S. «Entre dos luces: memoria y rememoración en padres imaginarios: autobiografía familiar de Sheila y Sandra Ortiz Taylor». Lenguaje y Textos 22 (2004): 81-88.

Vega GonzÁLEZ, Susana. «"Toni Morrison's Water World”: Watertime Writing in Love». Grove 11 (2004): 209-22.

— «Sites of Memory, Sites of Mourning and History: Danticat's Insights into the Past». Revista alicantina de estudios ingleses 17 (2004): 297-304.

— «Estudio comparado de The Farming of Bones, de Edwidge Danticat, y Beloved, de Toni Morrison». Estudios ingleses de la Universidad Complutense 13 (2005): 139-53.

— «Toni Morrison's Love and the Trickster Paradigm». Revista Alicantina de Estudios Ingleses 18 (2005):

Vera CAZORla, M. ${ }^{a}$ Jesús. «Marian Reyes: el humor de lo cotidiano». Géneros en contacto: viajes, crímenes, novela femenina y humor. Miscelánea de literatura inglesa y norteamericana. Ed. Santiago José Henríquez Jiménez. Las Palmas de Gran Canaria: Servicio de Publicaciones de la Universidad. La Caja de Canarias. 2004. 159-76.

WAHLSTRÖM, Helena. «(En)gendering Responsibility: Men, Feminism, and John Irving's The Ciderhouse Rules». Literature, Gender, Space. Ed. Sonia Villegas-López y Beatriz DomínguezGarcía. Huelva: Servicio de Publicaciones de la Universidad de Huelva, 2004. 97-106.

Wallhead, Celia M. «The Human Side of Science in the Novels of Alan Lightman». Revista canaria de estudios ingleses 50 (2005): 181-200.

WatKINS, Susan. «Women and Wives Mustn't Go Near it: Academia, Language and Gender in the Novels of Alison Lurie». Revista canaria de estudios ingleses 48 (2004): 129-46.

Waxman, Barbara. «Earthquakes, Fissures, and Bridges of Love: Tropes of the Transcultural, Translingual Experience in Marie Arana's "American Chica"». Revista canaria de estudios ingleses 48 (2004): 105-18. 


\section{LITERATURA POSTCOLONIAL EN LENGUA INGLESA}

Juan Francisco Elices Agudo

UNED. Madrid

jelices@flog.uned.es

ÍNDICE

1. Teoría y práctica postcolonial

2. Literatura postcolonial escrita en África

3. Literatura postcolonial escrita en Asia

4. Literatura postcolonial escrita en Australia

5. Literatura postcolonial escrita en Canadá

6. Literatura postcolonial escrita en el Caribe

7. Miscelánea

\section{TEORÍA Y PRÁCTICA POSTCOLONIAL}

GONZÁlez FERNÁNDEZ, Paula. «Linguistic Imperialism: a Critical Study.» Revista Alicantina de Estudios Ingleses 18 (2005): 111-128.

LORENTE, Maite. Diálogos entre culturas: una reflexión sobre el feminismo, género, desarrollo y mujeres indígenas kichwuas. Madrid: Instituto Complutense de Estudios Internacionales, Universidad Complutense de Madrid, 2005.

López Ropero, M. ${ }^{a}$ Lourdes. The Anglo-Caribbean Migration Novel: Writing from the Disapora. Alicante: Servicio de Publicaciones de la Universidad, 2004.

--. «Postcolonialism: Why should Things Fall Apart.» Actas del XXVII Congreso Internacional de AEDEAN. Ed. Antonio Rodríguez Celada et al. Salamanca: Universidad de Salamanca, 2004. [CD-ROM].

Martín LuCAS, M. ${ }^{a}$ Belén. «Why Do They Call It Global when They Mean American?: the Economic, Political and Cultural Effects of Neoimperialism.» Global Neo-Imperialism and National Resistance: Approaches from Postcolonial Studies. Eds. Belén Martín Lucas y Ana Bringas López. Vigo: Servicio de Publicaciones da Universidade de Vigo, 2004. 7-24.

MARTíneZ DE BRINGAS, Asier. La cultura como derecho en América Latina: ensayo sobre la realidad postcolonial en la globalización. Bilbao: Universidad de Deusto, Instituto de Derechos Humanos, 2005.

Moya GutiérRez, Ana. «From Crusoe to the English Patient, or the Transition from the Western Humanist Enlightenment Subject to the White Male Colonialist.» BELLS: Barcelona English Language and Literary Studies 13 (2004).

Simal GonzÁlez, Begoña. «Waging the Cultural War: Stereotyping the "Oriental" in Times of Conflict.» Global Neo-Imperialism and National Resistance: Approaches from Postcolonial Studies. Eds. Belén Martín Lucas y Ana Bringas López. Vigo: Servicio de Publicaciones da Universidade de Vigo, 2004. 87-103.

Varela Zapata, Jesús. «Globalization: where Cultural and Postcolonial Studies Meet.» Global Neo-Imperialism and National Resistance: Approaches from Postcolonial Studies. Eds. Belén Martín Lucas y Ana Bringas López. Vigo: Servicio de Publicaciones da Universidade de Vigo, 2004. 119-131. 
VÁzquez García, Celia. «Two Worlds, a Single Ticket: the Construction of a New Hybrid Identity in Postcolonial Adolescent Narratives of Migration.» About Culture. Ed. Elizabeth Woodward. Santiago de Compostela: Tórculo, 2004. 355-369.

WEEDON, Chris. «Miss world in Nigeria: eurocentrism and the problem of Islamophobia.» Revista Canaria de Estudios Ingleses 48 (2004): 77-88.

WoodHall, Winifred. «Margin to Margin, China to Jamaica: sexuality, ethnicity, and black culture in Global contexts.» Revista Canaria de Estudios Ingleses 48 (2004): 119-128.

\section{LITERATURA POSTCOLONIAL ESCRITA EN ÁFRICA}

Cúder DomíngueZ, Pilar. «(Re)Turning to Africa: Bernardine Evaristo's Lara and Lucinda Roy's Lady Moses.» Write Black, Write British: From Post Colonial to Black British Literature. Ed. Kadija Sesay. Hertford: Hansib, 2005. 300-313.

Elices Agudo, Juan Francisco. «Tracing George Orwell's Anti-Colonial Spirit in William Boyd's A Good Man in Africa: A Comparative Study.»Interactions 14.1 (2005): 14-27.

GonZÁlez Cruz, Isabel. «Lengua e identidad en Things Fall Apart, de Chinua Achebe.» Géneros en contacto. Viajes, crimen, novela femenina y humor. Miscelánea de literatura inglesa y norteamericana. Coord. Santiago J. Henríquez Jiménez. Las Palmas de Gran Canaria: Servicio de Publicaciones de la Universidad de Las Palmas de Gran Canaria/La Caja de Canarias, 2004. 53-78.

LóPEZ Morell, Beatriz. «The Place of Motherhood: Black Mother's Power in The Joys of Motherhood by Buchi Emecheta (1979)». Literature, Gender, Space. Ed. Sonia Villegas-López y Beatriz Domínguez-García. Huelva: Servicio de Publicaciones de la Universidad de Huelva, 2004. 43-51.

PICHLER Susanne. «Between Engagement and Familiarity: Construction(s) of (Un)liberating (Gendered) Space(s) in Buchi Emecheta's Kehinde (1994)». Literature, Gender, Space. Ed. Sonia Villegas-López y Beatriz Domínguez-García. Huelva: Servicio de Publicaciones de la Universidad de Huelva, 2004. 63-74.

RodríGUeZ GuerRero-STRACHAN, Santiago. «¿Híbrido, postmoderno o simplemente cuento? Los relatos de Ben Okri.» Creadores de Evocación. Nuevos Artículos sobre Relatos Cortos de Autores Británicos Contemporáneos. Ed. José Francisco Fernández Sánchez. Almería: Servicio de Publicaciones de la Universidad, 2005.

TuncA, Daria. «Ben Okri's The Landscapes Within and Dangerous Love: Vision and Revision.» BELL 2 (2004): 85-102.

\section{Literatura POSTCOLONIAL ESCRITA EN ASIA}

Blave, Raquel, Davis, Rocío G., Simal GonzÁlez, Begoña, y Otano, Alicia. «Cauc/Asian: Negotiating Biraciality in Asian American Literature.» Actas del XXVII Congreso Internacional de AEDEAN. Ed. Antonio Rodríguez Celada et al. Salamanca: Universidad de Salamanca, 2004. [CD-ROM]

Darias Beautell, Eva. «Camping in Waiting Rooms: Movement and Stasis in Anita Rau Badami's Tamarind Mem». Literature, Gender, Space. Ed. Sonia Villegas-López y Beatriz DomínguezGarcía. Huelva: Servicio de Publicaciones de la Universidad de Huelva, 2004. 153-63.

FERNÁNDEZ SÁNCHEZ, José Francisco. «La creatividad como salvación. Los relatos de Hanif Kureishi.» Creadores de Evocación. Nuevos Artículos sobre Relatos Cortos de Autores Británicos Contemporáneos. Ed. José Francisco Fernández Sánchez. Almería: Servicio de Publicaciones de la Universidad, 2005. 
Fresno Calleja, Paloma. "Chinese Whispers: Staging Evolving Identities in Linda ChanwaiEarle's Ka-Shue: Letters Home.» Actas del XVIII Congreso Internacional de AEDEAN. Ed. Juan José García de Leonardo et al. Valencia: Universitat de València, Departament de Filologia Anglesa i Alemanya, 2005. [CD-ROM].

KUORTTI, Joel. «Taking Place: The Emergence of Contemporary Indian English Women Writing». Literature, Gender, Space. Ed. Sonia Villegas-López y Beatriz Domínguez-García. Huelva: Servicio de Publicaciones de la Universidad de Huelva, 2004. 249-56.

Oliva CRuZ, Juan Ignacio. «¿Estancias desiertas»: la construcción femenina de la diáspora postcolonial angloindia.» Revista Canaria de Estudios Ingleses 49 (2004): 203-214.

PeCo GonZÁLEZ, Laura. «La subversión de los ideales femeninos a través de la violencia en Jasmine de Bharati Mukherjee.» EPOS 20-21 (2004): 189-202.

SÁnchez-Palencia CARAzo, Carolina. «Postales desde la diáspora: los relatos de Salman Rushdie.» Creadores de Evocación. Nuevos Artículos sobre Relatos Cortos de Autores Británicos Contemporáneos. Ed. José Francisco Fernández Sánchez. Almería: Servicio de Publicaciones de la Universidad, 2005.

Simal GonZÁLEZ, Begoña. «"Moving selves”: Immigration and Transnationalism in Gish Jen and Chitra Divakaruni.» Transnational, National, and Personal Voices: New Perspectives on Asian American and Asian Diasporic Women Writers. Eds. Begoña Simal y Elisabetta Marino. Münster: LIT Verlag, 2004.

- y MARINo, Elisabetta, eds. Transnational, National, and Personal Voices: New Perspectives on Asian American and Asian Diasporic Women Writers. Münster: LIT Verlag, 2004

Venegas CARo de la BarRera, José L. «Identity as Liminality in Post-colonial Fiction: Nadine Gordimer's The Pickup and Bessie Head's A question of power.» Odisea 6 (2005): 201-214.

\section{Literatura POStCOlOnial escrita en Australia y Nueva Zelanda}

Fresno Calleja, Paloma. «Travesías literarias en el pacífico: de los mares del sur a la nueva Oceanía.» BELLS: Barcelona English Language and Literary Studies 13 (2004).

--. «Herat Mothers and Local Goddesses: Maori Women Re/Writing Land». Literature, Gender, Space. Ed. Sonia Villegas-López y Beatriz Domínguez-García. Huelva: Servicio de Publicaciones de la Universidad de Huelva, 2004. 165-73.

\section{Literatura postColonial ESCRITA EN CANADÁ}

Cúder Domínguez, Pilar. «Domesticating Masculinity in Colonial Canada». Literature, Gender, Space. Ed. Sonia Villegas-López y Beatriz Domínguez-García. Huelva: Servicio de Publicaciones de la Universidad de Huelva, 2004. 77-84.

\section{Literatura POSTCOLONIAL ESCRITA EN EL CARIBE}

Carmona Rodríguez, Pedro. «Remember First to Possess his Books: Appropriation and Abrogation of Colonialist Authority in Marlene Nourbese Philip's Miranda Stories.» Actas del XVIII Congreso Internacional de AEDEAN. Ed. Juan José García de Leonardo et al. Valencia: Universitat de València, Departament de Filologia Anglesa i Alemanya, 2005. [CD-ROM]

SiXTo ReY, Paloma. «Looking under the Surface in Jamaica Kincaid's Lucy: Colour as a Descriptive Language.» Actas del XXVII Congreso Internacional de AEDEAN. Ed. Antonio Rodríguez Celada et al. Salamanca: Universidad de Salamanca, 2004. [CD-ROM]. 
--. «Implicaciones simbólicas del género gótico en la obra de Phillis Shand Allfrey The Orchid House.» Actas del XVIII Congreso Internacional de AEDEAN. Ed. Juan José García de Leonardo et al. Valencia: Universitat de València, Departament de Filologia Anglesa i Alemanya, 2005. [CD-ROM].

\section{MiscelÁNEA}

EstéVEZ SAÁ, Margarita. «Culture and History in Postcolonial and Multiethnic Fiction Written by Women in English.» About Culture. Ed. Elizabeth Woodward. Santiago de Compostela: Tórculo, 2004. 247-258.

FERNÁNDEZ Morales, Marta. «"Once you get the card you can do anything you want": Migrant Identities and Gender Transgression in Chicana Dramatic Literature.»Odisea 6 (2005): 85-96.

García GonZÁlez, M. ${ }^{a}$ Luisa. «Una reescritura de The Tempest desde la perspectiva Afronorteamericana: Tar Baby de Tony Morrison.» EPOS 20-21 (2004): 203-220.

IgLESIAS DÍAZ, Guillermo. «National Identity and Cinematographic Narration: the Representation of Irishness on the Screen.» Global Neo-Imperialism and National Resistance: Approaches from Postcolonial Studies. Eds. Belén Martín Lucas y Ana Bringas López. Vigo: Servicio de Publicaciones da Universidade de Vigo, 2004. 145-156.

LóPez-VArela AzCÁrate, Asunción, SáncheZ-Pardo GonZÁlez, Esther; Sánchez-Calle, Pilar, y MÉNDEZ GARCíA, Carmen. «¿Modernismo mestizo? Expatriación, diáspora e hibridación etnorracial y genérica en la construcción de la vanguardia anglonorteamericana.» Actas del XXVII Congreso Internacional de AEDEAN. Ed. Antonio Rodríguez Celada et al. Salamanca: Universidad de Salamanca, 2004. [CD-ROM]

OtAno, Alicia. Speaking the Past: Child Perspective in the Asian American Bildungsroman. Münster: LIT Verlag, 2004.

SALES SALVADOR, Dora. «La etnoliteratura de José María Arguedas: migración indígena y babelización de la ciudad en El zorro de arriba y el zorro de abajo.» Revista de Dialectología y Tradiciones Populares 60 (2005): 141-164.

VILlegas LóPEZ, Sonia, y CÚDER Domínguez, Pilar. «Biology and Identity: Miscegenation in Recent Chinese-North American Fiction.» Transnational, National, and Personal Voices: New Perspectives on Asian American and Asian Diasporic Women Writers. Eds. Begoña Simal y Elisabetta Marino. Münster: LIT Verlag, 2004. 


\title{
D. TRADUCCIÓN
}

\author{
M. a Antonia Álvarez CAlleja \\ UNED. Madrid \\ malvarez@flog.uned.es
}

ÍNDICE

1. Didáctica de la traducción

2. Historia de la traducción

3. Interpretación

4. Lingüística aplicada a la traducción

5. Teoría y proceso de la traducción

6. Búsqueda documental. Terminología

7. Traducción de lenguajes específicos

8. Traducción jurídica

9. Subtitulado y doblaje

10. Traducción literaria

\section{DidÁctica de la tRaducción}

AguilaR DEL Río, José Miguel. «La enseñanza de la traducción y su relación con las exigencias del mercado laboral: estudio de caso». TRANS 8 (2004): 11-28.

Bolaños Medina, Alicia. «Propuesta metodológica para la didáctica de la localización de sitios web». Traducción, lenguas, literaturas, sociedad del conocimiento: enfoques desde y hacia la cultura. Ed. Sonia Bravo Utrera. Las Palmas de Gran Canaria: Servicio de Publicaciones de la Universidad. 2004. 25-42.

CRuCEs Collado, Susana. «Reflexiones pedagógicas en torno a la enseñanza de la traducción especializada». Estudios sobre traducción: teoría, didáctica, profesión. Eds. Alberto Álvarez Logrís, José Yuste Frías. Vigo: Servicio de Publicaciones de la Universidad de Vigo. 2005. $113-22$.

CUÉllar LÁZARO, Carmen. «Un nuevo enfoque de la traducción en la enseñanza comunicativa de las lenguas». Hermeneus 6 (2004): 41-57.

DíAz FouCES, Oscar. «¿Qué Lingüística en la formación de traductores e intérpretes? Círculo de lingüística aplicada a la comunicación 20 (2004).

ESCUTIA LÓPEZ, Marciano. «El uso de la traducción en el aprendizaje de una lengua extranjera: el caso de los pronombres clíticos en español». Atlantis 27.1 (2005): 39-51.

FERNÁNDEZ POLO, Francisco Javier. «Internet en la formación del traductor». Nuevas tecnologías en lingüística, traducción y enseñanza de lenguas. Ed. Mario Cal Varela, Paloma Núñez Pertejo e Ignacio M. Palacios Martínez. Santiago de Compostela: Universidad de Santiago. 2005. 109-132.

KeLLY, Dorothy Anne. «El profesor universitario de traducción e interpretación ante el reto del espacio europeo de enseñanza superior». TRANS 8 (2005): 61-72.

LóPEZ, R. G. «Sobre didáctica de la traducción». Meta 2 (2004): 432-446.

LóPEZ GONZÁLEZ. Alberto. «La enseñanza de la traducción en estudiantes de "ELE": el uso de la prensa como caso práctico». Medios de comunicación y enseñanza del español como lengua 
extranjera: Actas del XIV Congreso Internacional de ASELE (Burgos 2003). Eds. Hermógenes Perdiguero Villarreal y Antonio A. Alvarez. Burgos: Servicio de Publicaciones de la Universidad de Burgos. 2004. 708-714.

LÓPEZ HERNÁNDEZ, Francisco. «La asignatura de "traducción directa en el entorno informático": una propuesta de actividad didáctica en la Escuela Universitaria de Informática de la Universidad Politécnica de Madrid». Perspectivas interdisciplinares de la lingüística aplicada. Vol. 2. Ed. María Luisa Carrió Pastor. 2005. 305-314.

Martín Santana, M. ${ }^{a}$ Carmen. «La importancia de la lengua C en la Facultad de Traducción e Interpretación: un concepto de aprendizaje de la lengua con un fin específico». Traducción, lenguas, literaturas; sociedad del conocimiento: enfoques desde y hacia la cultura. Ed. Sonia Bravo Utrera. Las Palmas de Gran Canaria: Servicio de Publicaciones de la Universidad. 2004. $141-52$.

MAYOR SERRANO, M. ${ }^{a}$ Blanca. «Consideraciones fundamentales en la formación de traductores: mercado de trabajo y tipo de alumnado». TRANS 9 (2005): 195-202.

MuÑOZ MARTín, Ricardo «Actualización de parámetros en la enseñanza de la traducción o de cómo Polifemo aprendió a usar el caleidoscopio». Estudios sobre traducción: teoría, didáctica, profesión. Eds. Alberto Álvarez Logrís, José Yuste Frías. Vigo: Servicio de Publicaciones de la Universidad de Vigo. 2005. 85-96.

TERCEDOR SÁNCHEZ, Maribel. «Parámetros profesionales en la didáctica de la traducción científica y técnica». Estudios sobre traducción: teoría, didáctica, profesión. Eds. Alberto Álvarez Logrís y José Yuste Frías. Vigo: Servicio de Publicaciones de la Universidad de Vigo. 2005. 97-112.

VALDÉs RodRíGUEZ, M. ${ }^{a}$ Cristina. «Aproximación a la enseñanza del inglés para el Turismo desde los Estudios de Traducción». Estudios de filología inglesa: IV Actas de las IV Jornadas de Filología Inglesa. Ed. M. ${ }^{a}$ Luisa Pascual Garrido. Córdoba: Universidad de Córdoba. 2001.

VALERO GARCÉs, Carmen. «Inglés como L3 en clases multilingües: estrategias utilizadas en la producción escrita». Porta Linguarum 2 (2004): 157-169.

VIDAL ClaRAn, M. ${ }^{a}$ del Carmen África. «El futuro de la enseñanza de la traducción y la pedagogía desconstructivista». Estudios sobre traducción: teoría, didáctica, profesión, Eds. Alberto Álvarez Logrís y José Yuste Frías. Vigo: Servicio de Publicaciones de la Universidad de Vigo. 2005. 35-42.

VILAR GARCÍA, Mar. Docentes, traductores e interpretes de la lengua inglesa en la España del siglo XIX: Juna Calderón, los hermanos Usoz y Pascual de Gayanos. Universidad de Murcia, Servicio de Publicaciones, 2004.

\section{HisTORIA DE LA TRADUCCIÓN}

Bueno García, Antonio. «Valor y sentido de la traducción monástica». La traducción en los monasterios. Ed. Antonio Bueno García. Valladolid: Secretariado de Publicaciones e Intercambio Editorial. Universidad de Valladolid. 2004. 9-26.

CARRERA DE LA RED, Avelina. «La traducción castellana de textos históricos de la antigüedad en tiempos de Isabel la Católica: un ejercicio literario al servicio de los monarcas». Insula 691692 (2004): 15-16.

FilgueIra FigueIRA, Marina. «El papel de las traductoras en la lengua inglesa a comienzos del siglo XVIII». Insights into translation, Vol. 7. Eds. Adolfo Luis Soto Vázquez y Begoña Crespo García. Coruña: Universidad de Coruña, 1998-2005.

GALlego Roca, Manuel. «De las vanguardias a la Guerra Civil». Historia de la traducción en España. Eds. Luis Pegenaute Rodríguez, Francisco Lafarga. Soria: Diputación Provincial. 2004. 479-526. 
IBÁÑEZ LLUCH, Santiago. «Saxo gramático, traductor». Hermeneus 6 (2004): 99-134.

JULIO, M. ${ }^{a}$ Teresa. «Hacia la dignificación de la lengua española en el XVI: la traducción como recurso». Lengua española y traducción. Eds. Marina Díaz Peralta et al. Las Palmas de Gran Canaria: Universidad de Las Palmas. Las Palmas de Gran Canaria: Universidad de Las Palmas. 2004. 131-44.

LAFARGa MAdUell, Francisco Mariano. «El siglo XVIII, de la Ilustración al Romanticismo». Historia de la traducción en España. Eds. Luis Pegenaute Rodríguez, Francisco Lafarga. Soria: Diputación Provincial. 2004. 209-320.

Mendiguren BereZiartu, Xavier. «El ámbito de la cultura vasca». Historia de la traducción en España. Eds. Luis Pegenaute Rodríguez, Francisco Lafarga. Soria: Diputación Provincial.2004. 791-816.

Micó, José M. ${ }^{a}$ «La época del Renacimiento y del Barroco». Historia de la traducción en España. Eds. Luis Pegenaute Rodríguez, Francisco Lafarga. Soria: Diputación Provincial. 2004. 175-208.

Noia CAmpos, M. ${ }^{a}$ Camino. «El ámbito de la cultura gallega». Historia de la traducción en Espa$\tilde{n} a$. Eds. Luis Pegenaute Rodríguez, Francisco Lafarga. Soria: Diputación Provincial. 2004. 721-790.

Pegenaute Rodríguez, Luis. «La época romántica» Historia de la traducción en España. Eds. Luis Pegenaute Rodríguez, Francisco Lafarga. Soria: Diputación Provincial. 2004. 321-396.

— «La época realista y el fin de siglo». Historia de la traducción en España. Eds. Luis Pegenaute Rodríguez, Francisco Lafarga. Soria: Diputación Provincial. 2004. 397-478.

— «La situación actual». Historia de la traducción en España. Eds. Luis Pegenaute Rodríguez, Francisco Lafarga. Soria: Diputación Provincial. 2004. 579-620.

Pujol, Josep M. «El ámbito de la cultura catalana». Historia de la traducción en España. Eds. Luis Pegenaute Rodríguez, Francisco Lafarga. Soria: Diputación Provincial. 2004. 623-720.

SÁNCHEZ RobAYnA, Andrés. «Canarias: la traducción como tradición». Anuario de estudios atlánticos 51 (2005): 21-44.

SANTOYO, Julio César. «Lengua española y traducción: "Nada queda por decir que no se haya dicho antes"». Lengua española y traducción. Eds. Marina Díaz Peralta et al. Las Palmas de Gran Canaria: Universidad de Las Palmas. 2004. 39-52.

— «Los inicios de la traducción monacal en Europa: Roma, Dume, Vivarium... (s. VI)» La traducción en los monasterios. Ed. Antonio Bueno García. Valladolid: Secretariado de Publicaciones e Intercambio Editorial. Universidad de Valladolid. 2004. 27-41.

— «Sobre la historia de la traducción en España: algunos errores recientes». Hermeneus 6 (2004): 169-82.

— «La "Escuela de traductores" de Íñigo López de Mendoza, marqués de Santillana». Ética y política de la traducción literaria. Málaga: Miguel Gómez. 2004. 99-120.

— «La Edad Media» Historia de la traducción en España. Eds. Luis Pegenaute Rodríguez y Francisco Lafarga. Soria: Diputación Provincial. 2004. 23-174.

SHAW, Patricia. «"Witts, fittes and fancies": Spanish "ingenio" in Renaissance England». Estudios ingleses de la Universidad Complutense 12 (2004): 131-148.

VAN DEN BROECK, Raymond. «William of Moerbeke (c. 1215-1286) as Translator of Aristotle: a Remarkable Stepping-stone in the Tradition of Literality». La traducción en los monasterios. Ed. Antonio Bueno García. Valladolid: Secretariado de Publicaciones e Intercambio Editorial. Universidad de Valladolid. 2004. 125-137.

Vega, Miguel Ángel. «De la Guerra Civil al pasado inmediato». Historia de la traducción en España. Eds. Luis Pegenaute Rodríguez, Francisco Lafarga. Soria: Diputación Provincial. 2004. 527-578. 


\section{INTERPRETACIÓN}

CAmbridge, Jan. «The Public Service Interpreter's Face: Rising to the Challenge of Expressing Powerful Emotion for Others». Revista canaria de estudios ingleses 51 (2005): 141-158.

ChaPA BAIXAUl, Carmen. «La lengua de signos: falsos tópicos: algunas particularidades en su proceso de interpretación». Experiencias de traducción: reflexiones desde la práctica traductora. Eds. Isabel García Izquierdo y Ana Cristina García de Toro. Castellón: Universidad Jaime I. 2005. 51-66.

DERNOSHEK, Darrell J. «Spanish/English Translation and Interpreting in the United States: Social, Profesional and Pragmatic Aspects». Experiencias de traducción: reflexiones desde la práctica traductora. Eds. Isabel García Izquierdo y Ana Cristina García de Toro. Castellón: Universidad Jaime I. 2005.

LÓPEZ Folgado, Vicente. «Interpretive Resemblance: a Pragmatic View of Translation». El espanol, lengua de cultura, lengua de traducción: aspectos teóricos, metodológicos y profesionales. IV Simposio Internacional sobre Traducción, Texto e Interferencias. Eds. Miguel Ángel García Peinado et al. Cuenca: Universidad de Castilla-La Mancha, Servicio de Publicaciones. Granada: Atrio. 2005. 169-78.

Martín CASAdo, Manuel y Sonsoles Sánchez-Reyes Peñamaría. «Necesidad de la provisión de un servicio de intérpretes en los hospitales». Hermeneus 6 (2004): 155-168.

OPdDENHOFF, J. Hendrik. «Alfa, épsilon, pi. Algunas reflexiones sobre la toma de notas en la enseñanza de la interpretación consecutiva». TRANS 8 (2004): 161-68.

RudVIN, Mette. «Power behind Discourse and Power in Discourse in Community Interpreting: The Effect of Institutional Power Asymmetry on Interpreter Strategies». Revista canaria de estudios ingleses 51 (2005): 159-80.

TORRES DíAz, M. ${ }^{a}$ Gracia. Enseñar y aprender a interpretar: curso de interpretación de lenguas (español-inglés). Málaga: Libros Encasa, 2004.

TIAYON, Charles. «Community Interpreting: an African Perspective». Hermeneus 7 (2005): 175-92.

TRICÁs PRECKLER, Mercedes. «Recorrido interpretativo y traducción: una estrategia holística». Estudios sobre traducción: teoría, didáctica, profesión. Eds. Alberto Álvarez Logrís y José Yuste Frías. Vigo: Servicio de Publicaciones de la Universidad de Vigo. 2005. 43-50.

\section{LINGÜÍSTICA APLICADA A LA TRADUCCIÓN}

AlCÁNTARA, M. ${ }^{a}$ Ángeles. «La traducción: una alternativa a la presencia de anglicismos en el discurso médico español». Lengua española y traducción. Eds. Marina Díaz Peralta et al. Las Palmas de Gran Canaria: Universidad de Las Palmas. 2004. 53-64.

Álvarez CAlleja, M. ${ }^{a}$ Antonia. «Análisis de cambios formales entre TO y TT». Actas II Congreso Internacional de AIETI. Madrid: Universidad Pontificia Comillas de Madrid. 2005. 526-33.

BOURNE, Julián. «Un análisis descriptivo de las traducciones al español de oraciones directivas expresadas con will y sus derivados en los diálogos de novelas inglesas». Sendebar 15 (2004: 3-28.

Breva Claramonte, Manuel. «Some Interference Issues in the Translation of English Compounds into Spanish». Actas XXVII Congreso Internacional AEDEAN. Salamanca: Universidad de Salamanca (CD-Rom). 2004. 58-63.

CANTERa ORTIZ DE URbina, José. «Fraseología española en relación con el mundo, el saber y con los nombres propios del lugar: Problemática de su traducción». Paremia 13 (2004): 31-42.

CARBOnell CoRTÉs, Ovidi. «Vislumbres de la otredad: hacia un marco general de la construcción semiótica del otro en traducción». Vasos comunicantes 28 (2004) 59-72. 
CARTONI, Flavia, Due, Claude y Heredia, José Ramón. «Las estructuras pronominales en español: guía descriptivo-didáctica, análisis contrastivo y diccionario multilingüe portugués, italiano, francés, alemán e inglés». El español, lengua de cultura, lengua de traducción: aspectos teóricos, metodológicos y profesionales. IV Simposio Internacional sobre Traducción, Texto e Interferencias. Eds. Miguel Ángel García Peinado et al. Cuenca: Universidad de Castilla-La Mancha, Servicio de Publicaciones. Granada: Atrio. 2005. 221-32.

EsCuTia LÓPEZ, Marciano. «El uso de la traducción en autoaprendizaje de la lengua extranjera: el caso de los pronombres clíticos en español». Atlantis 27.1 (2005): 39-51.

Felipe Soto, M. ${ }^{a}$ Rosario. «Revisión del concepto de norma en los Estudios de Traducción». Hermeneus 6 (2004): 59-74.

FERNÁNDEZ ANTOLín, Martín. «El procesamiento del texto como lenguaje natural». Hermeneus 6 (2004): 75-98.

FERNÁNDEZ CASAS, M. ${ }^{a}$ Xosé. «El relativismo lingüístico y la práctica de la traducción: aportaciones mutuas». Actas del V Congreso de Lingüística General. (León 5-8 de marzo de 2002). Ed. Milka Villayandre Llamazares. Vol. 1. León: Universidad de León. 2004. 917-928

FERNÁNDEZ, Francesc. «La relevancia traductiva de los análisis contrastivos de género: el ejemplo del folleto de cursos de idiomas en alemán y en español». Lengua española y traducción. Eds. Marina Díaz Peralta et al. Las Palmas de Gran Canaria: Universidad de Las Palmas. 2004. 113-130.

GAmbOA BelisARIO, Leylanis. «Sobre la traducción como destreza de mediación y la construcción de una competencia plurilingüe y pluricultural en el estudiante de ELE». RedELE. Revista electrónica de Didáctica 2 (2004).

García Domínguez, M. Jesús y Díaz Peralta, Marina. «El significado pragmático del texto en español: los signos de puntuación». Lengua española y traducción. Eds. Marina Díaz Peralta et al. Las Palmas de Gran Canaria: Universidad de Las Palmas. 2004. 83-111.

García YeBra, Valentín. Traducción y enriquecimiento de la lengua del traductor. Madrid: Gredos, 2004.

Gómez GuinOVART, Francisco Javier. «Procesamiento y aplicaciones de los corpus paralelos». Novática 175 (2005): 50-54.

JIMÉNEZ, Catalina. «La definición variable como base semántica del lenguaje controlado: un ejemplo en textos sobre procesos marinos». El español, lengua de cultura, lengua de traducción: aspectos teóricos, metodológicos y profesionales. IV Simposio Internacional sobre Traducción, Texto e Interferencias. Eds. Miguel Ángel García Peinado et al. Cuenca: Universidad de Castilla-La Mancha, Servicio de Publicaciones. Granada: Atrio. 2005. 465-77.

LóPEZ GARCÍA, Ángel. «Conexiones informáticas y conexiones neuronales: el problema de la traducción». Perspectivas interdisciplinares de la lingüística aplicada. Vol. 2. Ed. María Luisa Carrió Pastor. 2005. 31-42.

LORENZI ZANOLETTY, René. «Del registro al género: problemas de traducción de expresiones coloquiales en textos específicos del sector turístico» Quaderns de filología. Estudis lingüístics 10 (2005): 173-186.

Marín CALVARro, Jesús Ángel. «Polisemia e interpretación en el "Soneto IV" de Wiliam Shakespeare». Anuario de estudios filológicos 27 (2004): 147-56.

MARQUÉS AgUADO, Teresa. «Estudio contrastivo de los verbos de visión en inglés y en español». El español, lengua de cultura, lengua de traducción: aspectos teóricos, metodológicos y profesionales. IV Simposio Internacional sobre Traducción, Texto e Interferencias. Eds. Miguel Ángel García Peinado et al. Cuenca: Universidad de Castilla-La Mancha, Servicio de Publicaciones. Granada: Atrio. 2005. 233-40.

Mendiluce Cabrera, Gustavo y Hernández Bartolomé, Ana Isabel. «English/Spanish False Friends: a Semantic and Etymological Approach of Some Possible Mis-translations». Hermeneus 7 (2005): 131-146. 
Montero Martínez, Silvia y García De Quesada, Mercedes. «Esquemas frasémicos y análisis terminológico para la traducción». Sendebar 15 (2004): 115-39.

MonTEZANTI, Miguel Ángel. «"Entre tanta polvareda perdimos a don Beltrán”: o qué fue de la polisemia». TRANS 9 (2005): 85-98.

MOSQUERA GENDE, Ingrid. «La cuestionable, necesaria e innecesaria, traducción de los evitables anglicismos, inevitables en la lengua española». Interlingüística 15. 2 (2004): 1027-1034.

PóRTOLES, José. «Sobre el uso de "al contrario" en las traducciones». Lengua española y traducción. Eds. Marina Díaz Peralta et al. Las Palmas de Gran Canaria: Universidad de Las Palmas. 2004. 19-37.

RAMÓN GARCÍA, Noelia. «N +N Constructions in English and their Spanish Translations: Evidence from a Parallel Corpus». Actas XXVII Congreso Internacional AEDEAN. Salamanca: Universidad de Salamanca (CD-Rom). 2004.

Rosales SequeIRos, Xosé. «Formulaic Expressions in Translation». TRANS 8 (2004): 105-14

RUIZ Noguera, Francisco. «Sobre los fundamentos lingüísticos de los enfoques culturales de la traducción». Actas del V Congreso de Lingüística General (León 5-8 de marzo de 2002). Ed. Milka Villayandre Llamazares. Vol. 3. León: Servicio de Publicaciones de la Universidad de León. 2004. 2487-2494.

Sacau Fontenla, Elena y Gómez Guinovart, Fco. Javier. «Métodos de optimización de la extracción de léxico bilingüe a partir de corpus paralelos». Procesamiento del lenguaje natural 33 (2004): 133-140.

Sevilla Muñoz, Manuel y Sevilla MuÑoz, Julia. «La aplicación de las técnicas de la "traducción paremiológica" a las paremias populares relativas al vocablo pez en español, inglés y francés». Revista de literaturas populares 5.2 (2005): 349-368.

\section{TEORÍA Y PROCESO DE LA TRADUCCIÓN}

Alvarez Calleja, M. Antonia. «Kinga Klaudy: Languages in Translation. Lectures of Theory, Teaching and Practice of Translation». EPOS XX-XXI (2004-05): 456-61.

BELLVER NAVALÓN, Carmen, et al. «La importancia de una buena traducción». Revista ROL de enfermería 12 (2004): 857-862.

BOLAÑos CuÉLlAR, Sergio. «Hacia una visión integradora de la traducción: propropuesta del modelo traductológico dinámico (MTD)». Tonos digital: Revista electrónica de estudios filológicos 8 (2004). <www.tonosdigital.com>

Bravo Utrera, Sonia. «Cruce de caminos». Traducción, lenguas, literaturas; sociedad del conocimiento: enfoques desde y hacia la cultura. Ed. Sonia Bravo Utrera. Las Palmas de Gran Canaria: Servicio de Publicaciones de la Universidad. 2004. 13-24.

CARbonell Cortés, Ovidi. «La ética del traductor y la ética de la traductología». Ética y política de la traducción literaria. Málaga: Miguel Gómez. 2004. 17-45.

CAPRARA, Giovanni. «Andrea Camilleri en español: consideraciones sobre la (in)visibilidad del traductor». TRANS 8 (2004): 41-52.

Chesterman, Andrew. «Consilience in Translation Studies». Revista canaria de estudios ingleses 51 (2005): 19-32.

CoRdesillo García, Ana Isabel. «Tecnologías de la lengua y traducción: recursos y herramientas». Nuevas tecnologías en lingüística, traducción y enseñanza de lenguas. Ed. Mario Cal Varela, Paloma Núñez Pertejo e Ignacio M. Palacios Martínez. Santiago de Compostela: Universidad de Santiago. 2005. 67-88.

CRUZ TRAINOR, María M. «Traducción inversa: una realidad». TRANS 8 (2004): 53-60.

Delabastita, Dirk. «Research in Translation Between Paralysis and Pretence». Revista canaria de estudios ingleses 51 (2005): 33-50. 
Díaz Péres, Francisco Javier y Ortega Cebreros, Ana M. ${ }^{\text {a }}$, eds. A World of English, a World of Translation: Estudios Interdisciplinares sobre Traducción y Lengua Inglesa. Jaén: Universidad de Jaén, 2004.

FABER BeníteZ, Pamela y JimÉNEZ-HuRTADO, Catalina. Traducción, lenguaje y cognición. Albolote, Granada: Comares, 2004.

FRANCESCONI, Armando. «¿Qué traducción?: Los métodos de traducción en el análisis contemporáneo». Espéculo 27 (2004). <www.ucm.es/info/especulo>

FREI, Charlotte. «Traducir: introducir, retraducir». TRANS 9 (2005): 11-20.

García DE TORO, Cristina y GARCIA IzQUIERDO, Isabel. «La práctica profesional de la traducción». Experiencias de traducción: reflexiones desde la práctica traductora. Ed. Isabel García Izquierdo. Castellón: Universidad Jaime I. 2005. 15-30.

JÄÄSKELÄINEN Riitta y KUJAMÄKI, Pekka. «Foreignising vs. Domesticating? The Role of Cultural Context in Determining the Choice of Translation Strategy». Revista canaria de estudios ingleses 51 (2005): 71-84.

Kelly, Dorothy Anne. «"The Wrong Way Round?”: Consideraciones sobre la cuestión de la direccionalidad en la traducción profesional». Experiencias de traducción: reflexiones desde la práctica traductora. Ed. Isabel García Izquierdo. Castellón: Universidad Jaime I. 2005. 129-46.

LIENHARD, Martín. «Traducir para dominar: el aparato colonial y la traducción del discurso de los indios y los esclavos africanos». Vasos comunicantes 28 (2004): 51-58.

LóPEz GuIX, Gabriel. «Traducir para la prensa escrita: reflexiones de un traductor». El texto de opinión de la prensa escrita y su tratamiento en la traducción. 2005. 103-118.

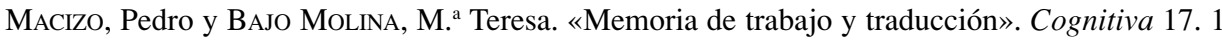
(2005): 29-54.

MANZONI, Cecilia. «Fernando Vallejo y el arte de la traducción». Cuadernos hispanoamericanos 651-652 (2004): 45-56.

MARCO, Joseph. « ¿Tareas o proyectos? ¿Senderos que se bifurcan en el desarrollo de la competencia traductora? TRANS 8 (2004): 75-83.

MARÍN HERNÁNDEZ, David. «La esencialización de la cultura y sus consecuencias en los estudios de traducción». TRANS 9 (2005): 73-84.

MARTín RuANO, M. ${ }^{a}$ Rosario. «Lenguaje (conciencia de), género y traducción: modelos establecidos, nuevas realidades». Cultura, lenguaje y traducción desde una perspectiva de género. Ed. Adela Martínez García. Málaga: Servicio de Publicaciones de la Universidad de Málaga. 2004. 255-68.

Montalt, Vicente y EzPELETA, Pilar. «¿Qué importa la traducción al español?» Contrastes 39 (2005): 80-83.

Moré LóPEZ, Joaquín, Oliver GonzÁlez, Antoni y Climent RocA, Salvador. Traducción asistida por ordenador: programas y recursos libres y gratuitos; material bilingüe. Barcelona: Planeta UOC, 2004.

MoYa, Virgilio. La selva de la traducción: teorías traductológicas contemporáneas. Madrid: Cátedra, 2004.

ORTIZ GARCíA, Javier. «Una propuesta de traducción cultural colonizadora». Vasos comunicantes 28 (2004): 41-50.

PEÑA MARTín, Salvador. «Narrativa de la traducción». TRANS 9 (2005): 99-114.

PINO, Marta y GARCíA, Amaya. «Traducción asistida por ordenador-Trados(tm)».

- Vasos comunicantes 30 (2004): 61-63.

RABADÁn, Rosa. «The Applicability of Description: Empirical Research and Translation Tools». Revista canaria de estudios ingleses 51 (2005): 51-70.

— «Niveles de teorización en la traducción: la transición entre teoría y práctica». Estudios sobre traducción: teoría, didáctica, profesión. Eds. Alberto Álvarez Logrís y José Yuste Frías. Vigo: Servicio de Publicaciones de la Universidad de Vigo. 2005. 21-34. 
Rollán GALLEGO, Álvaro. «Internet, una red de traducción». Minerva 17 (2004): 253-268.

Rubio SEMPER, Agustín. «Traducciones cotidianas». Hermeneus 6 (2004): 13-15.

Ruiz Casanova, José Francisco et al. De poesía y traducción. Madrid: Biblioteca Nueva, 2005.

SENZ BuENo, Silvia. «Normas de presentación de originales de traducción para la edición impresa». Panacea 6. 20 (2005): 161-68.

Simoes, Alberto et all. «Distributed Translation Memories Implementation Using WebServices». Procesamiento del lenguaje natural 33 (2004): 89-94.

Toledano Buendía, Carmen. «Contemporary Problematics in Translation Studies» Revista canaria de estudios ingleses 51 (2005): 1-18.

TOURY, Guideon, RABADÁn, Rosa y MERINo, Raquel. Los estudios descriptivos de traducción y más allá: metodología de la investigación en estudios de traducción. Madrid: Cátedra, 2004.

Verdegal Cerezo, José Manuel. «El permanente conflicto del neotraductor: antecedentes, riesgos y limitaciones». Hermeneus 7 (2005): 193-219.

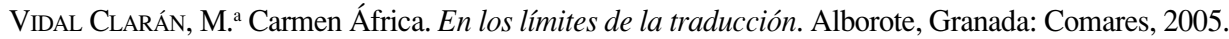

YACER LLORCA, Eusebio V. Sobre la traducción: ideas tradicionales y teorías contemporáneas. Valencia: Universidad de Valencia, 2004.

YUSTE FRÍAS, José. «Desconstrucción, traducción y paratraducción en la era digital». Estudios sobre traducción: teoría, didáctica, profesión. Eds. Alberto Álvarez Logrís y José Yuste Frías. Vigo: Servicio de Publicaciones de la Universidad de Vigo. 2005. 59-84.

— «Verdades de Perogrullo (y otras) para una iniciación a la traducción profesional». Estudios sobre traducción: teoría, didáctica, profesión. Eds. Alberto Álvarez Logrís y José Yuste Frías. Vigo: Servicio de Publicaciones de la Universidad de Vigo. 2005. 237-55.

\section{BÚSQuEDA DOCUMENTAL. TERMINOLOGÍA}

CASÁn, Gustavo y CASTAÑo, M. a Asunción. «Generación automática de codificaciones de vocabularios para Traducción Automática mediante Redes Neuronales». Inteligencia Artificial 22 (204): 175-86.

CERVERo, Verónica. «La cocina como laboratorio léxico y experimental de la ciencia y la tecnología: traducción terminológica». Linguax 2. 2 (2004): 2-13.

ChueCa Moncayo, Fernando J. «Aproximación didáctica a las nociones de lexicología y terminología textuales». Sendebar 15 (2004): 65-82.

DiRcKX, John H. «iTienen alas los búfalos? A Bilingual Glossary of English Animal Expressions». Panacea 6. 20 (2005): 86-92.

GómEZ GonZÁLEZ-Jover, Adelina. «Specialized Bilingual Dictionaries for Translators (Some Considerations for a User-Oriented Approach». Revista Alicantina de Estudios Ingleses 18 (2005): 71-83.

JUNG, Linus y PRIETO, Juan Antonio. «Acerca de la perspectiva en las unidades terminológicas». El español, lengua de cultura, lengua de traducción: aspectos teóricos, metodológicos y profesionales. IV Simposio Internacional sobre Traducción, Texto e Interferencias. Eds. Miguel Ángel García Peinado et al. Cuenca: Universidad de Castilla-La Mancha, Servicio de Publicaciones. Granada: Atrio. 2005. 191-99.

MOgORRÓN HUERTA, Pedro. «Los diccionarios electrónicos fraseológicos: perspectivas para la lengua y la traducción». Estudios de lingüística 1 (2004): 381-400.

RECODER, M. ${ }^{a}$ José. «Traducción y documentación: cooperar para difundir la información». Hipertext.net 1 (2004).

REYES DíAZ, M. Josefa. «A propósito de léxico y cultura». Traducción, lenguas, literaturas; sociedad del conocimiento: enfoques desde y hacía la cultura. Ed. Sonia Bravo Utrera. Las Palmas de Gran Canaria: Servicio de Publicaciones de la Universidad. 2004. 221-234. 


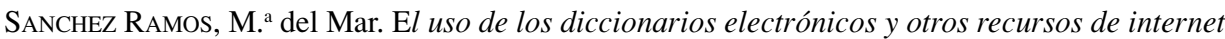
como herramientas para la formación del traductor (Inglés Español). Tesis doctoral. Dir. María Calzada Pérez. Universidad Jaume I, Castellón, Facultad de Ciencias Jurídicas y Económicas. Departamento de Traducción, Sociedad y Comunicación, 2004.

Singer, Lucía y IGEA, Juan Manuel. «Glosario trilingüe (EN-PT-ES) de términos y acrónimos usados con frecuencia en inmunología (1. ${ }^{\text {a }}$ parte)». Panacea 6. 20 (2005): 161-68.

Vitoria LóPEZ, Raquel. El vocabulario semitécnico de la informática e internet: problemas de traducción. San Vicente del Raspeig, Alicante: Universidad de Alicante, 2005.

\section{TRADUCCIÓN DE LENGUAJES ESPECÍFICOS}

Boquera MatarRedona, María. Las metáforas en textos de ingenieria civil: estudio contrastivo español-inglés. Tesis doctoral. Dirs. Jordi Piqué Angordans y Carlos Hernández Sacristán. Universidad de Valencia. Facultad de Filología. Departamento de Teoría del Discurso y la Comunicación Audiovisual, 2004.

Bosco CAMÓN, Juan. «Análisis de interferencias en traducciones de informática mediante corpus». El español, lengua de cultura, lengua de traducción: aspectos teóricos, metodológicos y profesionales. IV Simposio Internacional sobre Traducción, Texto e Interferencias. Eds. Miguel Ángel García Peinado et al. Cuenca: Universidad de Castilla-La Mancha, Servicio de Publicaciones. Granada: Atrio. 2005. 447-54.

Bravo Gonzalo, José María y Fernández Nistal, Purificación. «La traducción especializada inglés-español: las nuevas tecnologías de la información como garantía de calidad en la traducción inversa». Nuevas tecnologías en lingüística, traducción y enseñanza de lenguas. Eds. Mario Cal Varela, Paloma Núñez Pertejo e Ignacio L. Palacios Martínez. Santiago de Compostela: Servicio de Publicaciones de la Universidad. 2005. 89-108.

BRIK, Hugo. «El lenguaje y los libros científicos: un mismo título para el inmenso espacio del idioma español». Panacea 6. 19 (2005): 20-22.

Claros Díaz, Manuel Gonzalo. «MedTrad: un foro de traducción médica en internet». TRANS 9 (2005): 151-59.

GARCÍA SuÁREZ, P. «Noticias de agencia: características, problemas y retos de su traducción». $L a$ traducción periodística. Eds. M. ${ }^{a}$ Carmen Cortés Zaborras y M. ${ }^{a}$ José Hernández Guerrero. 2005. 175-96.

MARTíNEZ GARRIDO, Gema I. «La traducción de la cohesión textual en el discurso financiero español-inglés: análisis de elementos cohesivos y estrategias de traducción». Interlingüística 15.2 (2004): 897-908.

Gómez OrTiz, Francisco. «Cinco calas en la traducción bíblico-litúrgica». Tonos digital 9 (2005). $<$ www.tonosdigital.com>

HERNÁNDEZ GUERRERO, M. José. «La traducción de los géneros periodísticos» La traducción periodística. Eds. M. ${ }^{a}$ Carmen Cortés Zaborras y M. ${ }^{a}$ José Hernández Guerrero. 2005. 89-136.

— «Prensa y traducción». La traducción periodística. Eds. M. ${ }^{a}$ Carmen Cortés Zaborras y M. ${ }^{a}$ José Hernández Guerrero. 2005. 155-74.

Hodgson, Robert. «Traducción de la Biblia en la cultura y en los medios de comunicación». Tonos digital 9 (2005). <www.tonosdigital.com>

MERCADO LÓPEZ, Sebastián. «El análisis de géneros aplicado a la traducción: Los prospectos de medicamentos de Estados Unidos y de España». Linguax 2. 2 (2004): 3-21.

MONTERDE REY, Ana M. ${ }^{a}$ «Estudio terminológico de la relación entre formas de representación del conocimiento a nivel conceptual en textos dirigidos a legos en reabastecimiento en vuelo: aplicación a la traducción». Traducción, lenguas, literaturas; sociedad del conocimiento: enfoques 
desde y hacía la cultura. Ed. Sonia Bravo Utrera. Las Palmas de Gran Canaria: Servicio de Publicaciones de la Universidad. 2004. 153-77.

MONTES FERNÁNDEZ, Antonia. Traducción, publicidad y globalización: una aproximación contrastiva y traductológica a los textos publicitarios ingleses, españoles y alemanes. Tesis doctoral. Dir. Enrique Alcaraz Varó. Universidad de Alicante, Facultad de Filosofía y Letras. Departamento de Traducción e Interpretación de los Lenguajes Generales, Literarios y Específicos. 2004.

Montalt Resurrecció, Vicent. Manual de traducció científicotécnica. Vic: Eumo, 2005.

PARRILla, Laura. «La teletraducción en los servicios de emergencias 112 Andalucía». El español, lengua de cultura, lengua de traducción: aspectos teóricos, metodológicos y profesionales. IV Simposio Internacional sobre Traducción, Texto e Interferencias. Eds. Miguel Ángel García Peinado et al. Cuenca: Universidad de Castilla-La Mancha, Servicio de Publicaciones. Granada: Atrio. 2005. 515-23.

Ros, Joandomènec. «Reflexiones de un traductor científico sobre la grandeza y la servidumbre del oficio». Panacea 6. 19 (2005): 4-11.

SALADRIGAS, Verónica et al. «Vocabulario inglés-español de bioquímica y biología molecular (6. ${ }^{\mathrm{a}}$ entrega)». Panacea 6. 19 (2005): 12-19.

SÁNCHEZ TRIGO, Elena. «Investigación traductológica en la traducción científica y técnica». TRANS 9 (2005): 131-48.

SANTACRUZ, Víctor. «Traducción, adaptación y validación de la "paliative care outcome scale" al español». Medicina clínica 123. 11 (2004): 406-12.

SOCORRO TRUJILLO, Karina. «Un modelo didáctico para la traducción de documentos mercantiles inglés-español». Traducción, lenguas, literaturas; sociedad del conocimiento: enfoques desde y hacía la cultura. Ed. Sonia Bravo Utrera. Las Palmas de Gran Canaria: Servicio de Publicaciones de la Universidad. 2004. 245-54.

TERCEDOR SÁNCHEZ, Maribel. «Aspectos culturales en la localización de productos multimedia». Quaderns 12 (2005): 151-60.

VALDEÓN, Roberto A. «Media Translation in BBCMUNDO Internet Texts». Revista canaria de estudios ingleses 51 (2005): 105-120.

VAlero Garcés, Carmen y TAIBI, Mustapha. «Fuerza del español en una nueva sociedad multilingüe: retos que plantean los lenguajes especializados y la terminología». El español, lengua de cultura, lengua de traducción: aspectos teóricos, metodológicos y profesionales. IV Simposio Internacional sobre Traducción, Texto e Interferencias. Eds. Miguel Ángel García Peinado et al. Cuenca: Universidad de Castilla-La Mancha, Servicio de Publicaciones. Granada: Atrio. 2005. 201-10.

WAY, Catherine Louise. La traducción como acción social: el caso de los documentos académicos (español-inglés). Tesis doctoral. Dir. James Neil Douglas Mclarem. Universidad de Granada, Departamento de Filología Inglesa y Alemana, 2005.

\section{TRADUCCIÓN JURÍDICA}

Collantes Fraile, Carlos. «Derecho y traducción: nuevos rumbos comunes». Hermeneus 7 (2005): 21-38.

Duro Moreno, Miguel Jesús. Nolumus Leges Angliae Mutare: Propedéutica de la traducción jurídica inglés-español. Estudio de la influencia de los entornos en la traducción al español del Derecho inglés, con especial referencia a un caso. Tesis doctoral. Dir. Fernando Serrano Valverde. Universidad de Granada. Facultad de Filosofía y Letras. Departamento de Filología Inglesa. 2003.

- Introducción al derecho inglés: la traducción jurídica inglés-español en su entorno. Madrid: Edisofer, 2005. 
FAlCOI AlCÁNTARA, M. ${ }^{a}$ Carmen. «Lenguaje jurídico y traducción: hacia una propuesta didáctica». Traducción, lenguas, literaturas; sociedad del conocimiento: enfoques desde y hacía la cultura. Ed. Sonia Bravo Utrera. Las Palmas de Gran Canaria: Servicio de Publicaciones de la Universidad. 2004. 57-73.

GonZÁLEz Ruiz, Víctor M. «La ideología en el discurso de los profesionales del derecho: reflexiones en torno a la formación del traductor». Traducción, lenguas, literaturas; sociedad del conocimiento: enfoques desde y hacía la cultura. Ed. Sonia Bravo Utrera. Las Palmas de Gran Canaria: Servicio de Publicaciones de la Universidad.. 2004. 119-140.

MAYORAl AsENSIO, Roberto. «El polifacetismo del traductor (jurídico y jurado)». Experiencias de traducción: reflexiones desde la práctica traductora. Ed. Isabel García Izquierdo. Castellón: Universidad Jaime I. 2005. 165-80.

Monzó, Esther. «La web del traductor jurídico: compartir recursos para crear una comunidad». TRANS 9 (2005): 161-78.

— «Descripción de la práctica social y textual de los traductores jurídicos: el proyecto Active». El español, lengua de cultura, lengua de traducción: aspectos teóricos, metodológicos y profesionales. IV Simposio Internacional sobre Traducción, Texto e Interferencias. Eds. Miguel Ángel García Peinado et al. Cuenca: Universidad de Castilla-La Mancha, Servicio de Publicaciones. Granada: Atrio. 2005. 415-25.

Ruiz Moneva, M. ${ }^{a}$ Ángeles. «Legal Translation Explained». Miscelánea 31 (2005): 105-32.

SÁNCHEZ Febrero, José Luis. Legal English and Translation: Theory and Practice: Annotated Texts and Documents. San Vicente de Raspeig, Alicante: Club Universitario, 2003.

SORIANO BARABINO, Guadalupe. La traducción de expedientes de crisis matrimoniales entre España e Irlanda: un estudio jurídico-traductológico. Tesis doctoral. presentada por Guadalupe Soriano Barabino. Granada: Editorial Universidad de Granada, 2005.

VALDERREY REÑONES, Cristina. Análisis descriptivo de la traducción jurídica. Aportes para una mayor sistematización de su enseñanza. Salamanca: Universidad de Salamanca, 2004.

\section{Subtitulado y DOBlaJE}

AguiRRe, M. ${ }^{a}$ José. «La traducción de series de televisión». Experiencias de traducción: reflexiones desde la práctica traductora. Ed. Isabel García Izquierdo. Castellón: Universidad Jaime I. 2005. 43-50.

BERBER IRABIEN DE RAIKo, Diana y LAAKSONEN, Marjaana. «"ELE” y traducción audiovisual». Medios de comunicación y enseñanza del español como lengua extranjera. Actas del XIV Congreso Internacional de ASELE (Burgos 2003). Eds. Hermógenes Perdiguero Villarreal y Antonio A. Alvarez. Burgos: Servicio de Publicaciones de la Universidad de Burgos. 2004. 859-869.

CHAUME VARELA, Frederic. «El componente no verbal de los textos audiovisuales: la incidencia del código de movilidad en la traducción». Estudios sobre traducción: teoría, didáctica, y profesión. Eds. Alberto Álvarez Logrís José Yuste Frías. Vigo: Servicio de Publicaciones de la Universidad de Vigo. 2005. 213-36.

GARCÍA LuQUE, Francisca. «Técnicas de traducción aplicadas a la adaptación cinematográfica: nuevos horizontes para la traductología». TRANS 9 (2005): 21-36.

MARTíNEZ SiERRA Juan José. Estudio descriptivo y discursivo de la traducción del humor en textos audiovisuales. El caso de los Simpson. Tesis doctoral. Dir. Frederic Chaume Varela. Universidad de Jaume I, Castellón. Facultad de Ciencias Humanas y Sociales. Departamento de Traducción, Sociedad y Comunicacion (Interuniversitario), 2003.

— «La relevancia como herramienta para el análisis de la traducción del humor audiovisual: su aplicación al caso de "Los Simpson”» Interlingüística 15. 2 (2004): 927-936. 
Mendiluche Cabrera, Gustavo y Juan R. Hernández Bartolomé. «New Trends in Audiovisual Translation: the Latest Challenging Modes». Miscelánea 31 (2005): 89-99.

ToDA, Fernando. «Subtitulado y doblaje: traducción especializada». Quaderms 12 (2005): 119-32.

ZabALBEASCOA TERRÁN, Patrick. «La dimensión tecnológica de la traducción para el doblaje». Estudios sobre traducción: teoría, didáctica, profesión. Eds. Alberto Álvarez Logrís y José Yuste Frías. Vigo: Servicio de Publicaciones de la Universidad de Vigo. 2005. 197-212.

\section{TRADUCCIÓN LITERARIA}

Azaola, Miguel. «Mi traducción perversa». Peonza 72-73 (2005): 50-57.

BANDÍN FUERTES, Elena. «Traducción y censura del teatro clásico inglés (1939-1985). Construcción del catálogo». Interlingüística 15. 1 (2004): 169-176.

Bartol Hernández, Francisco y AísA Moreu, Diego. «La ciencia experimental en Roger Bacon: traducción, interpretación y notas de la parte sexta del Opus Maius de R. Bacon». Las raíces de la cultura europea: ensayos en homenaje al profesor Joaquín Lomba. Eds. José Solana Dueso, Elvira Burgos Díaz, Pedro Luis Blasco Aznar. 2004. 129-158.

Bergua CAVERO, Jorge. «Traduciendo al ritmo de Homero. Ética y política de la traducción literaria. Málaga: Miguel Gómez. 2004. 75-97.

BlanCo, Rogelio. «La traducción creadora». Vasos comunicantes 30 (2004): 99-101.

Breva-Claramonte, Manuel. «Some Considerations on the Translation of Poetic Metaphor: English-Spanish Phraseology». Actas XXVII Congreso Internacional AEDEAN. Salamanca: Universidad de Salamanca (CD-Rom). 2004.

CAmpillo Arnaiz, Laura. Estudio de los elementos culturales en las obras de Shakespeare y su traducción al español por Macpherson, Astrana y Valverde. Tesis doctoral. Dir. Angel Luis Pujante Álvarez-Castellanos. Universidad de Murcia. Facultad de Letras. Departamento de Inglés. 2004.

Camus Camus, M. ${ }^{a}$ Carmen. «Literatura, cine y traducción en el género del Oeste: un estudio preliminar». Encuentro de lenguas y literaturas. Eds. Margarita García Casado, Sean Scurfield, Gonzalo Martínez Camino. Santander: Universidad de Cantabria. 2004. 161-168.

CASADO, Miguel. «La experiencia de lo extranjero: traducir, leer, escribir poesía». Ética y política de la traducción literaria. Málaga: Miguel Gómez. 2004. 47-59.

CLOUET, Richard. «La traducción trasatlántica: un Mare Nostrum cultural». Traducción, lenguas, literaturas, sociedad del conocimiento: enfoques desde y hacía la cultura. Ed. Sonia Bravo Utrera. Las Palmas de Gran Canaria: Servicio de Publicaciones de la Universidad. 2004. 43-55.

ConNolly , David. «Crítica de la crítica de la traducción literaria: posibles criterios para la crítica de traducciones de poesía». Ética y política de la traducción literaria. Málaga: Miguel Gómez. 2004. 61-74.

Corchado PASCASIO, M. ${ }^{\text {a }}$ Teresa. «Análisis de la ambigüedad en una escena de «The Merry Wives of Windsor» y problemas que plantea su traducción» Anuario de estudios filológicos 28 (2005): 47-54.

Cuellar Irala, Jana y García-Falces Fernández, Andrea. «Cultura y humor: traductores al borde de un ataque de nervios». Linguax 2. 2 (2004). <www.uax.publicacioneslinguax/intei004-04>

DAHLgREN, Marta. «Translation and Relevance: The Appraisal of Poetry». Babel afial 14 (2005): 71-98.

EgEA FERnÁNDEZ-Montesinos, Alberto. «Viajeras inglesas y norteamericanas en Andalucía: visiones alternativas en textos inéditos en su traducción». Mujeres, espacio \& poder. Ed. Mercedes Arriaga Flórez. 2004. 224-232.

EnRíQuez ARANDA, M. Mercedes. La recepción de la poesía de John Keats a través de sus traducciones al español en el siglo XX. Tesis doctoral. Dirs. Francisco Ruiz Noguera y Juan Jesús 
Zaro Vera. Universidad de Málaga. Facultad de Filosofía y Letras. Departamento de Traducción e Interpretación. 2004.

— «Análisis externo de las antologías de traducción españolas del romanticismo poético inglés (1915-2002)». TRANS 8 (2004): 61-74.

ETTE, Tomar. «La traducción literaria como reto de la crítica literaria». Vasos comunicantes 28 (2004): 25-40.

GARCÍA CALDERÓN, Ángeles. «Poesía satírica inglesa de la Restauración: A Satyr against Mankind de John Wilmot (1667-1668) ». Alginge 17 (2005): 65-94.

García GonZÁLez José Enrique. Traducción y recepción de Walter Scott en España: Estudio descriptivo de las traducciones de Waverley al español. Tesis doctoral. Dirs. Fernando Toda Iglesia e Isidro Pliego Sánchez. Universidad de Sevilla. Facultad de Filología. Departamento de Filología Inglesa (Lengua Inglesa). 2004.

GARCÍA LUQUE, Francisca. «The Influence of the Film Industry: What's behind the Adaptation of a Novel?» El español, lengua de cultura, lengua de traducción: aspectos teóricos, metodológicos y profesionales. IV Simposio Internacional sobre Traducción, Texto e Interferencias. Eds. Miguel Ángel García Peinado et al. Cuenca: Universidad de Castilla-La Mancha, Servicio de Publicaciones. Granada: Atrio. 2005. 543-52.

GARCÍA DE TORO, Ana Cristina. «Tendencias de traducción entre lenguas en contacto en la literatura infantil». Anuario de investigación en literatura infantil y juvenil 3 (2005): 97-134.

García Yebra, Valentín. «El Quijote y la traducción». Panacea 6. 21-22 (2005): 277.

GonzÁlez SANTANA, Rosa Delia. «Sociedad del conocimiento: traducción e identidad cultural». Traducción, lenguas, literaturas, sociedad del conocimiento: enfoques desde y hacia la cultura. Ed. Sonia Bravo Utrera. Las Palmas de Gran Canaria: Servicio de Publicaciones de la Universidad. 2004. 105-17.

GUIRAO, Marta. «La traducción de las citas literarias: responsabilidad y estrategias». Ética y política de la traducción literaria. Málaga: Miguel Gómez. 2004. 239-63.

GutiéRrez GutiÉRREZ, José Ismael. «José Martí y la traducción de cuentos para niños: tradición y originalidad». Hispanófila 141 (2004): 31-46.

HERNÁNDEZ, Belén. «La traducción de dialectalismos en los textos literarios». Tonos digital 7 (2004). $<w w w . t o n o s d i g i t a l . c o m>$

HERRERO QUIRÓs, Carlos. «Traducción literaria y apropiación: apuntes para una tipología causal». ES 26 (2005): 147-56.

JiMÉNEZ CARRA, Nieves. «Estrategias de cambio de código y su traducción en la novela de Sandra Cisneros Caramelo or Puro Cuento». TRANS 9 (2005): 37-60.

KENFEL, Veljka Ruzicka y LORENZO GARCía, Lourdes, eds. Estudios críticos de traducción de literatura infantil y juvenil: Análisis de las traducciones de obras inglesas y alemanas a las cuatro lenguas oficiales de España. Oviedo: Septem, 2003.

LóPEZ PÉREZ, Magdalena. «Gulliver's Travels (Libro III): la sátira y su traducción». Hikma 4 (2005): 103-120.

LóPEZ VilLaLba, María. «Traducción y revolución: la obra de Rigas de Velestino (1757-1798)». Ética y política de la traducción literaria. 2004. 153-72.

Mackintosh, Fiona J. «A Happy Transmigration?: Silvina Ocampo Translates Emily Dickinson». Babel afial 14 (2005): 23-42.

MAÑAS CASTRO, Aurora y JiMÉNEZ GuTIÉRREZ, Isabel. «Una aproximación a las traducciones al inglés de la obra El ingenioso hidalgo Don Quijote de la Mancha, de Miguel de Cervantes Saavedra». El español, lengua de cultura, lengua de traducción: aspectos teóricos, metodológicos y profesionales. IV Simposio Internacional sobre Traducción, Texto e Interferencias. Eds. Miguel Ángel García Peinado et al. Cuenca: Universidad de Castilla-La Mancha, Servicio de Publicaciones. Granada: Atrio. 2005. 5-11. 
Marín CALVARRo, Jesús Ángel. «Polisemia e interpretación en el Soneto IV de William Shakespeare». Anuario de estudios filológicos 27 (2004): 147-156.

MARÍN HERNÁNDEZ, David. «Manipulaciones en "No habrá guerra de Troya"». Ética y política de la traducción literaria. Málaga: Miguel Gómez. 2004. 193-217.

Martínez CÁmARA, Mar. «La traducción del nombre propio en Harry Potter and The Philosopher's Stone: análisis de los NPS de los autores a estudiar en el Colegio Hogwarts de magia». Perspectivas interdisciplinares de la lingüística aplicada. Vol, 2. Ed. María Luisa Carrió Pastor. 2005. 553-560.

Mendiluce Cabrera, Gustavo y Hernández Bartolomé, A. «Este traductor no es un gallina: el trasvase del humor audiovisual en Chicken Run. Linguax 2. 2 (2004): 3-21.

Merino, Raquel. «From Catalogue to Corpus in DTS: Translations Censored under Franco. The Trace Project». Revista canaria de estudios ingleses 51 (2005): 85-104.

MORILLAS, Esther. «El Leopardi del bicentenario: clásicos y multitraducciones. Ética y política de la traducción literaria. Málaga: Miguel Gómez. 2004. 173-91.

MoRINI, Massimiliano. «Translating Scottish Poetry». Babel afial 14 (2005): 5-22.

MOURÓN FiguerOA, Cristina. «York's Guilds' Names in the 15th Century and their Translation into Spanish». Odisea 5 (2004): 95-108.

OlIVA CRUZ, Juan Ignacio. «Camafeos exóticos: traducciones del esperpento en «The high place», de Lisa St Aubin de Terán». Revista de filología de la Universidad de La Laguna 23 (2005): 209-230.

OzAETA GÁlvez, M. ${ }^{a}$ Rosario. «En torno a la traducción poética: un modelo de la época ilustrada». Palabras y recuerdos: homenaje a Rosa María Calvet Lora. Eds. María Rosario Ozaeta Gálvez, Doina Popa-Lisseanu. Madrid: UNED. 2004. 177-182.

PASCUA FEBLES, Isabel. «Translating Cultural Intertextuality in Children's Literature». Revista canaria de estudios ingleses 51 (2005): 121-140.

PÉREZ ÁlVAREZ, Ignacio. «Del guión original en inglés a la versión definitiva en castellano. Casos concretos de especial atención en el doblaje y adaptación: Terminator 2». Actas XXVII Congreso Internacional AEDEAN. Salamanca: Universidad de Salamanca (CD-Rom). 2004.

PÉREZ DíAz, Concha Sofía. «Traducción, cultura e identidad: apuntes sobre una traducción de Woman Hollering Creek de Sandra Cisneros» Traducción, lenguas, literaturas, sociedad del conocimiento: enfoques desde y hacía la cultura. Ed. Sonia Bravo Utrera. Las Palmas de Gran Canaria: Servicio de Publicaciones de la Universidad. 2004. 179-220.

PÉREZ L. DE HEREDIA, María. «Aventuras y reescrituras españolas del modelo escénico conservador norteamericano». El español, lengua de cultura, lengua de traducción: aspectos teóricos, metodológicos y profesionales. IV Simposio Internacional sobre Traducción, Texto e Interferencias. Ed. Miguel Ángel García Peinado et al. Cuenca: Universidad de Castilla-La Mancha, Servicio de Publicaciones. Granada: Atrio. 2005. 307-17.

PÉREZ ViCENTE, Nuria. «Presencia de narradoras españolas del siglo XX en Italia: las traducciones». TRANS 9 (2005): 119-32.

Petisco Martínez, Sonia. «A Theoretical and Practical Approach to Literary Translation: the Case of Poetry». Babel afial 14 (2005): 43-70.

Postigo PinAzo, Encarnación. «La literatura escrita por mujeres y su traducción». Cultura, lenguaje y traducción desde una perspectiva de género. Ed. Adela Martínez García. 2004. Málaga: Servicio de Publicaciones de la Universidad de Málaga. 195-234.

PUJALS GelASI, Esteban. «¿Poesía visual en traducción?: el otro "estilo internacional” de 1965». Ética y política de la traducción literaria. Málaga: Miguel Gómez. 2004. 265-91.

RÁBADE NAVARRO, Miguel Ángel. «La traducción o la belleza de la sobriedad». Nerter 7 (2004): 92-94.

Río, Eduardo R. del. «The Context of Translation: Richard Fanshawe and Spanish Verse». Revista alicantina de estudios ingleses 17 (2004): 65-80. 
RodRíGUEZ EsPINOSA, Marcos. «El discurso ideológico de la censura franquista y la traducción de textos literarios: Las aventuras de Barry Lindón y la Editorial Destino». Ética y política de la traducción literaria. Málaga: Miguel Gómez. 2004. 219-38.

— «Jordi Rabones, traductor de La fira de les vanitats» (1984) de William M. Thackeray». Quaderns 12 (2005): 59-75.

RodRíGUEZ RodRíGUEZ, Beatriz M. ${ }^{\mathrm{a}}$ «La problemática de los juegos de palabras en las traducciones de El Lazarillo de Tormes a la lengua inglesa» Odisea 5 (2004): 157-168.

— «Las referencias culturales en dos traducciones de El lazarillo de Tormes a la lengua inglesa: las traducciones de Robert Rudder (1973) y Stanley Appelbaum (2001)». Actas XXI Congreso Asociación Española de Lingüística Aplicada. Eds. J. M. Oro, Jesus Varela Zapata y JoDee Anderson. Universidad de Santiago de Compostela, Servicio de Publicacións e Intercambio Científico, D.L. 2005.

RomÁN, José Manuel. «Lenguaje, traducción y mesianismo en W. Benjamín: una revisión de la lectura de P. de Man». Estudios filosóficos 33. 152 (2004): 27-44.

SAles SALVAdor, Dora y TAIBI, Mustapha. «Estudios culturales, literatura postcolonial y traducción de literatura de minorías en la España de comienzos de siglo». Actas XXVIII Congreso Internacional AEDEAN. Valencia: Universidad de Valencia (CD-Rom), 2005. 608-23.

SÁNCHEZ RodRíGUEZ, Luis. «La función del malapropismo en Joseph Andrews, de Henry Fielding: notas para una traducción» Anuario de estudios filológicos 28 (2005): 277-283.

SASTRE PÉREZ, Juan José. Traducciones al español de canciones de The Beatles (1963-1996). Tesis doctoral. Dir. Raquel Merino Álvarez. Universidad del País Vasco. Facutad de Filología Geografía e Historia. Departamento de Filología Inglesa y Alemana, 2003.

SCHWARTZ, Ros. «La traducción literaria en Europa». Vasos comunicantes 29 (2004): 69-74.

SERRANo FernándeZ, Luis. Traducción y censuras de textos cinematográficos inglés-español 1970-1985. Tesis doctoral. Dir. Rosa Rabadán Álvarez. Universidad de León. Facultad de Filosofía y Letras. Departamento de Filología Moderna. 2003.

SHEERIN, Patrick, H. «Translating Patrick Kavanagh». ES 26 (2005): 213-22.

SCHWARTZ, Ros. «La traducción literaria en Europa». Vasos comunicantes: revista de ACE traductores 29 (2004): 69-74.

VALERO GARCÉS, Carmen. «La traducción como vehículo de comunicación: lenguas y culturas en la España de comienzos de siglo y traducción de literatura de las minorías». Perspectivas interdisciplinares de la lingüística aplicada. Vol. 2. Ed. M. ${ }^{a}$ Luisa Carrió Pastor. 2005. 593-600.

— «Sabor rural, tipismo, viajes y paisajes. La difícil tarea de traducir Viaje a la Alcarria, de C.J. Cela». Actas XXVII Congreso Internacional AEDEAN. Salamanca: Universidad de Salamanca (CD-Rom). 2004.

VÉLEZ NúÑEZ, Rafael. «Bucolic Uneasiness: A Comparative Study of Translations and Adaptations of Virgil's Second Eclogue in Early Middle English». BELLS 13 (2004).

Vella RAmírez, Mercedes. La sensibilidad en la poesía prerromántica inglesa y su influencia en Francia a través de la traducción: melancolía y "mal du siècle”. Tesis doctoral. Dir. Miguel Ángel García Peinado. Universidad de Córdoba, Departamento de Lenguas Romances, Estudios Semíticos y Traducción e Interpretación. 2004.

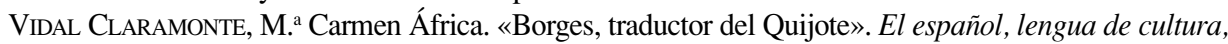
lengua de traducción: aspectos teóricos, metodológicos y profesionales. IV Simposio Internacional sobre Traducción, Texto e Interferencias. Eds. Miguel Ángel García Peinado et al. Cuenca: Universidad de Castilla-La Mancha, Servicio de Publicaciones. Granada: Atrio. 2005. 23-33.

VIERECK SALINAS, Roberto. La traducción como instrumento y estética en la literatura hispanoamericana del siglo XVI. Madrid: Universidad Complutense. 2005.

ZaRANDONA FERnÁNDEZ, Juan Miguel. «The English Letters by Don Manuel Álvarez Espriella, Ppseudo-translated by Robert Southey (1807)». Odisea 5 (2004): 187-98. 
— «Merlin, Alonso, Aldonza e Isidora y los arquetipos jungianos del ánima y el ánimus: entre otras cosas, incluso traducción». La literatura en la literatura: Actas del XIV simposio de la sociedad española de literatura general y comparada. Ed. Magdalena León Gómez. Alcalá de Henares: Ed. Centro Estudios Cervantinos. 2004. 157-164.

ZARO VERA, Jesús. «Traducción y contexto social y artístico en dos versiones españolas de The Taming of the Shrew de William Shakespeare». Ética y política de la traducción literaria. Málaga: Miguel Gómez. 2004. 121-44.

Zazo, Juan Jesús. «Consideraciones sobre la traducción de Persuasión de Jane Austen». Actas XXVIII Congreso Internacional AEDEAN. Valencia: Universidad de Valencia (CD-Rom), 2005. 561-68.

\section{E. CULTURA Y CINE}

MARÍA LUZ ARroYo VÁZQUEZ larroyo@flog.uned.es ANTONIA SAGREDo SANTOS asagredo@flog.uned.es UNED. Madrid

\section{ÍNDICE}

1. Cultura

2. Cine

\section{Cultura}

Alberro Rodríguez, Manuel. Diccionario Mitológico y folklorico céltico: desde Galicia a las Islas Shetland, pasando por Gran Bretaña, Irlanda e Isla de Man, Cornualles, Gales, Escocia y las Islas Orkney. Betanzos: Briga Ediciones, S. C., 2004.

AlCALÁ-ZAMORA, José N. La empresa de Inglaterra: «la Armada Invencible», fabulación y realidad. Madrid: Real Academia de la Historia, 2004.

Alfaya Lamas, Elena y Toro Santos, Antonio de. «Kernow, Cornwall: A History of Discontinuity». About Culture. Ed. Elizabeth Woodward Smith. Santiago de Compostela: Tórculo, 2004: 217-224.

Alonso GiRÁlDEZ, José Miguel. «El fulgor y la tragedia en la vida doméstica. Mito, realidad y «Sense of Place» en la poesía irlandesa contemporánea». About Culture. Ed. Elizabeth Woodward Smith. Santiago de Compostela: Tórculo, 2004: 177-188.

Arroyo Vázquez, M. ${ }^{a}$ Luz y Sagredo Santos, Antonia. Historia y Cultura de los países de habla inglesa. Madrid: UNED, 2005.

BALleSteros GonZÁlez, Antonio. Escrito por brujas. Lo sobrenatural en la vida y la literatura de grandes mujeres del siglo XIX. Madrid: Oberon (Grupo Anaya), 2005.

BARrY, Tom. A constitución de Irlanda Contemporánea: días de guerrilla en Irlanda. Noia: Ed. Toxosoutos, S. L., 2004.

BINCHI, Maeve. Tara Road, una casa en Irlanda. Barcelona: Publicaciones y Ediciones Salamandra, S. A., 2004. 
Blake, Andrew. La iresistible ascensión de Harry Potter. Madrid: Edaf, 2002.

Bosch SÁnchez, Aurora. «The Industrial City: The Multi-Ethnic Frontier of the Twentieth Century», Revista Complutense de Historia de América 30 (2004): 131-148.

Burrell, Paul. La vida real de Diana de Gales. Madrid: Ediciones Temas de Hoy, 2004.

Cabarcos Traseira, M. ${ }^{a}$ Jesús. «Peter Carey's «My life as a Fake»: The Unbearable Lightness of Being an Australian Writer». About Culture. Ed. Elizabeth Woodward Smith. Santiago de Compostela: Tórculo, 2004: 51-62.

CALDERÓN CUADRADO, Reyes. Empresarios Españoles en el proceso de independencia norteamericana. La Casa Gardoqui e Hijos de Bilbao. Madrid: Unión Editorial, S. A., 2004.

CAlviÑo Riveira, Elena M. ${ }^{a}$ "African-American Culture in «Everyday Use: Re-reading Maggie Johnson.» About Culture. Ed. Elizabeth Woodward Smith. Santiago de Compostela: Tórculo, 2004: 83-92.

CANCELo LóPEZ, Pablo. «Hackers», «Crakers», «Phreakers», y otros grupos del ciberespacio». About Culture. Ed. Elizabeth Woodward Smith. Santiago de Compostela: Tórculo, 2004: 37-47.

CAPORAle Bizzini, Silvia. We, the "Other Victorians»: Considering the Heritage of $19^{\text {th }}$ Century Throught. Alicante: Publicaciones de la Universidad de Alicante, 2003.

CARABí, Àngels \& Armengol, Josep M., eds. Debating Masculinity/La masculinidad a debate. Barcelona: Publicacions UB, 2005. (DVD, 35 mins).

CARIDAD BARreiro, M. ${ }^{a}$ Mercedes. «Culture and Humour in «The Black Adder.» About Culture. Ed. Elizabeth Woodward Smith. Santiago de Compostela: Tórculo, 2004: 383-394.

Castelo Montero, Miguel. «Multilingual Financial Culture: Simple Terms for Complex Concepts.» About Culture. Ed. Elizabeth Woodward Smith. Santiago de Compostela: Tórculo, 2004: 3-16.

CAstro Dopacio, M. ${ }^{a}$ Jesús. «Tradition vs. Modernity: The Virgin of Guadalupe at the Chicano/a Crossroads». About Culture. Ed. Elizabeth Woodward Smith. Santiago de Compostela: Tórculo, 2004: 521-530.

CEREZAL, Fernando, ed. De la práctica a la teoría. Reflexiones sobre la enseñanza y el aprendizaje del inglés». Alcalá de Henares: Servicio de Publicaciones de la Universidad de Alcalá de Henares, 2005.

Clark, David. «Football Chants in Scotland and England 1969-1979». About Culture. Ed. Elizabeth Woodward Smith. Santiago de Compostela: Tórculo, 2004: 329-344

Collado Rodríguez, Francisco, El orden del caos: literatura, política y posthumanidad en la narrativa de Thomas Pynchon, Valencia: Biblioteca Javier Coy d'Estudis Nordamericans, 2004.

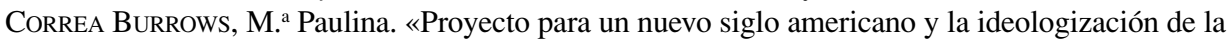
diplomacia estadounidense», Historia y Comunicación Social 10 (2005): 73-90.

Cortes PÉrez, Catuxa. «Comparing the Meaning of Africa in Alice Walker's and Steven Spielberg's «The Color Purple»: A Satinized White Version of a Black Experience?» About Culture. Ed. Elizabeth Woodward Smith. Santiago de Compostela: Tórculo, 2004: 73-82.

Couto Lorenzo, Gerardo. «Dealing with Cultural Problems in: «Annie Hall». About Culture. Ed. Elizabeth Woodward Smith. Santiago de Compostela: Tórculo, 2004: 373-382.

Crane, Linnette. «The Cultural Aspects of Exams». About Culture. Ed. Elizabeth Woodward Smith. Santiago de Compostela: Tórculo, 2004: 467-476.

Crespo García, Begoña. «General Survey of the Growth of Scientific Culture. A Historical Approach». About Culture. Ed. Elizabeth Woodward Smith. Santiago de Compostela: Tórculo, 2004: 157-165.

Dachs Ventura. «Multicultural Children's Stories in the Global Society of Non-native Learners of English». About Culture. Ed. Elizabeth Woodward Smith. Santiago de Compostela: Tórculo, 2004: 427-436.

DARKo, Amma. Más allá del horizonte. Barcelona: Ediciones del Cobre, 2003. 
Delgado Gómez-Escalonilla, Lorenzo y ElizALde, M. ${ }^{a}$ Dolores, eds. España y Estados Unidos en el siglo XX. Madrid: Consejo Superior de Investigaciones Científicas, 2005.

DíAz PÉREZ, Francisco Javier. La cortesía verbal en inglés y en español. Actos de habla y pragmática intercultural. Jaén: Universidad de Jaén, 2003.

Elices Agudo, Juan Francisco. Historical and Theoretical Approaches to English Satire. München: Lincom, 2005.

ELIot, T. S. La tierra baldía. (Edición, introducción y notas de Viorica Patea). Madrid: Cátedra: Letras Universales, 2005.

Estévez SaÁ, José Manuel \& BRowne SARTORI, Rodrigo. «Cultural Anthropophagy as a Form of Cannibalism Based on the Phenomenon of Iconophagy». About Culture. Ed. Elizabeth Woodward Smith. Santiago de Compostela: Tórculo, 2004: 103-111.

EstéveZ SAÁ, Margarita. «Culture and History in Postcolonial and Multiethnic Fiction Written by Women in English». About Culture. Ed. Elizabeth Woodward Smith. Santiago de Compostela: Tórculo, 2004: 247-258.

EynullaeVA, Ekaterina. «Languaje and Culture: Verbal, Cognitive, Motivational and Emotional Aspects of Intercultural Communication». About Culture. Ed. Elizabeth Woodward Smith. Santiago de Compostela: Tórculo, 2004: 17-26.

FERNÁNDEZ MORALES, Marta. «Chicana voices in U.S. theatre: «gorditas e ilegales» in Josefina López's «Real Women Have Curves». About Culture. Ed. Elizabeth Woodward Smith. Santiago de Compostela: Tórculo, 2004: 511-520.

FERnÁNDEZ DE MoRATín, Leandro. Apuntaciones sueltas de Inglaterra. Madrid: Ediciones Cátedra, 2005.

FERnÁNDEZ SÁnchez. José Francisco, ed. Creadores de evocación. Nuevos Artículos sobre Relatos Cortos de Autores Británicos Contemporáneos. Almería: Servicio de Publicaciones de la Universidad, 2005.

FIELDING, Henry. Don Quijote en Inglaterra. Madrid: Asociación de Directores de Escena de España (ADE), 2005.

FilgueIRA FigueIRA, Marina. «La dinastía de los Estuardo bajo un punto de vista femenino. «The Stuarts: a Pindarique Ode» de Penelope Aubin». About Culture. Ed. Elizabeth Woodward Smith. Santiago de Compostela: Tórculo, 2004: 269-276.

Floyd Moore Alan. «Two Discourses: The Printed and On-Line English-Language Press». About Culture. Ed. Elizabeth Woodward Smith. Santiago de Compostela: Tórculo, 2004: 395-404.

Fresno Calleja, Paloma. «Waves from Neighbour Shores: Tagata Pasifika in New Zealand». About Culture. Ed. Elizabeth Woodward Smith. Santiago de Compostela: Tórculo, 2004: 63-72.

Garcés Conejos, Pilar, Gómez Morón, Reyes, Férnandez Amaya, Lucía y Padilla Cruz, Manuel, eds. Current Trends in Intercultural, Cognitive, and Social Pragmatics. Sevilla: Research Group «Intercultural Pragmatic Studies, 2004.

García Álvarez, Lara. «What aspects of Reality Do Editorial Cartoons Represent?». About Culture. Ed. Elizabeth Woodward Smith. Santiago de Compostela: Tórculo, 2004: 405414.

García Martínez, M. ${ }^{a}$ Isabel, Álvarez Faedo, M. ${ }^{a}$ José y Simón Schuhmacher, Lioba. La educación de la mujer en el siglo XVII en España e Inglaterra. Madrid: Edwin Mellen, 2005.

GARCía SÁnchez, María Soraya. «Talking About Women, History, and Writing With Michèle Roberts,» Atlantis 27/2 (Dec. 2005): 137-147.

GloAguen, Philippe. Irlanda. Barcelona: Salvat Editores, S. A., 2005.

GONZÁLEZ, Rosa (ed.). The representation of Ireland. Images from Outside and from Within. Barcelona: PPU, 2003. 
GONZÁLEZ AdÁNEZ, Noelia. Monarquía, representación política e independencias americanas en el liberalismo ilustrado: Inglaterra y España. Madrid: Universidad Complutense de Madrid, Servicio de Publicaciones, 2005.

GoNZÁLEZ Souto, Irma. «Culturally distinct: What Makes «Looking for the Possible Dance.» A Specifically Scottish Nobel.» About Culture. Ed. Elizabeth Woodward Smith. Santiago de Compostela: Tórculo, 2004: 207-216.

GuERra GómEZ, Amparo. «Políticas y estrategias de comunicación de Jimmy Carter en los tratados del Canal de Panamá. Un repaso desde el siglo XXI», Historia y Comunicación Social 10 (2005): 91-115.

HAFFNER, Sebastian. Winston Churchill: una biografía. Madrid: Destino, 2002.

HenríQuez Jiménez, Santiago J. Géneros en contacto. Viajes, crimen, novela femenina y humor. Miscelánea de literatura inglesa y norteamericana. Las Palmas de Gran Canaria: Universidad de Las Palmas de Gran Canaria /Caja de Canarias, 2004.

HEYDON, Annette. «Transcending Culture: Adaptation by Overcoming Cultural and Linguistic Barriers». About Culture. Ed. Elizabeth Woodward Smith. Santiago de Compostela: Tórculo, 2004: 345-354.

Hoyo Barbolla, Ana M. ${ }^{a}$ del. «Estados Unidos desde la historiografía española», AYER 59 (2005): 299-309.

Ibarrola-Armendariz, Aitor y Blave, Raquel, eds. Entre dos mundos: Antología de relatos interculturales norteamericanos. Bilbao: Ediciones Mensajero, 2005.

Imicoz Beunza, José M.a ed. Casa, familia y sociedad. País Vasco, España y América. Bilbao: Universidad del País Vasco, 2004.

IRujo Ollo, Manuel de. Inglaterra y los vascos. Tafalla: Txalaparta Argitaletxea, S. L., 2004.

JiMÉNEZ PULIDO, Jesús. La educación intercultural a través del cine. Granada: Port Royal, 2005.

LAMO DE ESPINOSA, Emilio. ¿Una diferencia que marca la diferencia? Valores y cultura en Europa y Estados Unidos. Madrid: Instituto Elcano, 2005.

Lasa Álvarez, Begoña. «Be the Best You Can Be»: «Women's Magazines Will Help You». About Culture. Ed. Elizabeth Woodward Smith. Santiago de Compostela: Tórculo, 2004: 277-284.

LAVANDEIRA Rojo, Sonia. «Los aspectos socioculturales en la enseñanza de la Enseñanza Secundaria Obligatoria». About Culture. Ed. Elizabeth Woodward Smith. Santiago de Compostela: Tórculo, 2004: 451-466.

LoGAN, Joy. «Ricky Martín and the «Othering» of Latino Identities in U.S. Popular Culture». About Culture. Ed. Elizabeth Woodward Smith. Santiago de Compostela: Tórculo, 2004: 499-509.

LóPez RoPero, M. ${ }^{a}$ Lourdes. The Anglo-Caribbean Migration Novel: Writing from the Diaspora. Alicante: Publicaciones UA, 2004.

Lorenzo Modia, María Jesús, ed. All in All: A Plural View of Our Teaching and Learning. A Coruña: Universidade da Coruña, 2005.

MacCannell, Dean. «Turismo Cultural». Archipiélago. Cuaderno de Crítica de la Cultura 68. (noviembre 2005): 20-42.

Martín RodríGuez, Luis Fernando. Historia y leyendas celtas. Salinas: Los Cuentos del Urogallo, 2004.

MARTíNEZ FALQUINA, Silvia. Indias y fronteras: el discurso en torno a la mujer étnica. Oviedo: KRK, 2004.

MARTínEZ ZAPICO, Patricia. «England's History on the Romantic Opera Stage: Elizabeth Tudor Portrayed in Donizetti's Works». About Culture. Ed. Elizabeth Woodward Smith. Santiago de Compostela: Tórculo, 2004: 129-138.

Medina CASAdo, Carmelo y Ruiz MAs, José. El bisturí inglés: Literatura de viajes e hispanistas en lengua inglesa. Jaén: Universidad de Jaén y UNED, 2004. 
MÉNdeZ GarcíA, M. a del Carmen. «English-Speaking Countries: Cultural Diversity in EFL «Bachillerato» Textbooks.» About Culture. Ed. Elizabeth Woodward Smith. Santiago de Compostela: Tórculo, 2004: 437-450.

MirAlles ConTIJOCH, Francesc. Un curs d' estiv a Irlanda. Barcelona: Columna Edicions Llibres i Comunicació, S. A., 2004.

Montero Ameneiro, Lidia. «La sombra de la «Big House». About Culture. Ed. Elizabeth Woodward Smith. Santiago de Compostela: Tórculo, 2004: 189-198.

Mosquera GEnDE, Ingrid «Cross-Cultural Relationships: Ireland and Scotland. Edwin Muir and James Joyce.» About Culture. Ed. Elizabeth Woodward Smith. Santiago de Compostela: Tórculo, 2004: 199-206.

Mourón FigueroA, Cristina. «Shakespeare's «Richard III»: The Historical Truth Behind the Myth». About Culture. Ed. Elizabeth Woodward Smith. Santiago de Compostela: Tórculo, 2004: 115-128.

Munita LoInaZ, José Antonio, ed. Conflicto, violencia y criminalidad en Europa y América. Bilbao: Universidad del País Vasco, 2004.

NADALES RuIz. Marta «Anglo-Saxon Influence in the Nineteenth Century Spanish Academy». About Culture. Ed. Elizabeth Woodward Smith. Santiago de Compostela: Tórculo, 2004: 167-174.

NuÑEZ PuENTE, Carolina. «Inter-Cultural Criticisms: Third-World Women's Challenge to Contemporary Feminism.» About Culture. Ed. Elizabeth Woodward Smith. Santiago de Compostela: Tórculo, 2004: 259-267.

Peebles, Verónica F. «Cervantine Influence on Robert Coover's Work». About Culture. Ed. Elizabeth Woodward Smith. Santiago de Compostela: Tórculo, 2004: 539-547.

Pérez Rodríguez, Eva M. ${ }^{\mathrm{a}}$ «Private Judgement» With a Twist: William Godwin's Rational Attraction for Mythology and Superstition.» About Culture. Ed. Elizabeth Woodward Smith. Santiago de Compostela: Tórculo, 2004: 147-156.

PRIETO ARRANZ, J. Igor. «British or English? The Blurring of Cultural Identities in British Tourist Promotion». About Culture. Ed. Elizabeth Woodward Smith. Santiago de Compostela: Tórculo, 2004: 301-313.

Pujante, A. Luis \& Hoenselaars, Tom, eds. Four Hundred Years of Shakespeare In Europe. Newark: University of Delaware Press/Associated University Presses, Newark \& London, 2003.

Raley, Harold. «El pensamiento de Julián Marías en Norteamérica», Cuenta y Razón del Pensamiento Actual 1933 (verano 2004): 7-13.

RECIO MORALES, Óscar. Irlanda en Alcalá: la comunidad irlandesa en la Universidad de Alcalá y su proyección europea, 1579-1785. Alcalá de Henares: Fundación Colegio del Rey, 2004.

REgo FreIRE, Avelino. «When the Negro Wasn't in Vogue: Internalized Racism and Cultural Conflicts in "Reena".» About Culture. Ed. Elizabeth Woodward Smith. Santiago de Compostela: Tórculo, 2004: 93-101.

RodríGUez CAPARrinI, Bernardo. El «Eton» católico: el internado jesuita de Beaumon (Old Windsor, Inglaterra) durante el rectorado del padre Joseph M. Bampton G. J. (1901-1908). Cádiz: Universidad de Cádiz, Servicio de Publicaciones, 2004.

RODRÍGUEZ GoNZÁLEZ, Carla. Jackie Kay: biografías de una Escocia transcultural. Oviedo: KRK, 2005.

SAENGer, Paul. «The British Isles and the Modern Mode of Biblical Citation», Sintagma. Revista del Instituto del libro y la lectura 1 (2005): 15-26.

SAgREdo SANTOS, Antonia. «El discurso de la prensa católica ante el New Deal estadounidense: $E l$ Debate (1932-1936)», Hispania Sacra LVI/114 (2004): 687-707. 
— «La prensa católica de la Segunda República ante el modelo reformista de Franklin Delano Roosevelt» en Memoria e Identidades editado por Justo Beramendi y M. ${ }^{a}$ Xesús Baz. Santiago de Compostela, Servizio de Publicaciones e Intercambio Científico de la Universida de Santiago de Compostela, 2004: 1-26. (Soporte CD).

— «El discurso de la prensa madrileña de la Segunda República ante las elecciones presidenciales estadounidenses de 1932», Historia y Comunicación Social 10 (2005): 201-219.

SAles SALVADOR, Dora, Puentes sobre el mundo: Cultura, traducción y forma literaria en las narrativas de transculturación de José María Arguedas y Vikram Chandra. Nueva York: Peter Lang, 2004.

SAlORIO DíAz. M. ${ }^{a}$ Marta «Cultural Aspects of Barbie Doll Advertising». About Culture. Ed. Elizabeth Woodward Smith. Santiago de Compostela: Tórculo, 2004: 415-424.

SAPAG MuÑOZ DE LA PEÑA, Pablo. «External and Internal Factors Regarding a War Correspondent. A Theoretical Overview for IO and NGO Public Infoirmation», Historia y Comunicación Social 10 (2005): 221-232.

Schama, Simon. Auge y caída del Imperio Británico. Barcelona: Crítica, 2004.

SEgAdo BoJ, Francisco. «Tambores de guerra en viñetas: Spiderman y el 11-S», Historia y Comunicación Social 10 (2005): 233-246.

ShaKesPeARE, William, Eduardo III. Madrid: Asociación de Directores de Escena de España (ADE), 2005.

Simal, Begoña and Marino, Elisabetta, eds. Transnational, National, and Personal Voices: New Perspectives on Asian American and Asian Diasporic Women. Münster: LIT Verlag, 2004.

SIRGO FoYo. Elba M. ${ }^{a}$ «Bend in Like Beckham»: Intercultural Symbolic Violence as a Means of Female Socialization». About Culture. Ed. Elizabeth Woodward Smith. Santiago de Compostela: Tórculo, 2004: 227-236.

TERMIS SOTO, Fernando. Renunciando a todo. El régimen franquista y los Estados Unidos desde 1945 a 1963. Madrid: UNED, 2005.

Trainor de la Cruz, Patricia \& Krauel Heredia, Blanca. Humour and Tragedy in Ireland. Málaga: Universidad de Málaga, D. L., 2005.

TodD, Alpheus. El gobierno parlamentario en Inglaterra. Pamplona: Analecta Ed., 2004.

Torres Somalo, Antonio y Pérez Lamigueiro, Isabel. Irlanda. Madrid: Anaya Touring Club, 2005.

ToRres CANSINO, Mercedes. «El tratamiento del inglés como segunda lengua para estudiantes de minorías inmigrantes en Hawai: una reflexión sobre nuestro futuro cercano». About Culture. Ed. Elizabeth Woodward Smith. Santiago de Compostela: Tórculo, 2004: 485-495.

VALDÉs MiRAYes, J. Rubén. «The Prejudices of Education: Educational Aspects of the Scottish Enlightenment.» Atlatis 27/2 (Dic. 2005): 101-118.

Van Minnen, Cornelis \& Hilton, Sylvia L., eds. Frontiers and Boundaries in U.S. History. Amsterdam: VU University Press, 2004.

VÁzquez García, Celia. «Two Worlds, a Single Ticket: The Construction of a New Hybrid Identity in Postcolonial Adolescent Narratives of Migration». About Culture. Ed. Elizabeth Woodward Smith. Santiago de Compostela: Tórculo, 2004: 355-369.

VÁzQuez Maroño, M. ${ }^{a}$ Luz. «Comparative Legal Cultures in Common Law Countries: Law and Tradition in Minority Cultures». About Culture. Ed. Elizabeth Woodward Smith. Santiago de Compostela: Tórculo, 2004: 27-35.

VÉLEZ BARREIRO, Marco «Forms of Business Ownership and Other Related Concepts in Spain and the UK: Underlying Concepts and Business English Teaching». About Culture. Ed. Elizabeth Woodward Smith. Santiago de Compostela: Tórculo, 2004: 477-484.

Villegas-LóPez, Sonia \& Domínguez-García, Beatriz, eds. Literature, Gender, Space. Huelva: Servicio de Publicaciones de la Universidad de Huelva, 2004. 
WARD, Paul J. «The Permissive Society and the Break-up of Britain.» About Culture. Ed. Elizabeth Woodward Smith. Santiago de Compostela: Tórculo, 2004: 287-300.

WeIR, Alison. Enrique VIII. Barcelona: Ariel, 2003.

WIRT, Sises. Duendes británicos: floklore galés, mitología de las hadas, leyendas y tradiciones. Palma de Mallorca: José J. de Olañeta, 2004.

Woodward SMith, Elizabeth, ed. About Culture. Santiago de Compostela: Tórculo, 2004.

wOODWARD SMITH, Elizabeth. «In Search of Cultural Symbols and Values». About Culture. Ed. Elizabeth Woodward Smith. Santiago de Compostela: Tórculo, 2004: 315-328.

\section{CINE}

Allen, Woody. Hollywood Ending. Madrid: Ocho y Medio, 2002.

- Anything Else (Todo lo demás). Madrid: Ocho y Medio, 2003.

- Match Point. Madrid: Ocho y Medio, 2005.

— Melinda \& Melindat. Madrid: Ocho y Medio, 2005.

August, John. Big Fish. Madrid: Ocho y Medio, 2004.

BAXTER, John. Stanley Kubrick. Biografía. Madrid: T \& B Editores, 2005.

BERRIATÚA, Wiro. Cine Español-Spanish Cinema: 2004. Madrid: Instituto de la Cinematografía y de las Artes Audiovisuales, 2005.

Binh, N. T. \& Viviani, Christian. Lubitsch. Madrid: T \& B Editores, 2005.

BISKIND, Peter. Moteros tranquilos, toros salvajes: la generación que cambió Hollywood. Barcelona: Anagrama, 2004.

Bonet MoJica, Lluís. Regreso a la casa de citas. Hollywood habla. Segunda parte. Madrid: T \& B Editores, 2005.

Bonet MojicA, Lluís. Gary Grant. El capricho de las damas. Madrid: T \& B Editores, 2004.

Bonilla Agudo, María. «Cultura y Potsmodernidad in David Lynch's "Mulholland Drive"». About Culture. Ed. Elizabeth Woodward Smith. Santiago de Compostela: Tórculo, 2004: 531-538.

CARMONA, Luis Miguel. ¿Qué hace una estrella como yo en una película como esta? Madrid: T \& B Editores, 2005.

Carmona, Luis Miguel \& Peeping, Tom. La guía del Voyeur. Las estrellas al desnudo. Madrid: T \& B Editores, 2005.

Cohen, Ethan, Cohen, Joel, Stone, Mathew \& Ramsey, Robert. Crueldad Intolerable. Madrid: Ocho y Medio, 2003.

COMA, Javier. 50 amores clásicos. Madrid: Nikel Odeón, 2002.

- La ficción bélica: grandes novelas americanas y sus versiones cinematográficas sobre la Segunda Guerra Mundial. Barcelona: Inédita, 2005.

Comas, Ángel. William Wyler. Su obra, su época. Madrid: T \& B Editores, 2004.

ComAs, Ángel. Anthony Mann. Madrid: T \& B Editores, 2004.

—De Hitchcock a Tarantino: enciclopedia del «neo-noir» norteamericano. Madrid: T \& B Editores, 2005.

Corral, Juan M. Los estudios Ealing. Madrid: T \& B Editores, 2005.

CortiJo, Javier. El chef de Kubrick. Madrid: T \& B Editores, 2005.

CuRTIS, Richard. Love Actually. Madrid: Ocho y Medio, 2003.

DiEGo, José de. Henry Fonda: el héroe infeliz. Madrid: T \& B Editores, 2005.

DELEYTO, Celestino. Ángeles y demonios: representación e ideología en el cine contemporáneo de Hollywood. Barcelona: Paidós, 2003.

EDITORIAL QUATERMASS. Cine de terror, fantasía y ciencia ficción. Antología del cine fantástico británico. (Monográfico Revista Quatermass 6, Sep. 2004). Bilbao: Astiberri, 2004. 
FONTE, Jorge. Todo empezó con un ratón. El fantástico mundo de los cortos Disney. Madrid: T \& B Editores, 2004.

— Walt Disney. El universo animado de los largometrajes, 1937-1967. Madrid: T \& B Editores, 2005.

Fraile Marcos, Ana M. ${ }^{a}$ Planteamientos estéticos y políticos en la obra de Zora Neale Hurston. Valencia: Universitat de Valencia, 2003.

FraYling, Christopher. Sergio Leone. Algo que ver con la muerte. Madrid: T \& B Editores, 2005.

GoldMAN, William. Las aventuras de un guionista en Hollywood. Madrid: Plot, 2002.

Gual, Roger. Todo por un largo. Diario de rodaje de «Smoking Room». Madrid, Ocho y Medio, 2003.

Guijarro GonZÁlez, Juan Ignacio \& EsPejo Romero, Ramón, eds. Arthur Miller: Visiones desde el nuevo milenio. Valencia: Universitat de Valencia, 2004.

GutIÉRREZ DA SILVA, Manuel. Diccionario de actores cinematográficos. Madrid: T \& B Editores, 2004.

HaY, Peter. Sucedió en Hollywood. Teià, Barcelona: Ma Non Troppo, 2003.

HidALGo, Manuel. El testigo indiscreto. Madrid: T \& B Editores, 2005.

HUI, Arlene. «La frontera racial en «The Searches» de John Ford», Revista Complutense de Historia de América 30 (2004): 187-207.

JiMÉNEZ Pozo, Agustín. Qué pequeño es el cine que me ha cabido en este libro. Madrid: Espejo de Tinta, 2005.

LARA, Antonio. El cine ha muerto. Larga vida al cine. Madrid: T \& B Editores, 2005.

LAVERTY, Paul. Sweet Sixteen. Madrid. Ocho y Medio, 2003.

Lema Trillo, Eva Victoria. Los modelos de género masculino y femenino en el cine de Hollywood, 1990-2000. Madrid: D. L. 47816, 2005. (Cassette).

LóPEZ SILVESTRE, Federico. El paisaje virtual: el cine de Hollywood y el neobarroco digital. Madrid: Biblioteca Nueva, 2004.

LuQue, Ramón. En busca de Woody Allen. Sexo, muerte y cultura en su cine. Madrid Ocho y Medio, 2005.

MCBRIDE, Joseph. Tras la pista de John Ford. Madrid: T \& B Editores, 2004.

McGilligan, Patrick. Blackstory 3: conversaciones con los guionistas de los años 60. Madrid: Plot, 2003.

— Alfred Hitchcock. Una vida de luces y sombras. Madrid: T \& B Editores, 2005.

MemBA, Javier. La década de oro de la ciencia ficción, (1950-1960). Madrid: T \& B Editores, 2005.

- El cine de tensión de la Universal. Madrid: T \& B Editores, 2004.

— La Serie B. Madrid: T \& B Editores, 2005.

Merino, Raquel, SANTAMARÍA, J. M. y PAJARes, Eterio. Trasvases culturales: literatura, cine, traducción. 4. Bilbao: Universidad del País Vasco, 2005.

Mille, Cecil B. DE. Mis Diez Mandamientos: Memorias Cecil De Mille (1881-1959). (Clásicos Biografías de Cine). Madrid: J. C. 2005.

Minghela, Anthony. Cold Mountain. Madrid: Ocho y Medio, 2004.

Palacios, Jesús y WeinRichter, Antonio, eds. Gun Crazy. Serie negra se escribe con B. Madrid: T \& B Editores, 2005.

PARRA, Miguel Ángel y PANADERO, David G. Ed Wood. Platillos volantes y jerseys de angora. Madrid: T \& B Editores, 2005.

PaYÁn, Miguel Juan y OCio Costales, Juanjo. Hollywood confidencial. Los trapos sucios de las estrellas. Madrid: T \& B Editores, 2004.

PaYÁn, Miguel Juan. Los mitos del oeste en el cine. Madrid: Cacitel, S. L., 2004.

PaYÁn, Miguel Juan y NaVARro, Ramiro. Steve McQueen. Un rebelde en Hollywood. Madrid: T \& B Editores, 2004. 
PaYÁn, Miguel Juan. La cara oculta de las estrellas de Hollywood. Madrid: Jardín, 2005.

PAYÁn, Javier Juan y PAYÁn, Miguel Juan. Secretos y mentiras de Hollywood. Madrid: T \& B Editores, 2005.

PAVÉs Borges, Gonzalo. El cine negro de la RKO: en el corazón de las tinieblas. Madrid: T \& B Editores, 2005.

PeIrotTI, Miguel. Directores al infierno. Actores malditos, yonquis varios, casos perdidos. Madrid: T \& B Editores, 2005.

Platas Alonso, María. «Models of Empowerment in African-American Feminist Cinema: Julie Dash's». Daughters of the Dust.» About Culture. Ed. Elizabeth Woodward Smith. Santiago de Compostela: Tórculo, 2004: 237-245.

Porfirio, Robert, SILVER, Alain y URSINI, James. El cine negro americano: los secretos de los cineastas del período clásico. Barcelona: Laertes, 2005.

PRIETO, Miguel Angel. Desaparecidos en combate. ¿Dónde están las estrellas del nuevo Hollywood? Madrid: T \& B Editores, 2004.

- Blade Runner. Madrid: T \& B Editores, 2005.

— James Dean. El ángel oscuro. Madrid: T \& B Editores, 2005.

RAMIS, Cera. Los Xunguis en Hollywood. Barcelona: Parramón, 2005.

RODRíGUEZ, Eduardo y TEJERO, Juan. Diccionario de películas de cine norteamericano. Madrid: T \& B. Editores, 2002.

RUBIN DE CELIS, Santiago y Andrés. Blake Edwards... o atrapar un rayo en una botella. Madrid: T \& B Editores, 2004.

RUSSELl TAYLOR, John. Extraños en el paraíso. Los emigrados a Hollywood (1933-1950). Madrid: T \& B Editores, 2004.

SEdeÑo VAldellós, Ana M. “' «a música contemporánea en el cine», Historia y Comunicación Social 9 (2004): 155-162.

SERrano Cueto, José Manuel. Vincent Price. El terror a cara descubierta. Madrid: T \& B Editores, 2004. SIDNEY, George, dir. Levando Anclas. Madrid: Warner Home Video Española, 2005. (Vídeo-DVD).

SPOTO, Donald. Alfred Hitchoch. La cara oculta del genio. Madrid: T \& B Editores, 2004.

TAYLOR, John R. Extraños en el paraíso: los emigrados a Hollywood (1933-1950). Madrid: T \& B Editores, 2004.

TEJERO GARCÍA, Juan. iEste rodaje es la guerra! Segunda parte: sangre, sudor y lágrimas en el plató. Madrid: T \& B Editores, 2004.

TEJero García, Juan. ;Este rodaje es la guerra! Tercera parte: Apocalipsis final. Madrid: T \& B Editores, 2005.

Vilageliu, Josep. En pos de la ballena blanca. (Moby Dick). Madrid: T \& B Editores, 2004.

Wallovits, J. D. \& GUAL, Roger. Smoking Room. Madrid: Ocho y Medio, 2003.

WeINRICHTER, Antonio. Desvíos de lo real. El cine de no ficción. Madrid: T \& B Editores, 2004. 